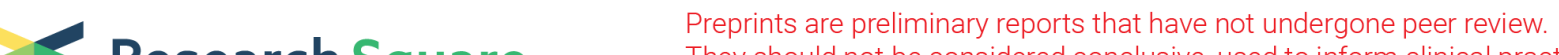 Research Square
Thr ef should not be considered conclusive, used to inform clinical practice,
on the media as validated information.
}

\section{Dictamnine, a Novel c-Met Inhibitor, Suppresses the Proliferation of Lung Cancer Cells by Downregulating the PI3K/AK/mTOR and MAPK Signaling Pathways}

Jiaojiao Yu

Kunming University of Science and Technology

Lijing Zhang

Kunming University of Science and Technology

Jun Peng

The First People's Hospital of Yunnan Province

Richard Ward

University of Glasgow

\section{Peiqi Hao}

Kunming University of Science and Technology

Jiwei Wang

Kunming University of Science and Technology

Na Zhang

Kunming University of Science and Technology

Yang Yang

Kunming University of Science and Technology

Xiaoxi Guo

Kunming University of Science and Technology

Cheng Xiang

Kunming University of Science and Technology

\section{Su An}

Kunming University of Science and Technology

Tian-rui Xu ( $\nabla$ tianruixu@kust.edu.cn )

Kunming University of Science and Technology

\section{Research}

Keywords: Dictamnine, c-Met, Lung cancer, PI3K/Akt/mTOR, MAPK, Gefitinib resistance

Posted Date: October 21st, 2020 
DOI: https://doi.org/10.21203/rs.3.rs-94028/v1

License: (c) (i) This work is licensed under a Creative Commons Attribution 4.0 International License. Read Full License 


\section{Abstract}

Background: Dictamnine (Dic), a naturally occurring furoquinoline alkaloid isolated from the root bark of Dictamnus dasycarpus Turcz., is reported to display a wide range of potential pharmacological properties including anticancer activity against multiple cancer types. However, little is known about the direct target proteins and anticancer mechanisms of Dic.

Methods: Anticancer effects of Dic and chemotherapy resistance of lung cancer were determined by CCK8, EdU and apoptosis assay. Boyden chamber migration and invasion, wound healing assay, plate colony formation and sphere formation assay were performed to explore the effects of Dic on metastasis and stemness of lung cancer cells. Protein docking analysis, cellular thermal shift assay (CETSA) and drug affinity responsive target stability (DARTS) were used for prediction and confirmation of the interaction between Dic and c-Met. qRT-PCR, Western blotting and immunohistochemistry (IHC) were used in mechanism investigation. Tumor xenograft model was used to evaluate the anti-tumor effects of Dic in vivo.

Results: Dic was found to suppress the proliferation of lung cancer cells and attenuate the activation of the PI3K/AKT/mTOR and mitogen-activated protein kinase (MAPK) signaling pathways by directly inhibiting the phosphorylation and activation of the receptor tyrosine kinase c-Met. Moreover, Dic treatment significantly inhibited the colony formation, migration, invasion, stemness, adhesive ability, epithelial-mesenchymal transition and in vivo xenograft tumor growth of A549 lung cancer cells. Notably, the combination of Dic and gefitinib synergistically inhibited the cell proliferation, induced apoptosis, and suppressed the PI3K/Akt/mTOR and MAPK signaling pathways in PC9 gefitinib resistant cells.

Conclusions: In conclusion, Dic was identified as a novel c-Met inhibitor and our results suggest the potential use of Dic as a new therapeutic agent in the treatment of lung cancer or other cancers with overactive c-Met pathway.

\section{Background}

Among all cancer types, lung cancer is still the leading cause of cancer-related deaths around the world and more than $85 \%$ of all lung cancer cases are classified as non-small-cell lung cancer (NSCLC). Improved understanding of the molecular mechanisms that cause tumor progression and metastasis of lung cancer has revolutionized the treatment of NSCLC. An oncogenic driver mutation has been identified in two-thirds of NSCLC patients. The tumorigenesis and malignant progression are usually caused by the hyper-activation of the two key signaling cascades, the PI3K/AKT/mTOR pathway and the Ras-Raf-MEKERK (also called the mitogen-activated protein kinase (MAPK)) pathway. The most common activating oncogenic mutations or fusions identified in lung cancer patients are receptor tyrosine kinase EGFR, serine/threonine-protein kinase K-Ras and B-Raf mutations, anaplastic lymphoma kinase (ALK) and proto-oncogene receptor tyrosine kinase (ROS1) fusions, which lead to the aberrant activation of $\mathrm{PI} 3 \mathrm{~K} / \mathrm{AKT} / \mathrm{mTOR}$ and MAPK pathways. The identification of these candidate oncogenic driver mutations 
in NSCLC and the findings of increasing number of clinically available inhibitors directly targeting these driver mutations provide a great opportunity to improve prognosis in patients with NSCLC. However, nearly all patients will develop resistance to targeted therapies due to intrinsic or acquired resistance [1].

Previous studies have reported that higher expression of c-Met is observed in $61 \%$ of NSCLCs and correlates with poor prognosis in NSCLC patients. c-Met is a receptor tyrosine kinase with only a single known ligand, the hepatocyte growth factor (HGF). Binding of HGF to c-Met stimulates c-Met receptor activation and then triggers downstream signaling pathways including PI3K/AKT/mTOR and MAPK pathways. Abnormal c-Met signaling can be activated by the somatic mutation or amplification of MET, or the overexpression of the c-Met receptor which drivers tumorigenesis and is related to metastasis and poor prognosis in a wide range of major human cancers including NSCLC. Indeed, it is well known that aberrant c-Met activity can confer lung cancer with acquired resistance to EGFR-TKI [2].

Dictamnine (4-methoxyfuro[2,3-b]quinolone, Dic), is a major bioactive component isolated from the root bark of Dictamnus dasycarpus Turcz. (Rutaceae). Dic, as a bioactive natural furoquinoline alkaloids, has been reported to possess many beneficial pharmacological activities, such as anti-platelet-aggregation, antibacterial, anti-mitosis, vascular-relaxing and anti-inflammation [3]. Because of its outstanding biopharmacological activities, Dic is usually used as a herbal medicine and recommended for the treatment of a variety of diseases including eczema, rheumatic arthritis, coronary atherosclerosis, jaundice hepatitis and others [3]. In addition, Dic has shown potent proliferation-inhibition and apoptosis-induced activities in various cancer-derived cell lines, such as human cervix, colon, oral carcinoma and human breast cancer cells [4]. Recently, Dic was reported to induce cell cycle arrest at low concentration and cell apoptosis at high concentration via mitochondria and caspase 3-independent mechanisms in A549 cells [5]. However, the detailed molecular mechanisms by which Dic induces apoptosis of A549 cells need to be further investigated.

In this study, we showed for the first time that Dic can strongly suppress the activation of the two classical signaling cascades, PI3K/Akt/mTOR and MAPK pathways by directly targeting receptor tyrosine kinase c-Met, leading to the inhibition of lung cancer cell proliferation and metastasis. Additionally, Dic was shown to induce apoptosis in lung cancer cells via the intrinsic apoptosis pathway and to increase Gefitinib sensitivity of EGFR-TKI-resistant PC9 cells through down-regulation of the activation of the c-Met signaling pathway.

\section{Materials And Methods}

\section{Patient specimens}

A total of 20 paired NSCLC tissues and their adjacent non-tumor tissues were collected from patients who underwent curative surgical resection in the department of thoracic surgery, The First People's Hospital of Yunnan Province. All patients were diagnosed and confirmed by experienced pathologists, and none of the patients underwent adjuvant chemotherapy or radiation treatment prior to surgery. This study was 
approved by Ethics Committee of Kunming University of Science and Technology and informed consent was obtained from all patients.

\section{Antibodies and reagents}

Dic was obtained from Chengdu Herbpurify Co., Ltd. (Chengdu, China), and was prepared by dissolving the compound in ethyl alcohol and diluted in DMSO. All antibodies used in Western blotting or IHC were shown in Additional file 1: Table S1. Polyvinylidene fluoride membrane (IPVH00010) was from Millipore (Merck Millipore Ltd., County Cork, Ireland). Cell Counting Kit-8 (C0039), Apoptosis and Necrosis Assay Kit (C1056), EdU Cell Proliferation Kit (C0088S) were purchased from Beyotime (Beyotime Biotechnology, Shanghai, China). TRIzol reagent (180411) was obtained from Ambion (Thermo Fisher Scientific, Inc. Waltham, MA, USA). FastStart Essential DNA Green Master (32597600) was supplied by Roche (Roche Diagnostics, Shanghai, China). RevertAid ${ }^{\mathrm{TM}}$ First Strand cDNA Synthesis Kit (K1622) was obtained from Thermo (Thermo Scientific, Waltham, MA, USA).

\section{Cell lines}

A549 (human non-small cell lung adenocarcinoma) cell line was obtained from Kunming Institute of Zoology, Chinese Academy of Sciences. Human lung carcinoma cell lines H1299 and PC9, liver cancer cell line HepG2, renal cell carcinoma cell line ACHN and cervical carcinoma cell line HeLa were purchased from the Cell Bank of the Chinese Academy of Sciences (Shanghai, China). Cells mentioned above were maintained in the RPMI-1640 (Hyclone, USA) supplemented with $10 \%$ (vol/vol) fetal bovine serum (FBS) (Gibco, Invitrogen) and antibiotics (10 mg/mL streptomycin sulfate, and $100 \mathrm{mg} / \mathrm{mL}$ penicillin $\mathrm{G}$ ). To establish a Gefitinib-resistant cell line, the PC9 cells were initially exposed to Gefitinib at $0.2 \mu \mathrm{M}$ for about 7 days. Then the cells were transferred to and cultured in medium without Gefitinib for about 14 days. Following the above steps, the exponential growth cells were harvested and seeded in 96-well microtiter plates, the concentration of Gefitinib was increased from $0.2 \mu \mathrm{M}$ to $5 \mu \mathrm{M}$. After about six months, the Gefitinib-resistant PC9 cells (PC9-GR) were established.

\section{Bioinformatics analysis}

The Gene Expression Profiling Interactive Analysis (GEPIA) browser (http://gepia.cancer-pku.cn/) is a friendly web-based tool to explore customizable functionalities based on the data provided by TCGA (https://tcga-data.nci.nih.gov/tcga/) and the Genotype-Tissue Expression project (GTEx, https://www.gtexportal.org/home/index.html). GEPIA was used to identify the transcriptional expression of c-Met between lung cancer and normal tissues. The prognostic value of c-Met expression in lung cancer patients was analyzed by using the Kaplan-Meier plotter online database (http://kmplot.com/analysis/).

\section{CCK-8 cell proliferation assay}


The viability of cancer cells was determined by using the CCK-8 assay according to the manufacturer's protocol. Cancer cells were seeded in 96 -well plates $\left(5 \times 10^{3}\right.$ cells per well) and cultured for $24 \mathrm{~h}$. The cells were treated with varying concentrations of Dic $(0,50,100,200 \mu \mathrm{M})$ for 2, 24, 48 and $72 \mathrm{~h}$. Then $10 \mu \mathrm{L}$ CCK-8 (Beyotime Biotechnology, Shanghai, China) was added to each well, and incubated at $37^{\circ} \mathrm{C}$ for $1.5 \mathrm{~h}$. The absorbance of each well was measured at a wavelength of $450 \mathrm{~nm}$ by using a microplate reader.

\section{EdU cell Proliferation assay}

A549 cells cultivated in 96 -well plates $\left(5 \times 10^{3}\right.$ cells per well) were treated with different concentrations of Dic $(0,50,100,200 \mu \mathrm{M})$ for 24 and $48 \mathrm{~h}$. After the administration of $30 \mu \mathrm{M}$ 5-ethynyl-2'-deoxyuridine (EdU; Beyotime Biotechnology, Shanghai, China) to each well, the cells were continually incubated for $2 \mathrm{~h}$ at $37^{\circ} \mathrm{C}$. Then the cells were fixed with $4 \%$ paraformaldehyde in PBS for $15 \mathrm{~min}$ at room temperature. After the removal of the fixative, A549 cells were washed with PBS and permeabilized with $0.3 \%$ Triton X-100 for another $15 \mathrm{~min}$, the cells were incubated with $100 \mu \mathrm{L} 0.3 \%$ hydrogen peroxide solution for $20 \mathrm{~min}$. After washing three times with $3 \%$ BSA in PBS, $50 \mu \mathrm{L}$ Click Reaction Solution was added to each well and the cells were incubated for $30 \mathrm{~min}$ at room temperature. The Click Reaction Solution was discarded and the washing repeated, $20 \mu \mathrm{L}$ Streptavidin-HRP was added and incubated for another $30 \mathrm{~min}$. After washing with $3 \%$ BSA in PBS, $100 \mu \mathrm{L}$ TMB was added to each well and incubated for about 30 min, the absorbance of each well was measured at $650 \mathrm{~nm}$.

\section{Apoptosis assay}

In order to measure cell death and apoptosis, cells were treated with Dic $(0,50,100,200 \mu \mathrm{M})$ for $24 \mathrm{~h}$ and then collected for Hoechst 33342/propidium iodide (PI) staining with an apoptosis and Necrosis Assay Kit (Beyotime Biotechnology, Shanghai, China). The stained cells were observed and photographed under a confocal microscope (Nikon A1, Tokyo, Japan), and the images analyzed using the ImageJ software program ( $\mathrm{NIH}$, Bethesda, MD). The percentage of dead cells was then calculated according to the following: PI positive cells/total cells $\times 100$.

\section{Plate colony formation assay}

For colony formation assays, 500 cells in the logarithmic phase were plated into 12-well plates with Dic $(0,50,100,200 \mu \mathrm{M})$ and incubated for 14 days. The cell culture medium was refreshed every three days. When the cells grew to form visible colonies, the supernatants were discarded and the colonies were fixed with $4 \%$ paraformaldehyde for $30 \mathrm{~min}$, and then washed with PBS and stained with crystal violet for $15 \mathrm{~min}$. Cell colonies were counted under an inverted microscope using the Image-Pro Plus software (Media Cybernetics, Inc. Rockville, MD). The assays were performed five times independently.

\section{Transwell migration and matrigel invasion analysis}


The migration and invasion assay were carried out using the transwell chambers (Corning Costar, Cambridge, Massachusetts, pore size $8 \mu \mathrm{m})$. A549 cells were treated with Dic $(0,50,100,200 \mu \mathrm{M})$ for $24 \mathrm{~h}$. Cells were then trypsinized, washed, and resuspended in serum-free RPMI-1640. Migration assays and invasive assays were performed using the uncoated transwell chamber and the chamber coated with Matrigel (BD Sciences, Franklin Lakes, NJ, USA), respectively. The Matrigel was diluted with DMEM medium (3:1) and dropped onto the chamber and incubated at $37^{\circ} \mathrm{C}$ for $2 \mathrm{~h}$. A total of $100 \mu \mathrm{L}$ cell suspension $\left(5 \times 10^{5} / \mathrm{mL}\right)$ was inoculated into the upper chamber, the bottom compartment contained 600 $\mu \mathrm{L}$ RPMI-1640 supplemented with 10\% FBS to serve as a chemoattractant. After incubation for $36 \mathrm{~h}$, transwell inserts were washed 3 times with PBS, fixed with $4 \%$ paraformaldehyde and stained with $0.1 \%$ crystal violet. The invading cells on the lower surface of the transwell insert were visualized with a light microscope, and counted in 5 randomly selected visual fields. The assays were performed five times independently.

\section{Wound healing assay}

The effects of Dic on the migratory behavior of lung cancer cells were assayed by means of a wound healing assay using a culture-insert (ibidi GmbH, Am Klopferspitz 19, Martinsried, Germany) according to the manufacturer's instructions. $200 \mu \mathrm{L}$ cell suspension $\left(1.5 \times 10^{5}\right.$ cells $\left./ \mathrm{mL}\right)$ was applied to the CultureInsert of each well and allowed to grow to a confluent monolayer at $37^{\circ} \mathrm{C}$ and $5 \% \mathrm{CO} 2$ for $24 \mathrm{~h}$. The insert was gently removed using sterile tweezers, and the cells were washed twice with PBS to remove any loose cells and fresh medium containing mitomycin was added. A549 cells were treated with Dic $(0,50$, $100,200 \mu \mathrm{M})$ and Photographs were taken at 0,24 and $48 \mathrm{~h}$ to assess cell migration into the wound using a light microscope.

\section{Sphere formation assay}

To investigate the effect of Dic on lung cancer stem cells, sphere formation assays were performed. Approximately $1 \times 10^{4}$ A549 cells were seeded into ultra-low attachment 6-well plates (Corning Inc, Corning, NY, USA) and cultured in serum-free DMEM/F-12 (1:1 ratio) media supplemented with B27 supplements (Thermo Fisher Scientific, Waltham, MA, USA), $20 \mathrm{ng} / \mathrm{mL}$ bFGF and $20 \mathrm{ng} / \mathrm{ml} \mathrm{rhEGF}$. Cells received treatment with various concentrations of Dic for $48 \mathrm{~h}$ at $72 \mathrm{~h}$ after cell seeding. The medium was exchanged every 3 days. After 2 weeks, cell spheres with diameters $\geq 50 \mu \mathrm{m}$ were counted using a microscope.

\section{Cell adhesion assay}

A549 cells were treated with Dic $(0,50,100,200 \mu \mathrm{M})$ for $24 \mathrm{~h}$ and were then seeded into 96-well plates pre-coated with $10 \mu \mathrm{g} / \mathrm{mL}$ fibrinogen, $10 \mu \mathrm{g} / \mathrm{mL}$ collagen type IV, and cultured at $37^{\circ} \mathrm{C}$ for $30 \mathrm{~min}$. Wells coated with $100 \mu \mathrm{g} / \mathrm{mL}$ poly-L-lysine were employed as a control condition. Subsequently, the medium was discarded, and the non-adherent cells were carefully removed by washing the cells three times with PBS. The attached cells were fixed with $4 \%$ paraformaldehyde for 30 min and stained with $0.1 \%$ crystal violet for $20 \mathrm{~min}$ at room temperature. Excess crystal violet was washed away using PBS and $100 \mu \mathrm{L}$ of 
acetic acid was added to each well with gentle shaking for 10 min to dissolve the purple crystals. Absorbance was measured at $590 \mathrm{~nm}$ by a Microplate Reader. The quantified cellular adhesion results were normalized to control cells and were represented as relative absorbance.

\section{Quantitative real-time PCR analysis}

Total RNA was extracted from cells using TRIzol regent. The RNA $(5 \mu \mathrm{g})$ was then reverse transcribed into cDNA using Revert Aid First Strand cDNA Synthesis Kit (Thermo Fisher Scientific, Waltham, MA, USA) according to the manufacturer's protocol. The level of mRNA was measured by real-time PCR using FastStart Essential DNA Green Master Mix (Roche Diagnostics, Shanghai, China) and was normalized to GAPDH. The sequences of primers used in the experiment were listed in Additional file 1: Table S2. The reaction was performed using the LightCycler® 96 . The results of q-PCR were expressed relative to threshold cycle (CT) values and fold changes were calculated using the $2^{-\triangle \Delta C T}$ method.

\section{Western blot analysis}

Western blotting was used to analyze the protein levels. Cells were collected and lysed with RIPA buffer. The nuclear protein and cytoplasmic Protein were extracted using the Nuclear and Cytoplasmic Protein Extraction Kit (Beyotime Biotechnology, Shanghai, China). Proteins of cell lysates were quantified by Enhanced BCA Protein Assay Kit (Beyotime Biotechnology, Shanghai, China). Equal amounts of cell lysate were separated on an SDS-PAGE gel and transferred to the PVDF membrane. After being blocked with $5 \%$ non-fat milk, the membranes were probed with primary antibodies overnight at $4{ }^{\circ} \mathrm{C}$. The primary antibodies were as follows: anti-c-Met, anti-phospho-c-Met, anti-PI3K, anti-phospho-PI3K, anti-AKT, antiphospho-AKT, anti-m-TOR, anti-phospho-m-TOR, anti-STAT3, anti-phospho-STAT3, anti-B-Raf, antiphospho-B-Raf, anti-ERK, anti-phospho-ERK, anti-GSK-3 $\beta$, anti-phospho-GSK-3 $\beta$, anti- $\beta$-catenin, anti-c-Myc, anti-cyclin D1, anti-CDK1, anti-IL-1 $\beta$, anti-GAPDH, anti-Actin, anti-Tubulin, anti-H2A. The information of antibodies was listed in Additional file 1: Table S1. After subsequent washing with TBST, the membranes were then incubated with corresponding secondary antibodies for $1.5 \mathrm{~h}$ at room temperature. Protein bands were visualized by a chemiluminescence system (GeneGnome, Syngene, UK).

\section{Cellular Thermal Shift Assay (CETSA)}

CETSA was performed using cell lysates and intact cells as previously described [6, 7]. For a CETSA in A549 cell lysates, A549 cells were lysed with lysis buffer (50 mM Tris- $\mathrm{HCl}$ pH 7.2, $150 \mathrm{mM} \mathrm{NaCl}, 1.5 \mathrm{mM}$ $\mathrm{MgCl}_{2}, 0.2 \% \mathrm{NP}-40,5 \%$ glycerol, $25 \mathrm{mM} \mathrm{NaF}$ and $1 \mathrm{mM} \mathrm{Na}_{3} \mathrm{VO}_{4}$ ) supplemented with $0.1 \%$ protease inhibitor cocktail. The cell suspensions were rapidly frozen and thawed three times using liquid nitrogen, and incubated on ice for $30 \mathrm{~min}$, the lysates were centrifuged at $20000 \times \mathrm{g}$ for $20 \mathrm{~min}$ at $4{ }^{\circ} \mathrm{C}$, supernatants were transferred to new tubes and protein concentrations were measured by BCA Protein Assay Kit. The cell lysates were diluted with appropriate volume of lysis buffer, and $50 \mu \mathrm{L}$ of the lysates at $0.6 \mathrm{mg} / \mathrm{mL}$ were incubated with DMSO or Dic at different concentrations for $2 \mathrm{~h}$ at room temperature and then heated individually at different temperature for $3 \mathrm{~min}$ in a PCR machine (Applied Biosystems). The heated lysates were centrifuged to separate the precipitated proteins from the soluble fractions. The 
equal portions of the supernatants were loaded onto SDS-PAGE gels followed by Western blot analysis. For a CETSA in intact A549 cells, the cells cultured in 12-well plates $\left(3.0 \times 10^{5}\right.$ cells/well) were treated with different concentrations of Dic for $2 \mathrm{~h}$, the control cells were exposed to an equal volume of DMSO. After incubation, the cells were washed with PBS and $500 \mu \mathrm{L}$ of lysis buffer was added to each well, then the lysates were heated and analyzed by Western blotting as described above.

\section{Drug affinity responsive target stability (DARTS)}

DARTS was used to assess the binding affinity of Dic to c-Met using protease protection from pronase digestion (Roche Applied Science, Inc.) as previously described [8]. A549 cells were washed with cold PBS and lysed using cold M-PER lysis buffer (Thermo Scientific, Inc.) supplemented with a protease inhibitor cocktail and phosphatase inhibitors. The cell lysates were centrifuged at $20000 \times \mathrm{g}$ for $10 \mathrm{~min}$ at $4{ }^{\circ} \mathrm{C}$, and the supernatants were diluted with $10 \times \mathrm{TNC}$ buffer $(500 \mathrm{mM}$ Tris-HCl pH 8.0, $500 \mathrm{mM} \mathrm{NaCl}$ and $100 \mathrm{mM} \mathrm{CaCl}_{2}$ ). The lysates in $1 \times \mathrm{TNC}$ buffer were incubated with DMSO or Dic at the indicated concentrations for $2 \mathrm{~h}$ at room temperature. After incubation, each sample was proteolyzed with $1 \mu \mathrm{g}$ pronase to every 3000 or $4000 \mu \mathrm{g}$ of total protein in lysate for $20 \mathrm{~min}$ at room temperature. Proteolysis was stopped by adding $5 \times$ SDS sample loading buffer $(250 \mathrm{mM}$ Tris- $\mathrm{HCl} \mathrm{pH} \mathrm{6.8,} \mathrm{10 \%} \mathrm{SDS,} \mathrm{50 \%} \mathrm{glycerol,}$ $0.5 \%$ bromophenol blue and $5 \% \beta$-mercaptoethanol) and boiling at $100{ }^{\circ} \mathrm{C}$ for $5 \mathrm{~min}$. An equal portion of each sample was loaded onto SDS-PAGE gels and analyzed by Western blotting.

\section{Molecular modeling of Dic with c-Met}

The crystal structure of c-Met was obtained from the Protein Data Bank (PDB: 4IWD). AutoDock Tool was utilized to prepare the input PDBQT file for c-Met and set the size and the center of the grid box. Hydrogen atoms were added and all water molecules were removed from the structure of c-Met. The center of the grid box was set with the dimension $(X=-8.833, Y=12.926$, and $Z=-16.482)$ using $0.1 \mathrm{~nm}$ spacing and a box size of $20 \times 20 \times 20$. The three-dimensional structure of Dic was generated using Open Babel software. Molecular docking of Dic at the active site of c-Met was achieved using AutoDock Vina. The best pose on the basis of binding affinity and docking was selected and post-docking results were analyzed using LigPlot+.

\section{Subcutaneous xenografts in nude mice}

All animal experiments were approved by our Institutional Animal Care and Treatment Committee. Four to five weeks-old female BALB/c nude mice were purchased from Shanghai Lingchang Biotechnology Co., Ltd. (Shanghai, China) and maintained under specific pathogen-free conditions with controlled light and humidity, receiving food and water ad libitum. Before inoculating into mice, A549 cells were washed twice and counted, approximately $5 \times 10^{6}$ cells suspended in $100 \mu \mathrm{L} \mathrm{PBS/animal} \mathrm{were} \mathrm{inoculated}$ subcutaneously into the right armpits of mice. The mice were randomly assigned into 2 groups, an experimental group and a control group, each of 6 mice. Treatment with Dic began 9 days after inoculation of the cells when the tumors reached a volume of $100-150 \mathrm{~mm}^{3}$. The experimental group was treated with i.p. injections of Dic ( $50 \mathrm{mg} / \mathrm{kg}$ body weight) for the next 15 days, while the control 
group received an equal volume of vehicle. All mice were weighted daily during the treatment time, and tumor volume was calculated using the following formula: $0.5 \times$ length $\times(\text { width })^{2}$. One day after the last treatment mice were sacrificed, and then the tumors were dissected, weighed and subjected to hematoxylin-eosin (HE) staining combined with immunohistochemistry (IHC) analysis.

\section{Hematoxylin-eosin, immunohistochemistry and fluorescence staining}

Solid tumors from control and treatment groups were fixed with $4 \%$ paraformaldehyde and embed in paraffin for H\&E staining and IHC. Tissue sections were deparaffinized in xylene, dehydrated in graded ethanols and finally hydrated in distilled water, the sections were then counterstained with HE. For IHC, epitope retrieval was performed by directly boiling the slides in $10 \mathrm{mM}$ sodium citrate $(\mathrm{pH} \mathrm{6.0)}$ for $30 \mathrm{~min}$, immunohistochemistry was performed according to the manufacturer's guidelines and recommendations. Briefly, the sections were treated with $3 \%$ hydrogen peroxide for 10 min to quench endogenous peroxidase and non-specific binding was blocked with $5 \%$ normal goat serum/TBST (Cell Signaling Technology, Cambridge, USA \#5425). The slides were incubated overnight at $4^{\circ} \mathrm{C}$ with anti-Ki67 antibody (rabbit polyclonal antibody, diluted 1:200, Merck-Millipore, Darmstadt, Germany \#AB9260). After incubation, the tissues were incubated with Signalstain Boost IHC detection reagent (HRP, rabbit, Cell Signaling Technology, Cambridge, USA \#8114) for $30 \mathrm{~min}$ at room temperature and detected with the Signalstain DAB substrate kit (Cell Signaling Technology, Cambridge, USA \#8059), followed by counterstaining with hematoxylin. Apoptotic cells in tumors were detected using a terminal deoxynucleotidyl transferase dUTP nick-end labeling (TUNEL) assay according to the manufacturer's protocol (KeyGEN BioTECH, Nanjing, China \#KGA700). Images were taken using an Olympus microscope and quantified by the image analyzer ImageJ.

\section{Statistical analysis}

All quantitative Data were presented as the mean \pm standard deviation (SD). Statistically significant differences were obtained using an unpaired two-tailed student's $t$-test or by one-way ANOVA. A $P$ value of less than 0.05 was considered statistically significant.

\section{Results}

\section{Dic inhibits the proliferation of cancer cells expressing c-Met and attenuates HGF-activated proliferative response in A549 cells}

Dic is a 4-methoxyfuro (2,3-b) quinolin compound (Fig. 1a). c-Met, the only known high-affinity receptor for hepatocyte growth factor (HGF), is usually overexpressed, highly activated, and sometimes mutated in NSCLC tissues [9]. Bioinformatics analysis also indicated that c-Met expression in both lung adenocarcinoma (LUAD) and lung squamous cell carcinoma (LUSC) from TCGA database was significantly higher than that in normal tissues (Fig. 1b). The high expression of c-Met in lung cancer tissues was further confirmed by Western blotting and qRT-PCR analysis (Supplementary Fig. 2). Survival analysis showed that patients with high c-Met expression had a poor overall survival rate (Fig. 1c). To 
determine the specific inhibitory effect of Dic on c-Met-dependent proliferation of cancer cells, various types of cancer cells with c-Met overexpression were treated with different concentrations of Dic, and the c-Met low-expressing cell line HEK293 was used as control. As shown in Fig. 1d, Dic significantly inhibited the proliferation of A549 and H1299 human non-small-cell lung cancer cells, HeLa cervical cancer cells, HepG2 liver cancer cells, as well as ACHN renal carcinomal cells in a dose- and time-dependent manner, while having no obvious effect on the proliferation of HEK293 cells. The inhibitory effect of Dic on A549 cell proliferation was further confirmed by EdU assay (Fig. 1e). Furthermore, when A549 cells were serumstarved overnight and treated with HGF $(100 \mathrm{ng} / \mathrm{mL})$ or Dic $(100 \mu \mathrm{M})$ for $24 \mathrm{~h}$, or treated with indicated concentrations of Dic for $24 \mathrm{~h}$ in the presence of HGF $(100 \mathrm{ng} / \mathrm{mL})$, cells stimulated with HGF alone exhibited greater proliferative response than did cells from control group, and whilst treatment with Dic resulted in a concentration-dependent inhibition of proliferative response induced by HGF in A549 cells (Fig. 1f).

Additionally, we successfully established a gefitinib-resistant NSCLC cell line PC9GR from the gefitinibsensitive PC9 cell line after approximately six months of gefitinib treatment (Supplementary Fig. 2A). Then the combined effects of Dic and gefitinib on proliferation inhibition were measured by CCK8. As shown in Supplementary Fig. 2B, the combination of gefitinib $(1 \mu \mathrm{M})$ and Dic $(50,100$ and $200 \mu \mathrm{M})$ achieved a synergistic effect on proliferation inhibition in PC9GR cells and resulted in significantly higher inhibition of cell growth relative to single-gefitinib treatment over $72 \mathrm{~h}$. EdU assay showed that single-Dic treatment was as effective as the combination of Dic and gefitinib as far as proliferation inhibition of PC9GR was considered (Supplementary Fig. 2C).

\section{Dic suppresses A549 cell clonogenicity, invasiveness and migration}

We assessed the effects of Dic on the multiple properties linked to lung cancer metastasis. As shown in Fig. 2a, Dic exhibited a strong inhibition of colony formation in a dose-dependent manner in A549 lung cancer cells which were cultured at low density and allowed to grow and form colonies over a two-week period. Furthermore, Dic showed an equivalent efficacy to that of a combined treatment with gefitinib and Dic in inhibiting the colony formation of PC9GR cells (Supplementary Fig. 3A). The potential effect of Dic on A549 cell invasion and migration was tested and results from the transwell assay and matrigel transwell assay indicated that Dic could potently inhibit A549 cell migration and invasion, respectively (Fig. 2b). Additionally, a single dose Dic $(100 \mu \mathrm{M})$ was as effective as a combination treatment with Dic and gefitinib in blocking the migration of PC9GR cells (Supplementary Fig. 3B). Performing a scratch wound-healing assay, we further confirmed that treatment with Dic dose-dependently inhibited wound closure in A549 cells (Fig. 2c). Together, these results demonstrate that Dic inhibits in vitro the colony formation, migration and invasion of A549 cells.

\section{Validation of c-Met as a protein target of Dic}

The cellular thermal shift assay (CETSA) is a newly-developed fast method to assess the binding affinity of drugs to targeted proteins in cells, and it is based on thermal stabilization of target proteins after binding by their ligands [6]. To identify whether Dic directly binds to c-Met, CETSA was employed to 
validate the binding of Dic to c-Met in A549 cell lysates. As shown in Fig. 3a, Dic treatment significantly enhanced the thermal stability of c-Met in the supernatant fraction. Next, to test whether Dic binds to cMet in intact A549 cells, A549 cells treated with Dic or DMSO were collected, lysed and heated. In comparison with the control groups, Dic incubation resulted in a markedly increased thermal stability of c-Met at different temperatures (Fig. 3b) in a dose-dependent manner (Fig. 3c). Moreover, to investigate the incubation time effects, we treated A549 cells with Dic for the indicated time periods, while the concentration of Dic, time of heating and temperature were kept constant. A time-course experiment indicated that after 2 to 3 hours, c-Met was saturated with Dic (Fig. 3d). In brief, the enhanced thermal stability of c-Met after treatment with Dic suggests an interaction between Dic and c-Met.

Additionally, the binding of a drug to its target protein can induce conformational changes which increase proteolytic stability of the target protein by decreasing its protease sensitivity. Therefore, we performed a drug affinity response target stability (DARTS) assay to test whether Dic directly binds to and stabilizes cMet. As shown in Fig. 3e-f, the pre-incubation of Dic with A549 cell lysate effectively protected c-Met from digestion, even at pronase to protein ratios of 1:4000 and 1:3000. In addition, Dic stabilized c-Met in a dose-dependent manner as shown by an increase in the abundance of c-Met bands. Particularly, 100 and $200 \mu \mathrm{M}$ of Dic noticeably protected c-Met from digestion in comparison with vehicle control. Furthermore, we also analyzed the binding sites for Dic in c-Met with a molecular docking study. Using the final computational docking model, we found that there were several hydrogen bonds formed between Dic and c-Met (Fig. 3g). In short, these data demonstrate that Dic potently and selectively binds to c-Met.

\section{Inhibitory effects of Dic on c-Met signaling pathway}

c-Met has been reported to control a wide variety of cellular processes including proliferation, differentiation and survival by regulating the PI3K/Akt/mTOR and MAPK signaling pathways. To evaluate the specific inhibitory effect of Dic on c-Met and elucidate the mechanisms responsible for the inhibitory effect of Dic on cancer cells with c-Met overexpression, we tested the influence of Dic treatment on the phosphorylation levels of major components of PI3K/Akt/mTOR and MAPK pathways, and also observed the influence of Dic on the activity or expression level of major downstream substrates and transcription factors regulated by these two pathways.

As shown in Fig. 4a, the tyrosine phosphorylation of c-Met in a control culture of A549 cells was obviously detectable, whereas c-Met phosphorylation was markedly suppressed in the cells treated with Dic in a dose-dependent manner. When A549 cells were treated with various concentrations of Dic for $36 \mathrm{~h}$, the phosphorylation of B-Raf, C-Raf and ERK, recognized as the core components of MAPK signaling pathway (Fig. 4b), the phosphorylation of PI3K, Akt and mTOR, and the phosphorylation of transcription factor signal transducer and activator of transcription 3 (STAT3) regulated by MAPK and $\mathrm{PI3K} / \mathrm{Akt} / \mathrm{mTOR}$ pathway were significantly decreased in comparison with the controls (Fig. 4c).

Furthermore, when A549 cells were treated with indicated concentrations of Dic in serum-free medium for $24 \mathrm{~h}$, following stimulation with or without $100 \mathrm{ng} / \mathrm{mL} \mathrm{HGF}$ for $5 \mathrm{~min}$, we found that cells stimulated with HGF alone exhibited higher phosphorylation levels of c-Met, PI3K, Akt, mTOR and GSK3 $\beta$ than cells from 
control group. Treatment with Dic led to a concentration-dependent inhibition of c-Met, PI3K, Akt, mTOR and GSK3 $\beta$ phosphorylation in response to HGF in A549 cells (Fig. 4d). GSK3 $\beta$ is a major substrate of Akt which inhibits GSK3 $\beta$ activity by phosphorylating its $\mathrm{N}$-terminal serine to form an autoinhibitory pseudosubstrate domain [10]. Additionally, GSK3 $\beta$ plays an important role in the cross-talk between $\mathrm{PI3K} / \mathrm{Akt} / \mathrm{mTOR}$ and Wnt/ß-catenin signaling pathways [11].

Among the many well-known transcription factors regulated by PI3K/Akt and MAPK pathways are $\beta$ catenin, cyclin-D1, c-Myc, NF-KB and STAT3 [12-17]. Therefore, we assessed the effects of Dic on the activity of downstream transcription factors of PI3K/Akt and MAPK pathways to further understand the mechanisms by which Dic inhibits the proliferation of lung cancer cells. As shown in Supplementary Fig. 4A, Dic strongly inhibited the expression of $\beta$-catenin, cyclin-D1, CDK1 and c-Myc as well as the phosphorylation of GSK3 $\beta$. Notably, Dic treatment essentially inhibited the nuclear translocation of $\beta$ catenin, STAT3, p-STAT3 and NF-KB in a dose-dependent manner (Supplementary Fig. 4B-C).

Furthermore, the expression levels of c-Met, Akt, ERK and GSK3 $\beta$ in PC9GR cells were found to be higher than those in PC9 cells (Supplementary Fig. 5A). Unlike that in parental PC9 cells, the phosphorylation of Akt and ERK in the PC9GR cells was maintained in the presence of gefitinib (Supplementary Fig. 5B), while the combination of gefitinib and Dic achieved a synergistic effect on the phosphorylation inhibition of c-Met, Akt, ERK and GSK3 $\beta$ in PC9GR cells (Supplementary Fig. 6A), as well as the inhibition of their phosphorylation response to HGF in PC9GR cells (Supplementary Fig. 6B).

\section{Dic induces intrinsic apoptosis by activating caspase-7 and regulating the expression of pro- and anti- apoptotic proteins}

Since decreased PI3K/Akt and MAPK signaling pathways have been reported to cause apoptosis [18], we sought to test whether the retardation of cell proliferation in response to Dic treatment reflected cell apoptosis, and so we analyzed cell apoptosis in response to various Dic concentrations $(0,50,100$ and $200 \mu \mathrm{M}$ ) for $24 \mathrm{~h}$. Dual Hoechst 33342/PI staining showed that Dic promoted the apoptosis of A549 cells in a dose-dependent manner (Fig. 5a). Next, we assessed the mRNA expression of Bax, Bid and Bcl-2 in A549 cells by qRT-PCR analysis. The results revealed that Dic significantly upregulated the mRNA expression of pro-apoptotic proteins Bax and Bid and downregulated the mRNA expression of antiapoptotic protein Bcl-2 in a dose-dependent manner (Fig. 5b). In addition, combined treatment with gefitinib and Dic had a synergistic promotional effect on the mRNA expression of Bax in PC9GR cells, and Dic alone exhibited an equivalent efficacy of both drugs in inhibiting Bcl-2 mRNA expression (Supplementary Fig. 7).

Furthermore, Dic induced dose-dependent upregulation of p53, p53 upregulated modulator of apoptosis (PUMA), Bax, cleaved-caspase-7, IL-1 $\beta$ and c-Jun expression, and downregulation of Bcl-2, and IL-6 expression. This is consistent with the pro-apoptotic functions of p53, PUMA, Bax, cleaved-caspase-7, IL$1 \beta$ and c-Jun being activated and the anti-apoptotic functions of Bcl-2 and IL- 6 being suppressed upon exposure to environment stress, whereas Dic had no detectable effect on the expression of c-Fos (Fig. 5cd). 


\section{Dic inhibits the stemness, adhesive ability and MMP2/MMP9 expression of A549 cells}

Lung cancer cell populations are highly heterogeneous and contain cancer stem-like cells which facilitate therapeutic resistance and tumor recurrence [19]. We next investigated the effect of Dic on the stemness of A549 cells via sphere formation assays. Significantly decreased sphere diameter as well as sphere numbers under all tested concentrations was observed in the Dic treated groups in comparison with controls (Fig. 6a). Additionally, Dic substantially inhibited the expression of CD44 which has been recognized as a cell surface marker for stem cells. Thus, Dic treatment reduces the population of lung cancer cells with typical cancer stem-like phenotype.

Since cell-extracellular matrix (ECM) adhesion is required for the migration and spreading of cancer cells, we assessed the effect of Dic on the ability of A549 cells to adhere to collagen and fibrinogen. Results showed that Dic markedly inhibited the adhesion of A549 cells to collagen and fibrinogen in a dosedependent manner (Fig. 6b).

Furthermore, as an important downstream effector of the c-Met signaling pathway, the focal adhesion kinase (FAK) plays a critical role in regulating cell adhesion and the expression of matrix metalloproteinase-2 (MMP-2)/MMP-9 to promote the migration and invasion of cancer cells [20, 21]. As shown in Fig. 6c, Dic efficiently inhibited the phosphorylation of FAK at Tyr-397 and Ser-722 to suppress its activity, whereas Dic had no obvious effect on FAK protein expression. Additionally, Dic strongly counteracted HGF-induced MMP2/MMP9 expression in A549 cells (Fig. 6d). Taken together, these results suggest that the anti-metastatic effect of Dic is related, at least in part, to the inhibition of stemness and FAK activation.

\section{Dic inhibits epithelial-mesenchymal transition (EMT) in A549 cells}

It is well known that EMT plays an important role in cancer progression, and is associated with the enhanced cellular migration and a stem-like phenotype, so we further observed the anti-EMT activity of Dic in A549 cells by detecting the expression levels of the epithelial marker E-Cadherin and mesenchymal markers N-Cadherin and Vimentin. During EMT, the expression of epithelial marker E-Cadherin is suppressed, while the expression of mesenchymal markers N-Cadherin and Vimentin is upregulated [22]. As shown in Fig. 7a, quantitative PCR revealed that Dic significantly inhibited the mRNA expression levels of N-Cadherin and Vimentin, while E-Cadherin mRNA expression was stimulated by Dic. Similar results were also observed when TGF- $\beta$ was used to induced EMT (Fig. 7b).

As shown in Fig. 7c, a more epithelial-like phenotype was acquired by A549 cells with the increasing Dic concentration, Dic treatment resulted in the upregulation of epithelial-like marker E-Cadherin as well as the downregulation of mesenchymal-like markers N-Cadherin and Vimentin. Moreover, when TGF- $\beta$ was used to stimulate the EMT process, we found that Dic abolished TGF- $\beta$-induced E-Cadherin suppression and the expression of $\mathrm{N}$-Cadherin and Vimentin (Fig. 7d). These results indicate that Dic efficiently inhibits EMT phenotypes. 


\section{Suppression of xenograft tumor growth by Dic administration}

To further investigate the anti-tumorigenic potential of Dic, an A549 lung cancer xenograft model was employed to evaluate the inhibitory efficiency of Dic in vivo. A549 cells were injected subcutaneously into the right armpit of nude mice $(n=12)$, when the tumor volume reached $100-150 \mathrm{~mm}^{3}$, the tumor-bearing mice were randomly divided into two groups (groups Dic and vehicle) with six mice per group. The Dictreated group received an intraperitoneal injection of Dic $(50 \mathrm{mg} / \mathrm{kg})$ once a day for 15 consecutive days. As shown in Fig. 8a-b, Dic significantly inhibited A549 cell growth when compared with that of the control group in vivo. Consistently, tumor volume increased rapidly in the control group compared with the treatment group (Fig. 8c). Additionally, treatment with Dic was well tolerated without notably body weight loss (Fig. 8d). H\&E (Haemotoxylin and Eosin) staining results indicated that tumor cells in the control group were dense and uniform, and the cell nucleus was intensely stained, while nuclear pyknosis, fragmentation and broad dissolved necrotic area were observed in Dic-treated group (Fig. 8e). We then examined the effects of Dic on the Ki67 tumor proliferation marker by using immunohistochemistry. The expression of Ki67 was significantly decreased by treatment with Dic (Fig. 8e-f). To confirm the apoptosis-inducing effect of Dic in vivo, TUNEL staining was used in xenograft tumor tissue, a significantly higher number of TUNEL-positive cells was observed in Dic-treated group than in the control group (Fig. 8e-g).

\section{Discussion}

c-Met is a receptor tyrosine kinase (RTK) whose only known natural ligand is HGF. HGF binding promotes the dimerization of c-Met and activates signaling pathways including PI3K/Akt/mTOR, MAPK [2, 23], the GSK3/ $\beta$-catenin pathways, and enhances the expression of transcription factors such as STAT3 $[24,25]$, NF-KB [26], c-Myc [27] and cyclin D1 [28]. Normal c-Met signaling plays a critical role in embryogenesis, liver generation [29] and wound healing [30] by regulating cell proliferation and differentiation. As a protooncogene, aberrant HGF/c-Met activation has been closely linked to the initiation and metastasis of various types of human cancers [23, 31-33], especially NSCLC [2,34], through the regulation multiple biological processes such as tumor proliferation, metastasis, survival and EMT [23]. Aberrantly activated c-Met signaling can arise from the mutation of c-Met, amplification of MET, or c-Met overexpression due to increased HGF level [23] which also mediates the acquired resistance of EGFR-TKIs such gefitinib in NSCLC. Additionally, c-Met overexpression is observed in $61 \%$ of NSCLCs and is positively correlated with advanced stage, poor prognosis and poor survival in NSCLC [35].

Since c-Met is overexpressed in a wide range of tumors and is emerging as an important target for cancer therapy, a number of small molecule c-Met inhibitors have been developed over the past few decades. Two multi-target c-Met inhibitors, Crizotinib and Cabozantinib, have been approved by the U.S. Food and Drug Administration (FDA) for the treatment of locally advanced or metastatic NSCLC patients and patients with advanced renal cell carcinoma or hepatocellular carcinoma, respectively. However, most cMet inhibitors currently being developed are multi-target inhibitors which may lead to unwanted side effects. Although monoclonal antibodies specifically target c-Met or HGF, they still face the same 
common disadvantages as other large biological molecules [2]. Thus, great efforts should be dedicated towards developing selective c-Met TKIs.

Dic, a naturally occurring furoquinoline alkaloid, has been reported to possess a wide range of beneficial pharmacological activities including anticancer activity against multiple tumor types. Dic has shown potent proliferation-inhibition and apoptosis-induced activities in various human cancer-derived cell lines such as cervix, colon and breast cancer cells [4]. Recently, Dic was reported to induce cell cycle arrest at low concentration and apoptosis at high concentration in lung cancer cells by mitochondria and caspase3-independent mechanisms [5]. In addition, Dic was shown to inhibit the proliferation of colorectal carcinoma HCT 116 cell and promote HCT 116 apoptosis by downregulating hypoxia inducible factor-1a (HIF-1a) and slug [36]. However, the detailed molecular mechanisms and the direct target by which Dic inhibits cancer cell proliferation and induces cancer cell apoptosis are still unclear.

In the present study, expectedly, Dic potently inhibited the proliferation of various types of cancer cell lines including A549, H1299, HepG2, ACHN and HeLa. All these cells possess a shared characteristic in that they display a strong c-Met expression [37-39], notably Dic showed no significant effect on the proliferation of HEK293 cells which have undetectable expression of c-Met. Next, we demonstrated that Dic is a novel inhibitor of c-Met based on the following evidence: (a) Dic blocked HGF-induced c-Met phosphorylation; (b) Dic inhibited HGF-induced A549 cell proliferation and the activation of c-Met signaling pathway; (c) CETSA, DARTS and molecular docking indicated that Dic directly interacted with cMet.

Consistently with previous reports, we found that there is a higher expression of c-Met in both lung adenocarcinoma and squamous cell carcinoma of lung compared with normal tissue as determined by bioinformatics analysis, Western blotting and qRT-PCR. In addition to proliferation inhibition, we also found that Dic treatment significantly inhibited the colony formation, migration, invasion, stemness, adhesive ability, EMT and in vivo xenograft tumor growth of A549 lung cancer cells. When exploring the mechanisms involved in Dic's effect on A549 cells, the results demonstrated that Dic markedly suppressed the activation of PI3K/AkT/mTOR and MAPK signaling pathways, inhibited the expression of transcription factors including $\beta$-catenin, cyclin D1, c-Myc and STAT3 phosphorylation, and prevented the nuclear translocation of $\beta$-catenin, p-STAT3, STAT3 and NF-KB. Additionally, Dic was shown to promote the apoptosis of A549 cells via intrinsic apoptosis pathways. Notably, the combination of Dic and gefitinib synergistically inhibited the cell proliferation, induced apoptosis, and suppressed the $\mathrm{PI3K} / \mathrm{Akt} / \mathrm{mTOR}$ and MAPK signaling pathways in PC9GR cells.

It is well known that PI3K/Akt/ mTOR and MAPK signaling pathways are the two key pathways in c-Metmediated signal transduction [2, 23]. Abnormal c-Met signaling promotes the development and metastasis of NSCLC, and is associated with initial resistance and acquired resistance to EGFR-TKIs in patients with NSCLC [40-42]. Our results demonstrated that Dic treatment inhibited the phosphorylation of the key components of PI3K/Akt/mTOR pathway including PI3K, Akt and mTOR in the presence or 
absence of HGF, and also inhibited the phosphorylation of the key components of MAPK pathway including B-Raf, C-Raf and ERK1/2.

STAT3 is an important transcription factor, its persistent phosphorylation has been demonstrated in $22 \%$ $\sim 65 \%$ of NSCLC. STAT3 can be activated by receptor tyrosine kinases such as c-Met in a Janus family kinase-mediated way $[25,43]$. NF-KB is an ubiquitously expressed transcription factor and a key player in cancer initiation and progression by promoting proliferation of cancer cells and inhibiting cancer cells apoptosis [44]. Recently, it was found that c-Met can activate PI3K/Akt signaling pathway, leading to downstream activation of NF-KB to promote tumor metastasis [26]. c-Myc, one of the critical transcription factors, has been shown to be implicated in promoting the metastasis of many cancers, mainly through enhancing tumor growth and cancer cell survival [45]. c-Myc was found to function as the downstream effector of c-Met to drive cell growth in NSCLC and gastric cancer cells [27]. Cyclin D1 is an important cell cycle regulator and has been proved to be a mediator of c-Met-induced hepatocarcinogenesis [28]. It is noteworthy that both c-Myc and cyclin D1 are considered to be the major downstream target of $\beta$-catenin $[46,47]$.

Furthermore, the c-Met signaling pathway is closely related to the Wnt/GSK3/ 3 -catenin pathway and prevents the phosphorylation of $\beta$-catenin by GSK3, and this, in turn, promotes the nuclear translocation of $\beta$-catenin and enhance its transcriptional activity, facilitating tumorigenesis [48-50]. The phosphorylation level of GSK3 $\beta$, $\beta$-catenin expression and its translocation from cytoplasm to nucleus were significantly inhibited in A549 cells after treatment with Dic.

$\beta$-catenin is the key component in the canonical Wnt pathway. When cells are not stimulated with Wnt ligand, $\beta$-catenin is maintained at low level due to phosphorylation by GSK, resulting in the ubiquitination and degradation of $\beta$-catenin. GSK is one of the first identified substrates of Akt kinase. GSK-activity is inhibited after phosphorylation by Akt due to the formation of an autoinhibitory pseudosubstrate domain in the N-terminus of GSK. Interestingly, Akt phosphorylates GSK and inhibits its activity, while the phosphorylation of $\beta$-catenin, as a GSK substrate, is not affected by changes of Akt activity [51, 52]. Presently, it is known that $\beta$-catenin is phosphorylated by GSK inside the $\beta$-catenin destruction complex, and ubiquinated and degraded via the proteasome [53]. In fact, only a very small portion of GSK and $\beta$ catenin is involved in the formation of $\beta$-catenin destruction complex. More importantly, phosphorylated GSK in this complex still has the ability to phosphorylate $\beta$-catenin $[10,53]$. Thus, it is necessary to be very careful when interpreting the relationship between GSK phosphorylation level and the level of $\beta$ catenin. In this study, Dic not only inhibited GSK phosphorylation and downregulated the level of $\beta$ catenin, but also suppressed the nuclear translocation of $\beta$-catenin.

In conclusion, our results show that Dic directly binds to c-Met and inhibits its phosphorylation, which leads to the suppression of lung cancer growth in vitro and in vivo by the downregulation of $\mathrm{PI} 3 \mathrm{~K} / \mathrm{Akt} / \mathrm{mTOR}$ and MAPK signaling pathways (Fig. 8h). Notably, Dic and gefitinib exhibit synergistic effects on EGFR-TKI-resistant lung cancer cells. These findings together suggest the potential use of Dic as a new therapeutic agent in the therapy of lung cancer or other cancers with overactive c-Met pathway. 


\section{Conclusions}

Dic has been reported to possess various pharmacological properties. However, the anticancer activity of Dic and its mechanisms against lung cancer have not been characterized. In the current study, Dic was identified as a novel c-Met inhibitor that exhibits anticancer properties in vitro and in vivo by downregulating the PI3K/Akt/mTOR and MAPK signaling pathways. Therefore, our findings suggest the potential use of Dic as a new therapeutic agent in the treatment of lung cancer or other cancers with overactive c-Met pathway.

\section{Abbreviations}

Dic: Dictamnine; CCK8: Cell Counting Kit-8; EdU: 5-ethynyl-2'-deoxyuridine; CETSA: cellular thermal shift assay; DARTS: drug affinity responsive target stability; IHC: immunohistochemistry; mTOR: mammalian target of rapamycin; MAPK: mitogen-activated protein kinase; NSCLC: non-small-cell lung cancer; ALK: anaplastic lymphoma kinase; HGF: hepatocyte growth factor; EGFR-TKI: epidermal growth factor receptor- tyrosine kinase inhibitor; STAT3: signal transducer and activator of transcription 3; GEPIA: Gene Expression Profiling Interactive Analysis; TCGA: The Cancer Genome Atlas; bFGF: fibroblast growth factor-basic; rhEGF: recombinant human epidermal growth factor; HE: hematoxylin-eosin; GSK-3B: glycogen synthase kinase $3 \beta$; CDK1: cyclin-dependent kinases 1; TUNEL: terminal deoxynucleotidyl transferase dUTP nick-end labeling; LUAD: lung adenocarcinoma; LUSC: lung squamous cell carcinoma; PUMA: p53 upregulated modulator of apoptosis; ECM: extracellular matrix; FAK: focal adhesion kinase; MMP-2: matrix metalloproteinase-2; MMP-9: matrix metalloproteinase-9; EMT: epithelial-mesenchymal transition; RTK: receptor tyrosine kinase; HIF-1a: hypoxia inducible factor-1a;

\section{Declarations}

\section{Acknowledgements}

None.

\section{Authors' contributions}

Tian-rui Xu and Su An conceived the study and wrote the paper. Richard Ward reviewed and revised the manuscript. Jiaojiao Yu, Lijing zhang, Peiqi Hao, Jiwei Wang, Na Zhang, Yang Yang, Xiaoxi Guo and Cheng Xiang performed the experiments. Jun Peng provided lung cancer tissues and clinical data. All authors read and approved the final manuscript.

\section{Funding}

This work was supported by the Key Fund of Yunnan Basic Research Program (No.201901S070097), the National Natural Science Foundation of China (NSFC) (No.81760264 and No.81960394), the National 
Key Research and Development Project (No.2018YFA0801404) and conducted in the University Based Provincial Key Laboratory of Screening and Utilization of Targeted Drugs.

\section{Availability of data and materials}

Supplemental Figures (1, 2, 3, 4, 5, 6 and 7) and associated figure legends are provided as supplemental material and are available online with the paper.

\section{Ethics approval and consent to participate}

All experiments involving human tissues and animal in this study were performed in accordance with the ethical standards. Informed consent was obtained from all patients and animal study was approved by the Institutional Animal Care and Treatment Committee in Kunming University of Science and Technology.

\section{Consent for publication}

Consent for publication was obtained from all authors.

\section{Competing interests}

All authors declare no competing interests.

\section{References}

1. Chen Z, Fillmore CM, Hammerman PS, Kim CF, Wong KK. Non-small-cell lung cancers: a heterogeneous set of diseases. Nat Rev Cancer. 2014;14(8):535-46.

2. Wu YL, Soo RA, Locatelli G, Stammberger U, Scagliotti G, Park K. Does c-Met remain a rational target for therapy in patients with EGFR TKI-resistant non-small cell lung cancer? Cancer Treat Rev. 2017;61:70-81.

3. Wang P, Sun JB, Xu JY, Yan Q, Gao EZ, Qu W, et al. Pharmacokinetics, tissue distribution and excretion study of dictamnine, a major bioactive component from the root bark of Dictamnus dasycarpus Turcz. (Rutaceae). J Chromatogr B Analyt Technol Biomed Life Sci. 2013;942:1-8.

4. Wang P, Zhao YL, Zhu YD, Sun JB, Yerke A, Sang SM, et al. Metabolism of dictamnine in liver microsomes from mouse, rat, dog, monkey, and human. J Pharm Biomed Anal. 2016;119:166-74.

5. An FF, Liu YC, Zhang WW, Liang L. Dihydroartemisinine Enhances Dictamnine-induced Apoptosis via a Caspase Dependent Pathway in Human Lung Adenocarcinoma A549 Cells. Asian Pac J Cancer Prev. 2013;14(10):5895-900.

6. Molina DM, Jafari R, Ignatushchenko M, Seki T, Larsson EA, Dan C, et al. Monitoring Drug Target Engagement in Cells and Tissues Using the Cellular Thermal Shift Assay. Science. 2013;341(6141):84-7. 
7. Huber KVM, Olek KM, Muller AC, Tan CSH, Bennett KL, Colinge J, et al. Proteome-wide drug and metabolite interaction mapping by thermal-stability profiling. Nat Methods. 2015;12(11):1055-7.

8. Lomenick B, Hao R, Jonai N, Chin RM, Aghajan M, Warburton S, et al. Target identification using drug affinity responsive target stability (DARTS). Proc Natl Acad Sci U S A. 2009;106(51):21984-9.

9. Ma PC, Jagadeeswaran R, Jagadeesh S, Tretiakova MS, Nallasura V, Fox EA, et al. Functional expression and mutations of c-met and its therapeutic inhibition with SU11274 and small interfering RNA in non-small cell lung cancer. Cancer Res. 2005;65(4):1479-88.

10. Beurel E, Grieco SF, Jope RS. Glycogen synthase kinase-3 (GSK3): Regulation, actions, and diseases. Pharmacol Ther. 2015;148:114-31.

11. Yang J, Nie J, Ma XL, Wei YQ, Peng Y, Wei XW. Targeting PI3K in cancer: mechanisms and advances in clinical trials. Mol Cancer. 2019;18.

12. Chang PH, Hwang-Verslues WW, Chang YC, Chen CC, Hsiao M, Jeng YM, et al. Activation of Robo1 Signaling of Breast Cancer Cells by Slit2 from Stromal Fibroblast Restrains Tumorigenesis via Blocking PI3K/Akt/beta-Catenin Pathway. Cancer Res. 2012;72(18):4652-61.

13. Wang W, Medeiros LJ. Utility of Cyclin D1 in the Diagnostic Workup of Hematopoietic Neoplasms: What Can Cyclin D1 Do for Us? Adv Anat Pathol. 2019;26(5):281-91.

14. Xie YB, Shi XF, Sheng K, Han GX, Li WQ, Zhao QQ, et al. PI3K/Akt signaling transduction pathway, erythropoiesis and glycolysis in hypoxia. Mol Med Rep. 2019;19(2):783-91.

15. Dunn KL, Espino PS, Drobic B, He SH, Davie JR. The Ras-MAPK signal transduction pathway, cancer and chromatin remodeling. Biochem Cell Biol. 2005;83(1):1-14.

16. Cheng $\mathrm{JCH}$, Chou $\mathrm{CH}$, Kuo ML, Hsieh CY. Radiation-enhanced hepatocellular carcinoma cell invasion with MMP-9 expression through PI3K/Akt/NF-kappa B signal transduction pathway. Oncogene. 2006;25(53):7009-18.

17. Ma JH, Qin L, Li X. Role of STAT3 signaling pathway in breast cancer. Cell Commun Signal. 2020;18(1).

18. An S, Yang Y, Ward R, Liu Y, Guo XX, Xu TR. A-Raf: A new star of the family of raf kinases. Crit Rev Biochem Mol Biol. 2015;50(6):520-31.

19. MacDonagh L, Gray SG, Breen E, Cuffe S, Finn SP, O'Byrne KJ, et al. Lung cancer stem cells: The root of resistance. Cancer Lett. 2016;372(2):147-56.

20. Zhang C, Stockwell SR, Elbanna M, Ketteler R, Freeman J, Al-Lazikani B, et al. Signalling involving MET and FAK supports cell division independent of the activity of the cell cycle-regulating CDK4/6 kinases. Oncogene. 2019;38(30):5905-20.

21. Syed ZA, Yin W, Hughes K, Gill JN, Shi R, Clifford JL. HGF/c-met/Stat3 signaling during skin tumor cell invasion: indications for a positive feedback loop. BMC Cancer. 2011;11:180.

22. Yan L, Xu F, Dai CL. Relationship between epithelial-to-mesenchymal transition and the inflammatory microenvironment of hepatocellular carcinoma. J Exp Clin Cancer Res. 2018;37(1):203. 
23. Zhang YZ, Xia MF, Jin K, Wang SF, Wei H, Fan CM, et al. Function of the c-Met receptor tyrosine kinase in carcinogenesis and associated therapeutic opportunities. Mol Cancer. 2018;17.

24. Van Schaeybroeck S, Kalimutho M, Dunne PD, Carson R, Allen W, Jithesh PV, et al. ADAM17Dependent c-MET-STAT3 Signaling Mediates Resistance to MEK Inhibitors in KRAS Mutant Colorectal Cancer. Cell Rep. 2014;7(6):1940-55.

25. Harada D, Takigawa N, Kiura K. The Role of STAT3 in Non-Small Cell Lung Cancer. Cancers. 2014;6(2):708-22.

26. Hao NB, Tang B, Wang GZ, Xie R, Hu CJ, Wang SM, et al. Hepatocyte growth factor (HGF) upregulates heparanase expression via the PI3K/Akt/NF-kappa B signaling pathway for gastric cancer metastasis. Cancer Lett. 2015;361(1):57-66.

27. Shen AJ, Wang L, Huang M, Sun JY, Chen Y, Shen YY, et al. c-Myc Alterations Confer Therapeutic Response and Acquired Resistance to c-Met Inhibitors in MET-Addicted Cancers. Cancer Res. 2015;75(21):4548-59.

28. Patil MA, Lee SA, Macias E, Lam ET, Xu CR, Jones KD, et al. Robe of Cyclin D1 as a Mediator of c-Metand beta-Catenin-Induced Hepatocarcinogenesis. Cancer Res. 2009;69(1):253-61.

29. Huh CG, Factor VM, Sanchez A, Uchida K, Conner EA, Thorgeirsson SS. Hepatocyte growth factor/cmet signaling pathway is required for efficient liver regeneration and repair. Proc Natl Acad Sci U S A. 2004;101(13):4477-82.

30. Chmielowiec J, Borowiak M, Morkel M, Stradal T, Munz B, Werner S, et al. c-Met is essential for wound healing in the skin. J Cell Biol. 2007;177(1):151-62.

31. Zhang QW, Ye ZD, Shi L. c-Met kinase inhibitors: an update patent review (2014-2017). Expert Opin Ther Pat. 2019;29(1):25-41.

32. Zhang HL, Feng QQ, Chen WD, Wang YD. HGF/c-MET: A Promising Therapeutic Target in the Digestive System Cancers. Int J Mol Sci. 2018;19(11).

33. Czyz M. HGF/c-MET Signaling in Melanocytes and Melanoma. Int J Mol Sci. 2018;19(12).

34. Pasquini G, Giaccone G. C-MET inhibitors for advanced non-small cell lung cancer. Expert Opin Investig Drugs. 2018;27(4):363-75.

35. Miranda O, Farooqui M, Siegfried JM. Status of Agents Targeting the HGF/c-Met Axis in Lung Cancer. Cancers. 2018;10(9).

36. Wang JY, Wang Z, Li MY, Zhang ZH, Mi CL, Zuo HX, et al. Dictamnine promotes apoptosis and inhibits epithelial-mesenchymal transition, migration, invasion and proliferation by downregulating the HIF-1 alpha and Slug signaling pathways. Chem Biol Interact. 2018;296:134-44.

37. Luo T, Zhang SG, Zhu LF, Zhang FX, Li W, Zhao K, Wen XX, Yu M, Zhan YQ, Chen H, Ge CH, Gao HY, Wang L, Yang XM, Li CY. A selective c-Met and Trks inhibitor Indo5 suppresses hepatocellular carcinoma growth. J Exp Clin Cancer Res. 2019;38(1):130.

38. Gibney GT, Aziz SA, Camp RL, Conrad P, Schwartz BE, Chen CR, et al. c-Met is a prognostic marker and potential therapeutic target in clear cell renal cell carcinoma. Ann Oncol. 2013;24(2):343-9. 
39. Peng J, Qi S, Wang P, Li W, Liu C, Li F. Diagnosis and Prognostic Significance of c-Met in Cervical Cancer: A Meta-Analysis. Dis Markers. 2016;2016:6594016..

40. Wang W, Li Q, Takeuchi S, Yamada T, Koizumi H, Nakamura T, et al. Met Kinase Inhibitor E7050 Reverses Three Different Mechanisms of Hepatocyte Growth Factor-Induced Tyrosine Kinase Inhibitor Resistance in EGFR Mutant Lung Cancer. Clin Cancer Res. 2012;18(6):1663-71.

41. Engelman JA, Zejnullahu K, Mitsudomi T, Song YC, Hyland C, Park JO, et al. MET amplification leads to gefitinib resistance in lung cancer by activating ERBB3 signaling. Science. 2007;316(5827):103943.

42. Benedettini E, Sholl LM, Peyton M, Reilly J, Ware C, Davis L, et al. Met Activation in Non-Small Cell Lung Cancer Is Associated with de Novo Resistance to EGFR Inhibitors and the Development of Brain Metastasis. Am J Pathol. 2010;177(1):415-23.

43. Zhang YW, Wang LM, Jove R, Vande Woude GF. Requirement of Stat3 signaling for HGF/SF-Met mediated tumorigenesis. Oncogene. 2002;21(2):217-26.

44. Kaltschmidt C, Banz-Jansen C, Benhidjeb T, Beshay M, Forster C, Greiner J, et al. A Role for NF-kappa B in Organ Specific Cancer and Cancer Stem Cells. Cancers. 2019;11(5).

45. Chanvorachote P, Sriratanasak N, Nonpanya N. C-myc Contributes to Malignancy of Lung Cancer: $A$ Potential Anticancer Drug Target. Anticancer Res. 2020;40(2):609-18.

46. Shtutman M, Zhurinsky J, Simcha I, Albanese C, D'Amico M, Pestell R, et al. The cyclin D1 gene is a target of the beta-catenin/LEF-1 pathway. Proc Natl Acad Sci U S A. 1999;96(10):5522-7.

47. He TC, Sparks AB, Rago C, Hermeking H, Zawel L, da Costa LT, et al. Identification of c-MYC as a target of the APC pathway. Science. 1998;281(5382):1509-12.

48. Tuynman JB, Vermeulen L, Boon EM, Kemper K, Zwinderman AH, Peppelenbosch MP, et al. Cyclooxygenase-2 inhibition inhibits c-Met kinase activity and wnt activity in colon cancer. Cancer Res. 2008;68(4):1213-20.

49. Holland JD, Gyorffy B, Vogel R, Eckert K, Valenti G, Fang L, et al. Combined Wnt/beta-Catenin, Met, and CXCL12/CXCR4 Signals Characterize Basal Breast Cancer and Predict Disease Outcome. Cell Rep. 2013;5(5):1214-27.

50. Previdi S, Maroni P, Matteucci E, Broggini M, Bendinelli P, Desiderio MA. Interaction between humanbreast cancer metastasis and bone microenvironment through activated hepatocyte growth factor/Met and beta-catenin/Wnt pathways. Eur J Cancer. 2010;46(9):1679-91.

51. McManus EJ, Sakamoto K, Armit LJ, Ronaldson L, Shpiro N, Marquez R, et al. Role that phosphorylation of GSK3 plays in insulin. EMBO J. 2005;24(8):1571-83.

52. Ng SS, Mahmoudi T, Danenberg E, Bejaoui I, de Lau W, Korswagen HC, et al. Phosphatidylinositol 3Kinase Signaling Does Not Activate the Wnt Cascade. J Biol Chem. 2009;284(51):35308-13.

53. Li VSW, Ng SS, Boersema PJ, Low TY, Karthaus WR, Gerlach JP, et al. Wnt Signaling through Inhibition of beta-Catenin Degradation in an Intact Axin1 Complex. Cell. 2012;149(6):1245-56. 

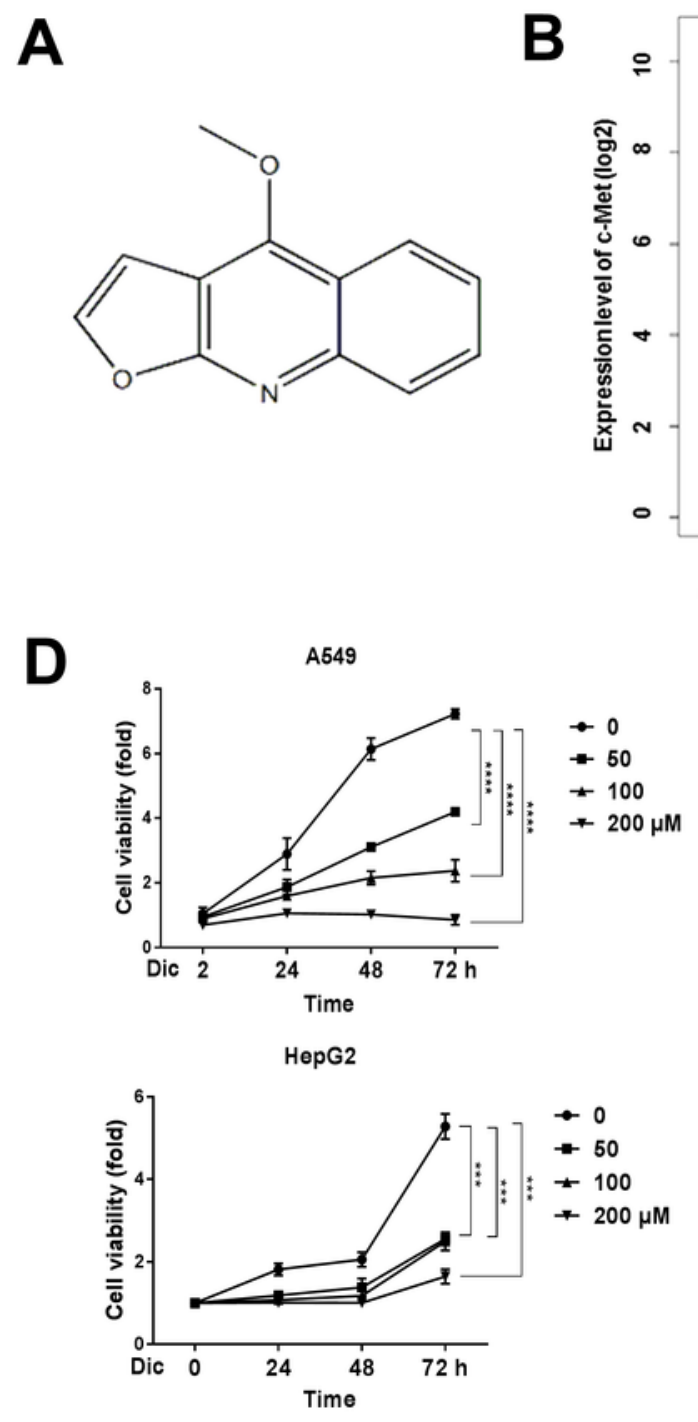

E

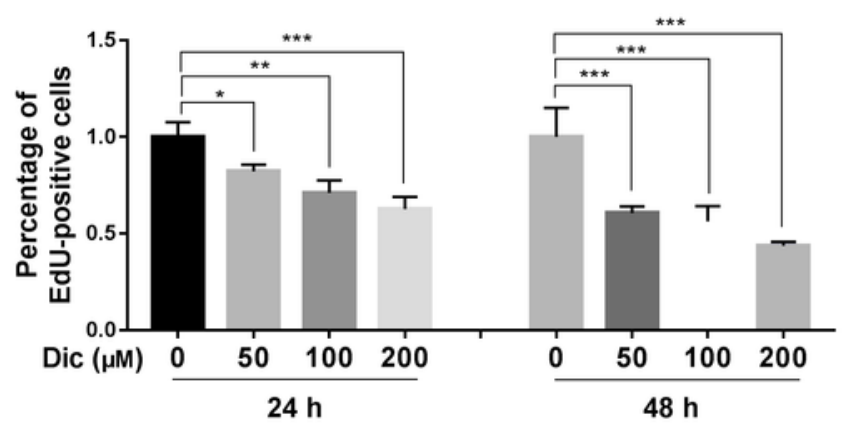

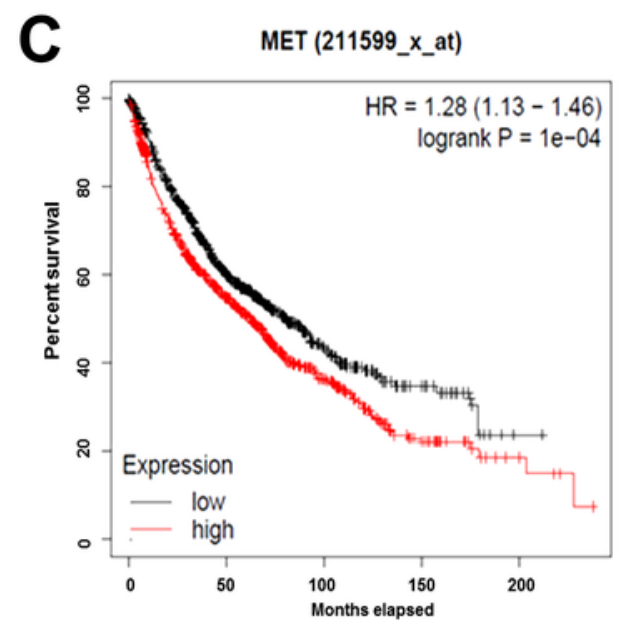

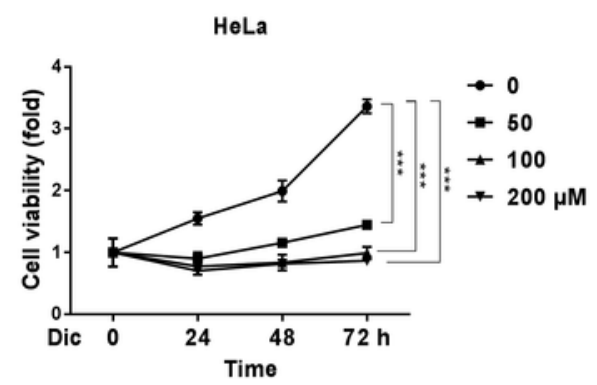

ACHN
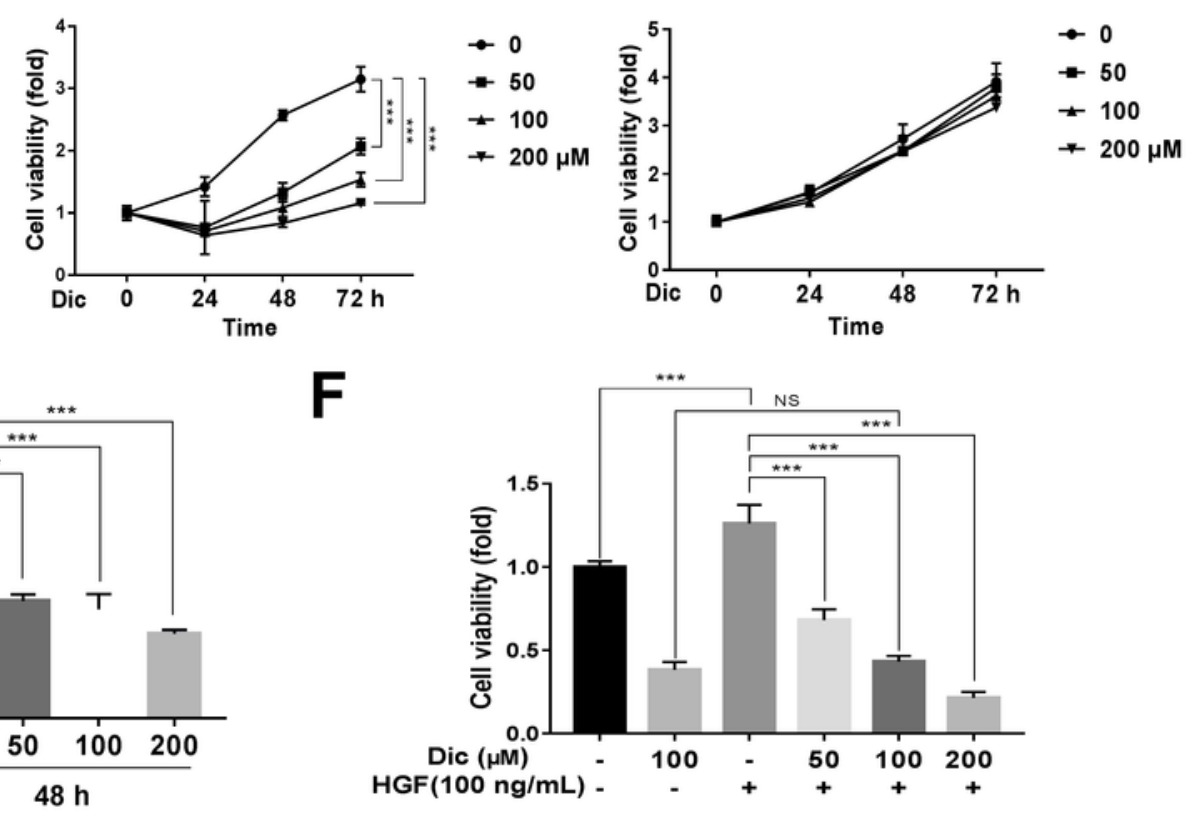

Figure 1

Dic inhibits the proliferation of cancer cells with c-Met over-expression. a Chemical structure of Dic. b Bioinformatics analysis of c-Met mRNA expression levels in LUAD, LUSC and normal lung tissues from the TCGA dataset. c The prognostic value of c-Met was evaluated in the TCGA cohort. $d$ Various types of 
cancer cells (A549, H1299, HeLa, HepG2 and ACHN) with c-Met over-expression or c-Met low-expressing HEK293 cells used as control were treated with different concentrations of Dic for the indicated times, following which cell proliferation was analyzed using the CCK8 assay $(n=6)$. e EdU incorporation assays were applied to examine the EdU positive A549 cells after treatment with Dic for 24 or $48 \mathrm{~h}$. $\mathrm{f}$ The effect of Dic on HGF-activated proliferation response in A549 cells was evaluated by CCK-8 assay. Data were expressed as the mean \pm S.D. from three independent experiments. The significance was determined by one-way ANOVA with Dunnett's test and ${ }^{*} p<0.05$, ${ }^{*} p<0.01$, ${ }^{\star \star *} p<0.001$ and ${ }^{* \star *} \mathrm{p}<0.0001$ for the designated treatment versus the control.

A<smiles>COc1c2ccccc2nc2occc12</smiles>

B

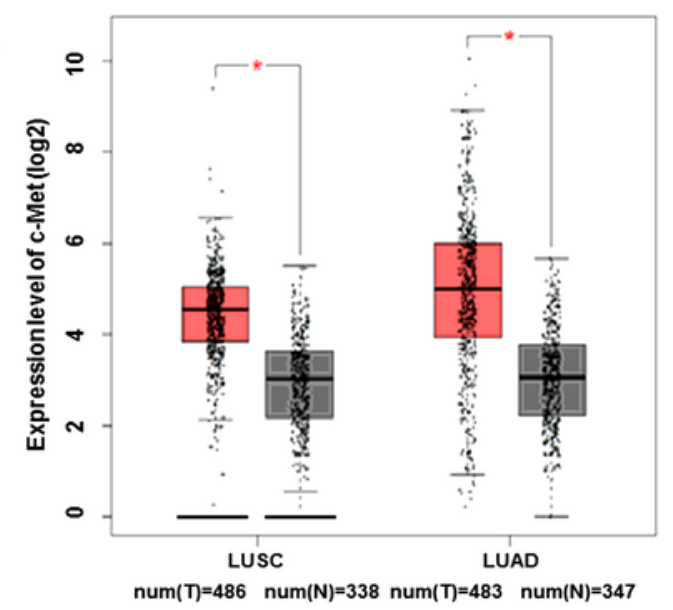

H1299

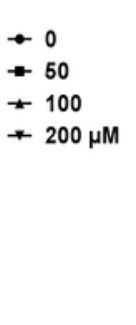

HepG2

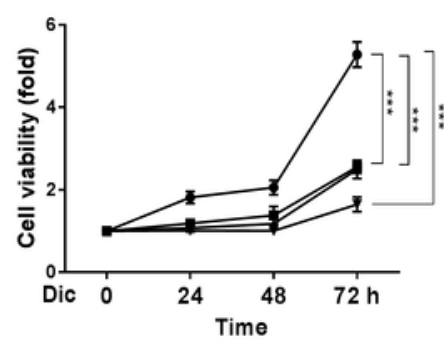

E

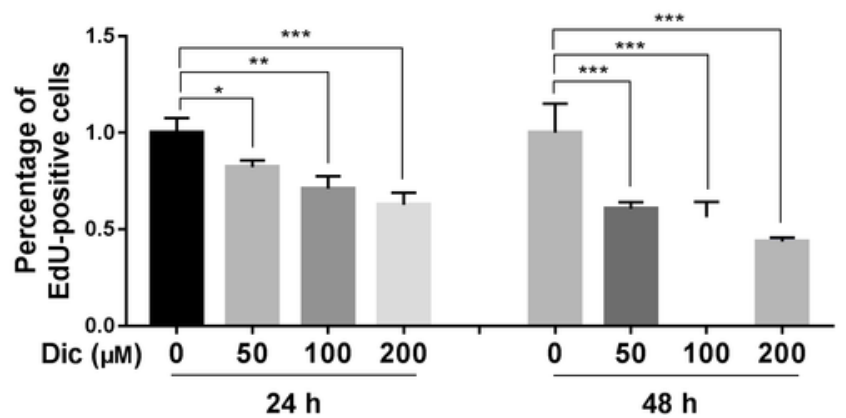

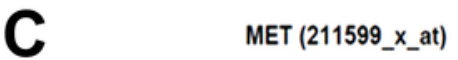

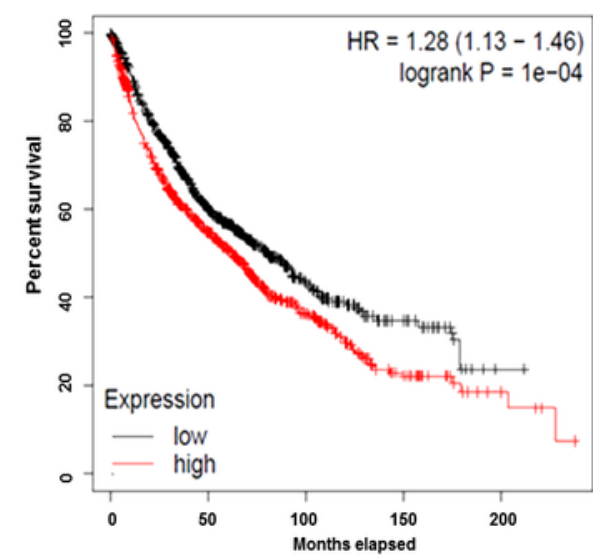

HeLa

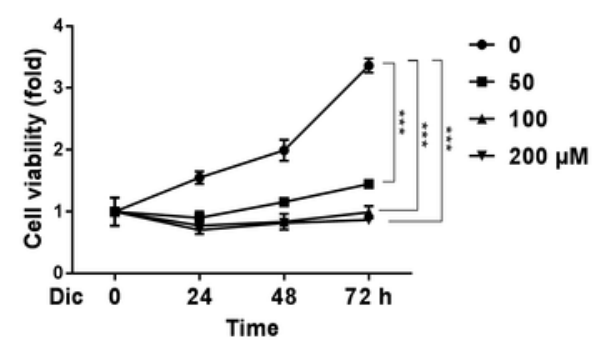

HEK293

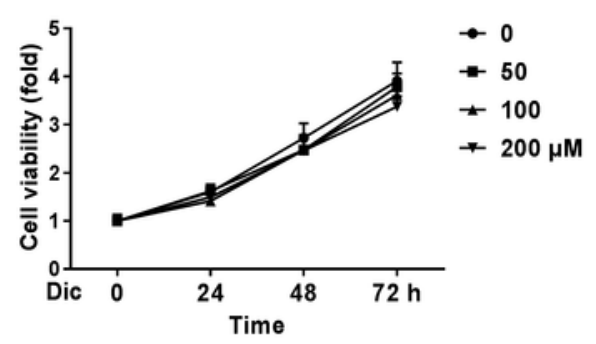




\section{Figure 1}

Dic inhibits the proliferation of cancer cells with c-Met over-expression. a Chemical structure of Dic. b Bioinformatics analysis of c-Met mRNA expression levels in LUAD, LUSC and normal lung tissues from the TCGA dataset. c The prognostic value of c-Met was evaluated in the TCGA cohort. $d$ Various types of cancer cells (A549, H1299, HeLa, HepG2 and ACHN) with c-Met over-expression or c-Met low-expressing HEK293 cells used as control were treated with different concentrations of Dic for the indicated times, following which cell proliferation was analyzed using the CCK8 assay $(n=6)$. e EdU incorporation assays were applied to examine the EdU positive A549 cells after treatment with Dic for 24 or $48 \mathrm{~h}$. $\mathrm{f}$ The effect of Dic on HGF-activated proliferation response in A549 cells was evaluated by CCK-8 assay. Data were expressed as the mean \pm S.D. from three independent experiments. The significance was determined by one-way ANOVA with Dunnett's test and ${ }^{*} p<0.05$, ${ }^{\star \star} p<0.01$, ${ }^{\star \star *} p<0.001$ and ${ }^{* \star \star \star} p<0.0001$ for the designated treatment versus the control. 
A<smiles></smiles>

B
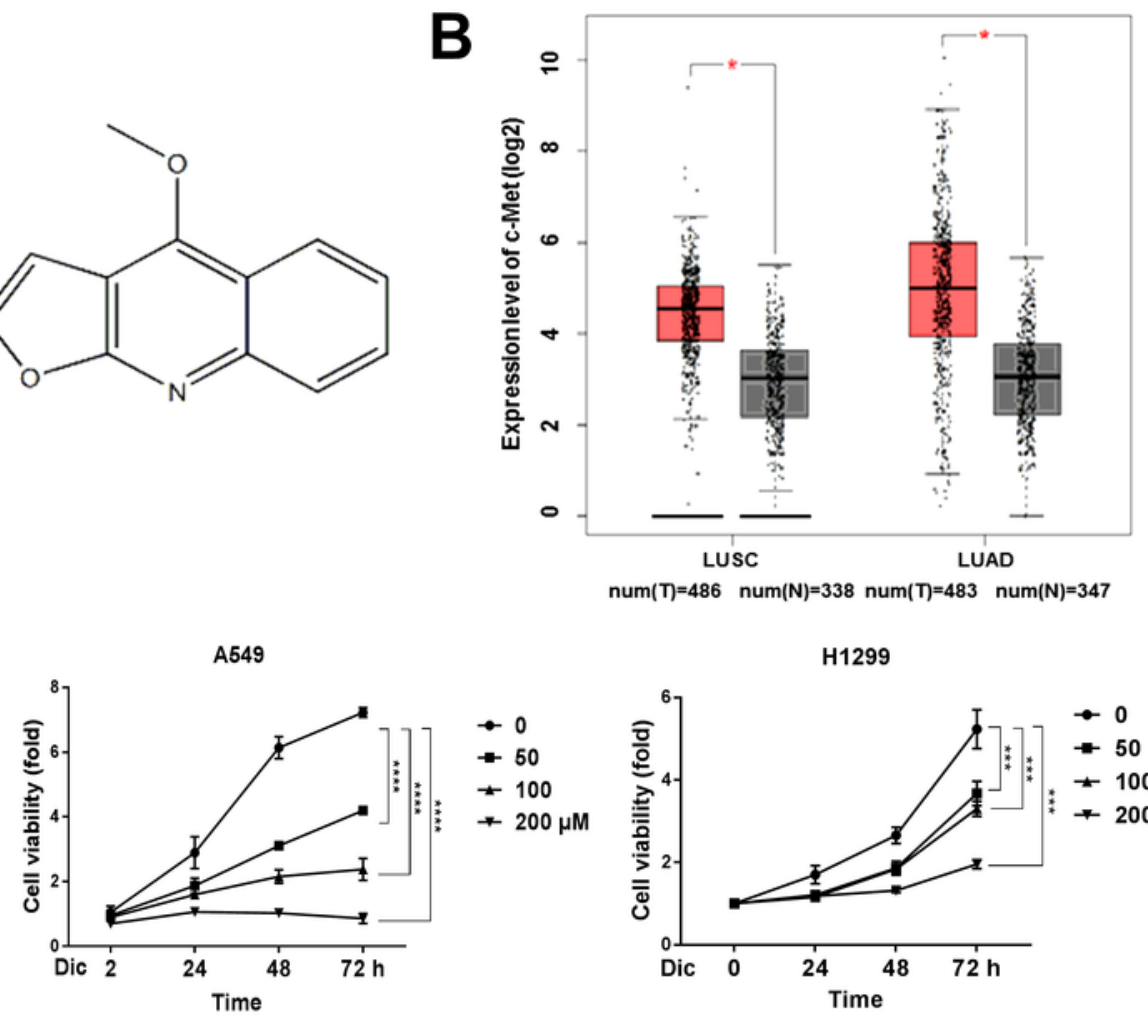

HepG2

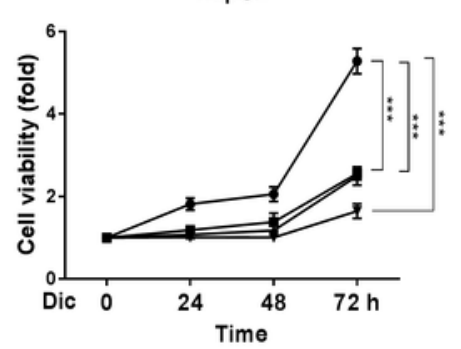

E

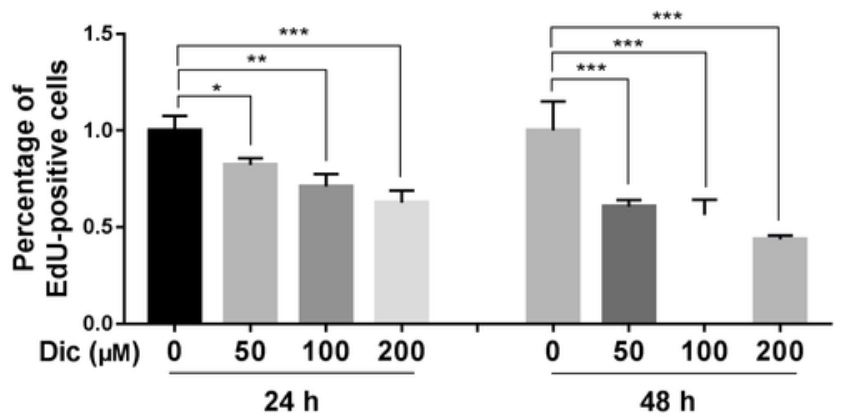

H1299

C

MET (211599_x_at)

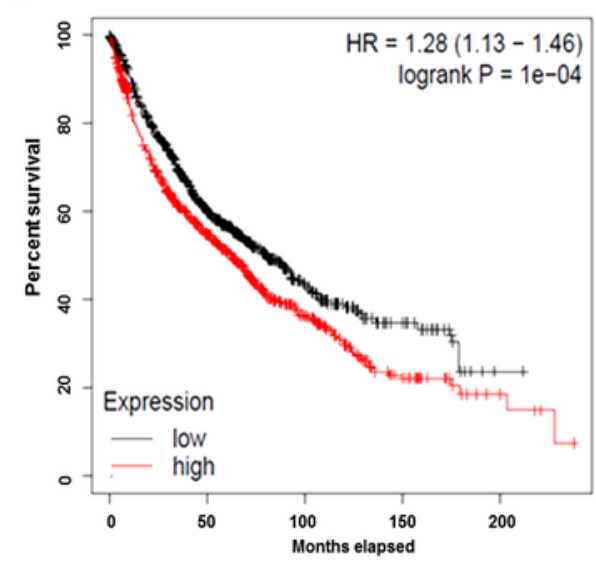

HeLa

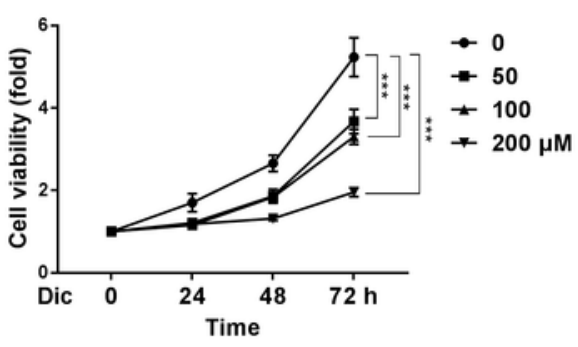

ACHN

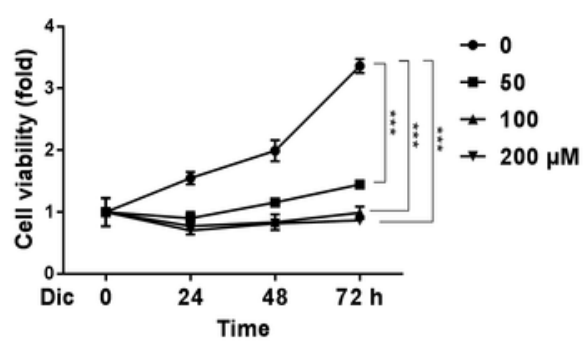

HEK293
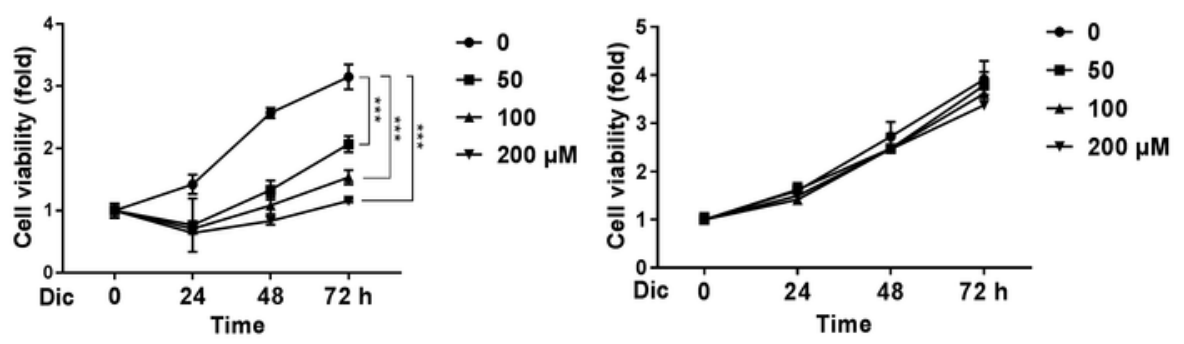

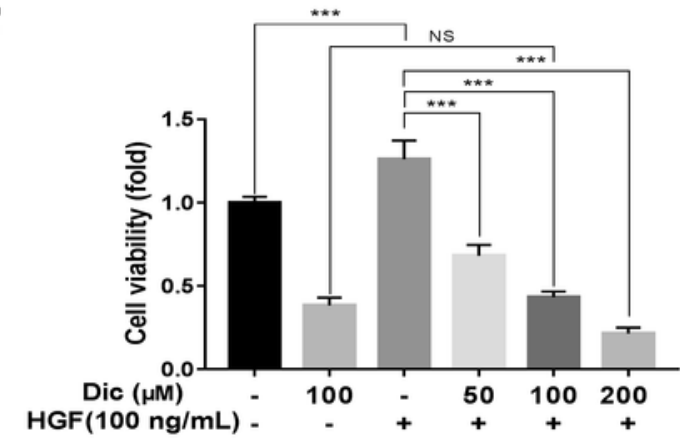

\section{Figure 1}

Dic inhibits the proliferation of cancer cells with c-Met over-expression. a Chemical structure of Dic. b Bioinformatics analysis of c-Met mRNA expression levels in LUAD, LUSC and normal lung tissues from the TCGA dataset. c The prognostic value of c-Met was evaluated in the TCGA cohort. $d$ Various types of cancer cells (A549, H1299, HeLa, HepG2 and ACHN) with c-Met over-expression or c-Met low-expressing HEK293 cells used as control were treated with different concentrations of Dic for the indicated times, 
following which cell proliferation was analyzed using the CCK8 assay $(n=6)$. e EdU incorporation assays were applied to examine the EdU positive A549 cells after treatment with Dic for 24 or $48 \mathrm{~h}$. $\mathrm{f}$ The effect of Dic on HGF-activated proliferation response in A549 cells was evaluated by CCK-8 assay. Data were expressed as the mean \pm S.D. from three independent experiments. The significance was determined by one-way ANOVA with Dunnett's test and ${ }^{*} p<0.05$, ${ }^{*} p<0.01$, ${ }^{\star \star *} p<0.001$ and ${ }^{* \star * *} p<0.0001$ for the designated treatment versus the control.

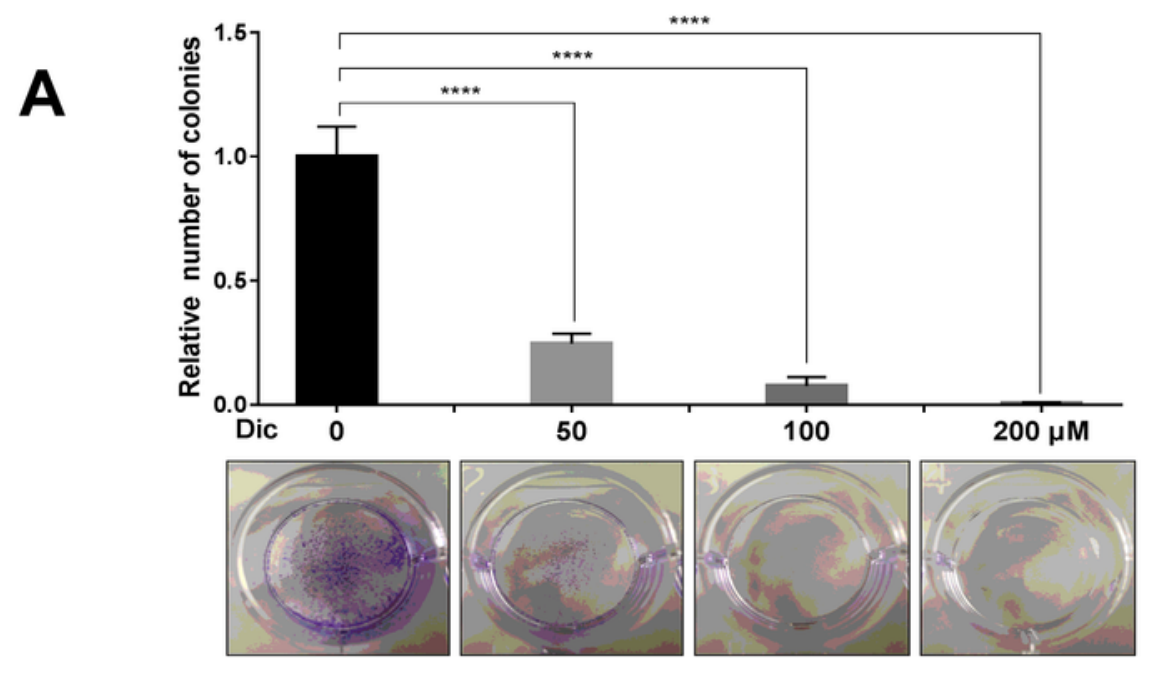

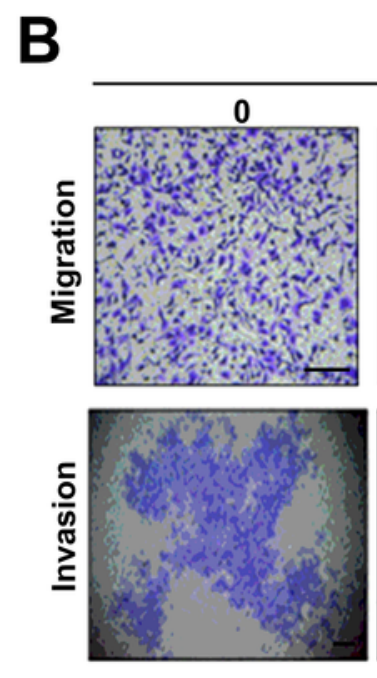

C

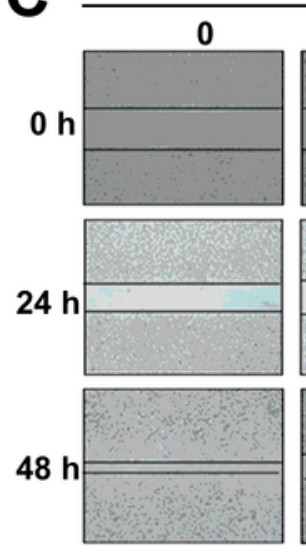

Dic $(36 \mathrm{~h})$
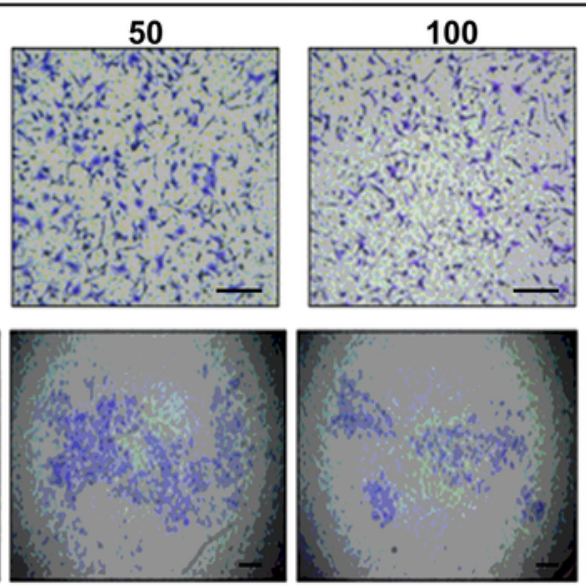

Dic

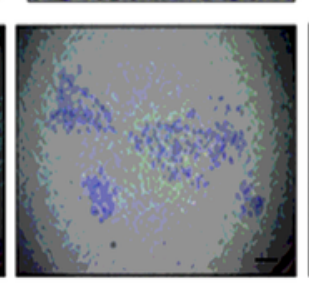

50
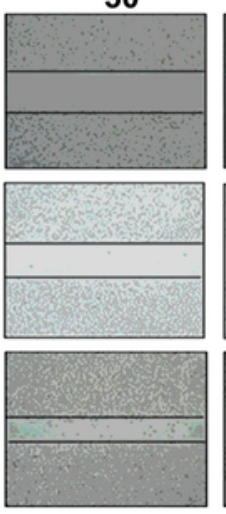

100

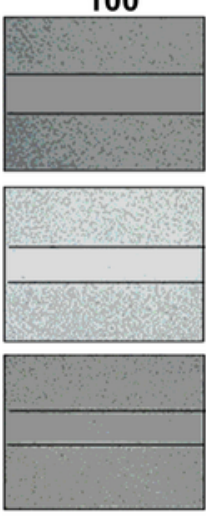

$200 \mu \mathrm{M}$
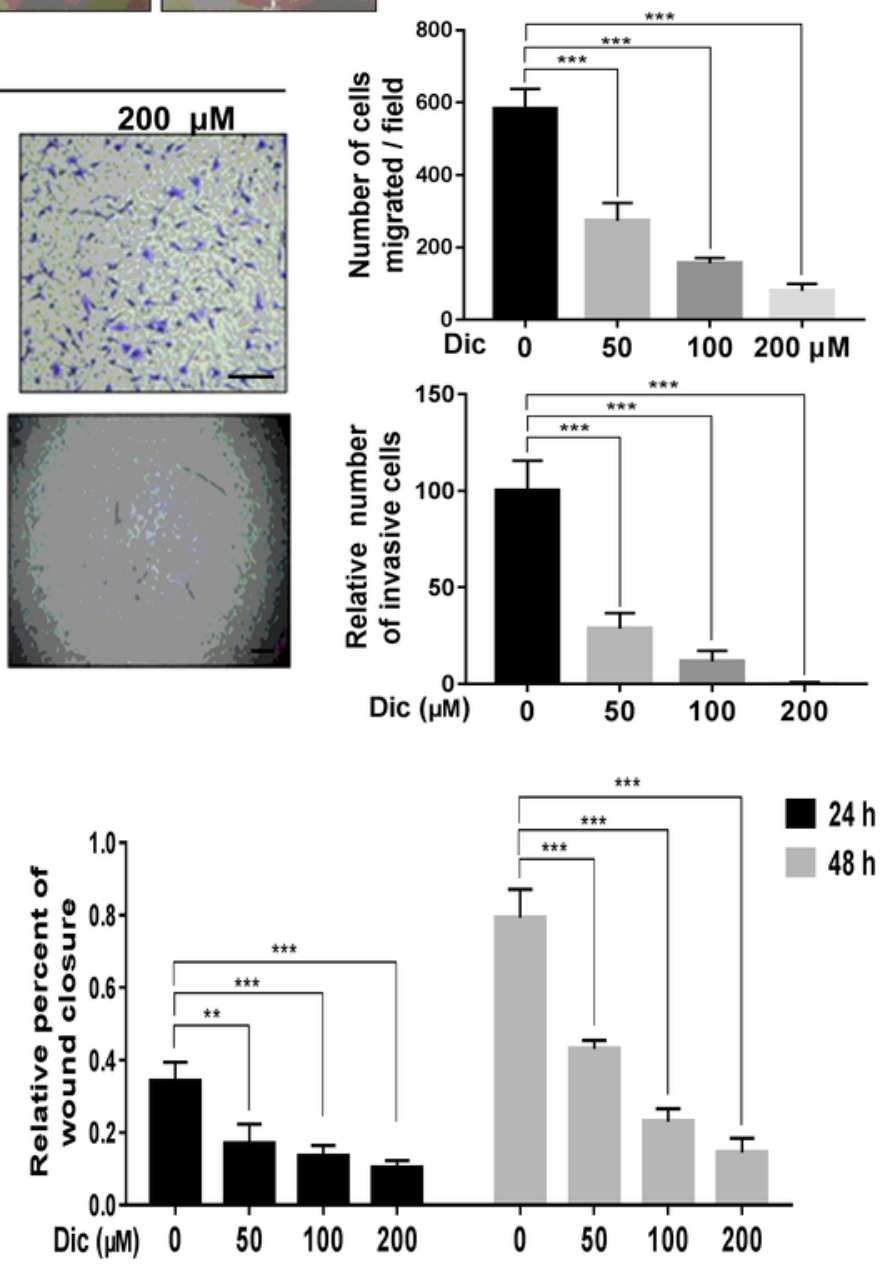

Figure 2 
Dic suppresses A549 cell clonogenicity, invasiveness and migration. a Effect of Dic on the colony formation of A549 cells. Cells were treated with Dic and incubated for 2 weeks, colony numbers were counted using a microscope and the Image-Pro plus software program. The effect of Dic on A549 cell migration and invasion were tested by using scratch wound-healing assay (c)/transwell assay (b, upper panel) and matrigel transwell assay (b, lower panel), respectively. Scale bar $=80 \mu \mathrm{m}$. Data shown as the mean \pm S.D. For each assay, $n=5$, the significance was determined by one-way ANOVA with Dunnett's test and ${ }^{* *} p<0.01$ and ${ }^{* * *} p<0.001$ compared with the controls.

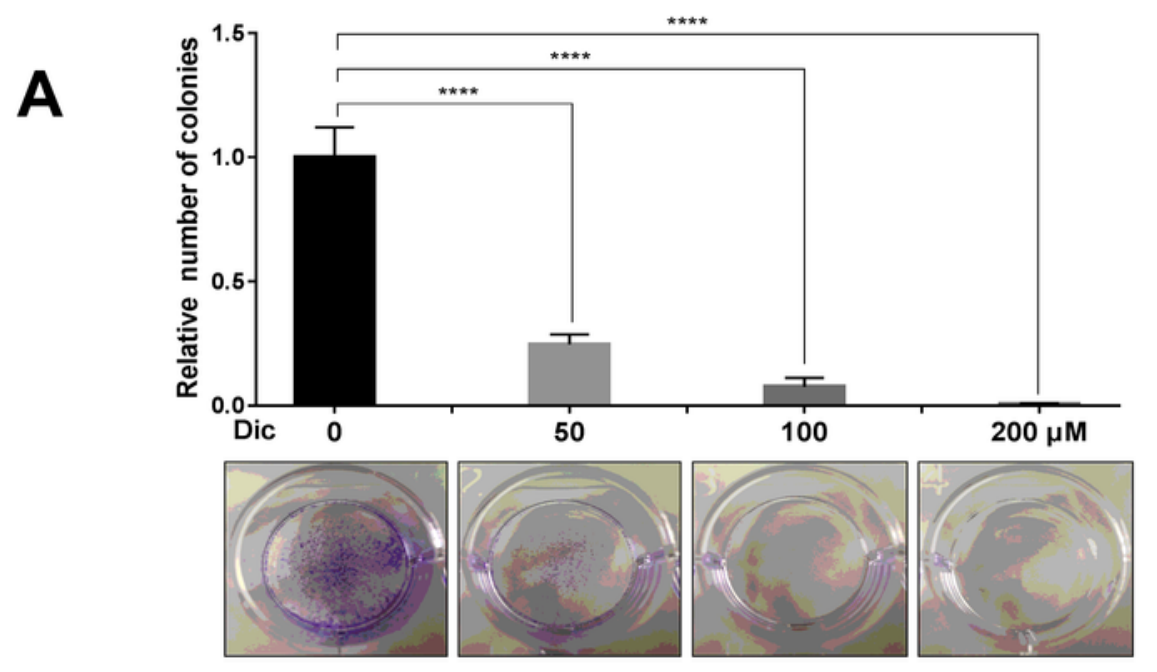

B
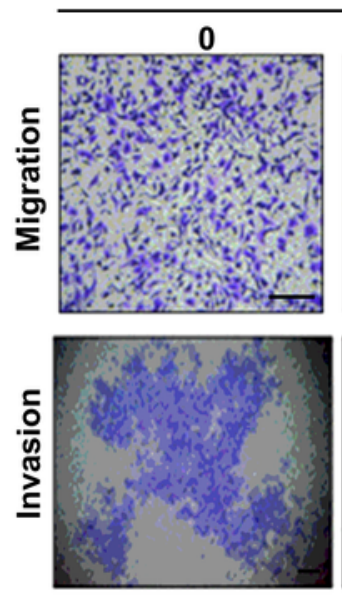

C
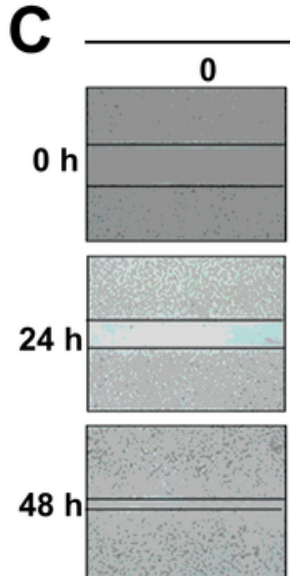

Dic (36 h)
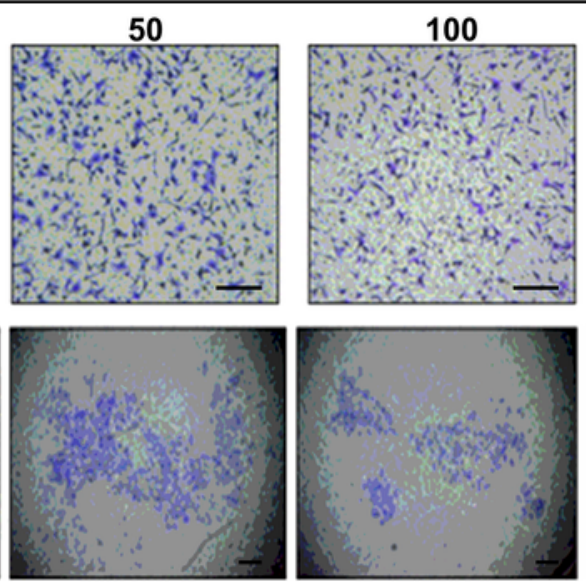

Dic

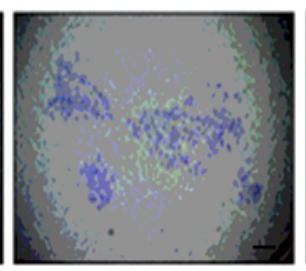

100
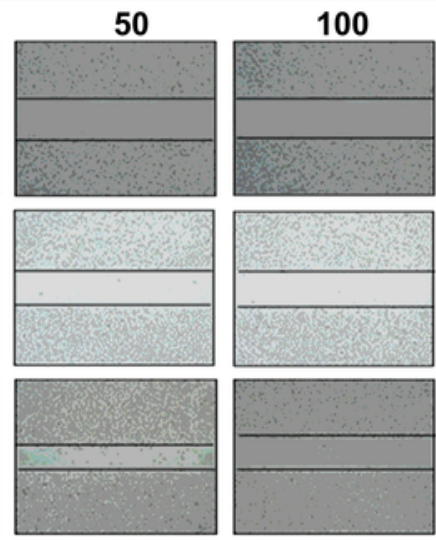

$200 \mu \mathrm{M}$
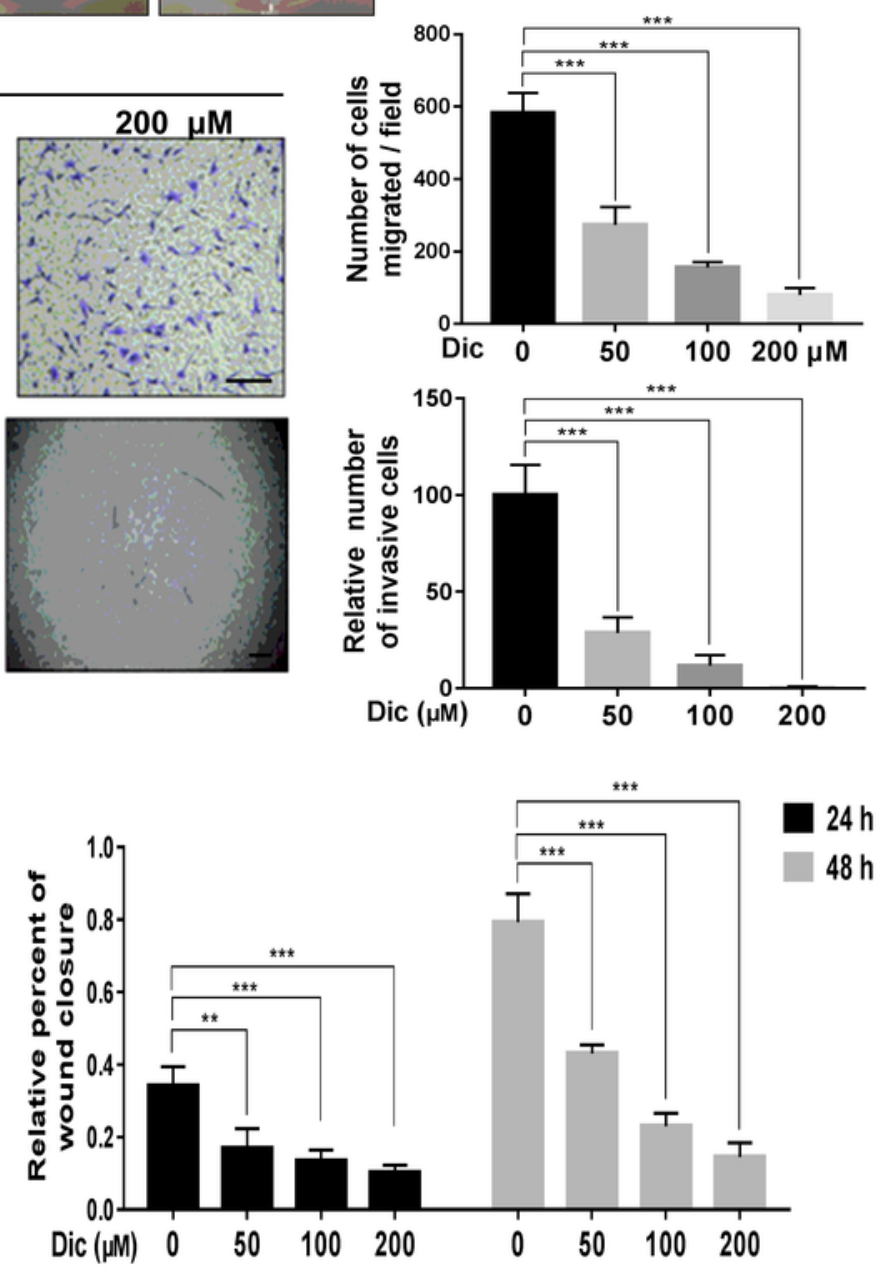


\section{Figure 2}

Dic suppresses A549 cell clonogenicity, invasiveness and migration. a Effect of Dic on the colony formation of A549 cells. Cells were treated with Dic and incubated for 2 weeks, colony numbers were counted using a microscope and the Image-Pro plus software program. The effect of Dic on A549 cell migration and invasion were tested by using scratch wound-healing assay (c)/transwell assay (b, upper panel) and matrigel transwell assay (b, lower panel), respectively. Scale bar $=80 \mu \mathrm{m}$. Data shown as the mean \pm S.D. For each assay, $n=5$, the significance was determined by one-way ANOVA with Dunnett's test and ${ }^{* *} p<0.01$ and ${ }^{* * *} p<0.001$ compared with the controls. 


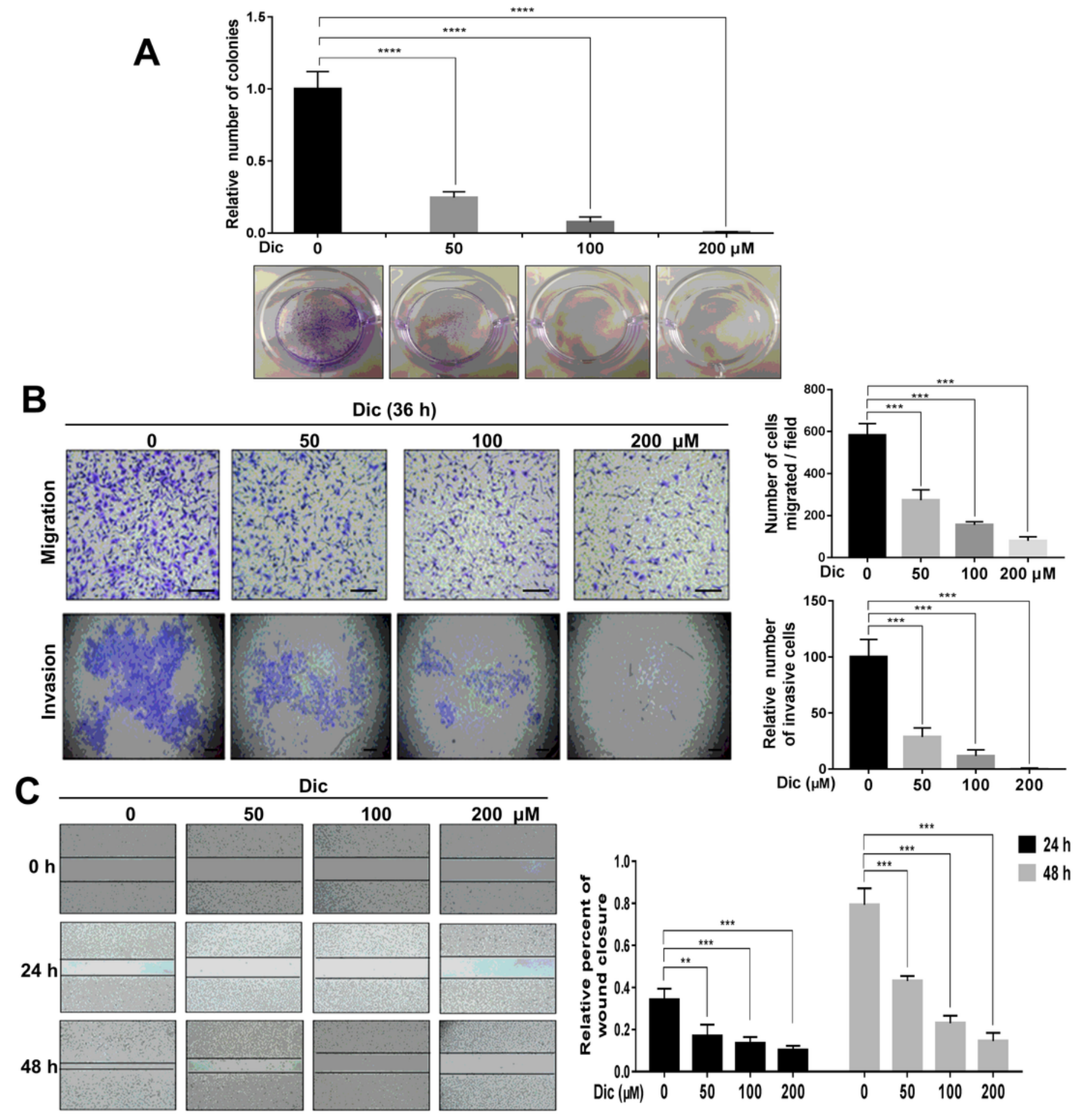

Figure 2

Dic suppresses A549 cell clonogenicity, invasiveness and migration. a Effect of Dic on the colony formation of A549 cells. Cells were treated with Dic and incubated for 2 weeks, colony numbers were counted using a microscope and the Image-Pro plus software program. The effect of Dic on A549 cell migration and invasion were tested by using scratch wound-healing assay (c)/transwell assay (b, upper panel) and matrigel transwell assay (b, lower panel), respectively. Scale bar $=80 \mu \mathrm{m}$. Data shown as the 
mean \pm S.D. For each assay, $n=5$, the significance was determined by one-way ANOVA with Dunnett's test and ${ }^{* *} p<0.01$ and ${ }^{* * *} p<0.001$ compared with the controls.

A
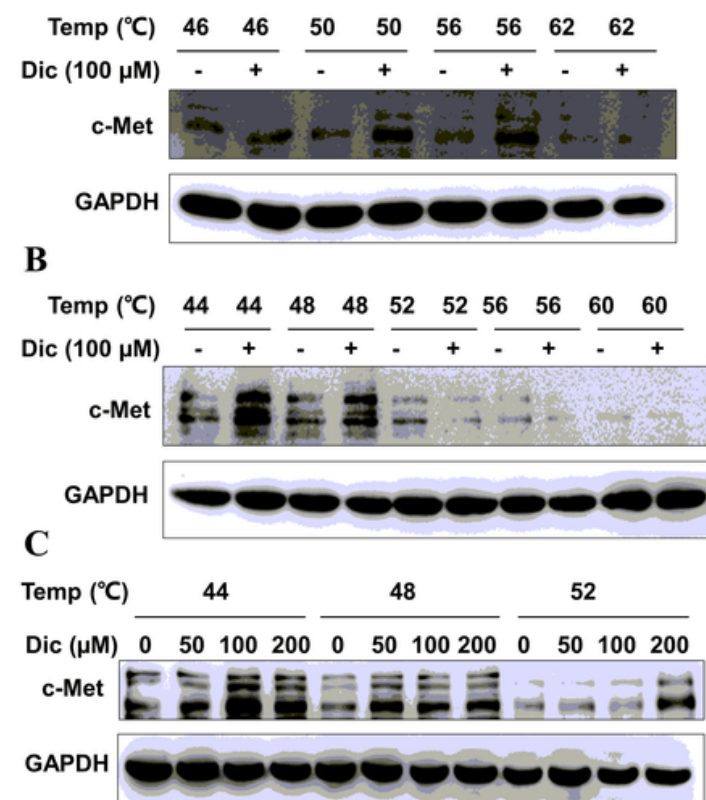

D

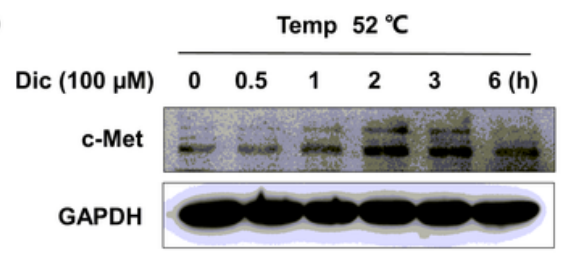

E

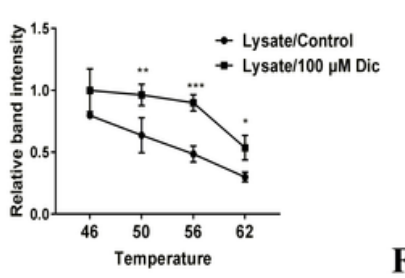

Pronase Total proten

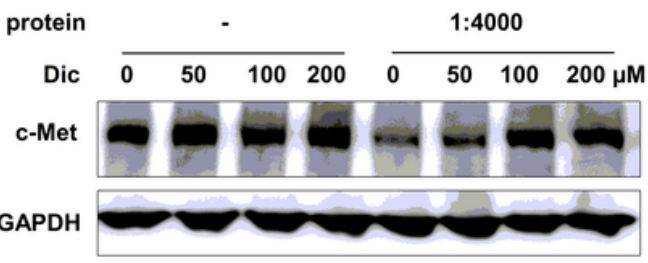

F
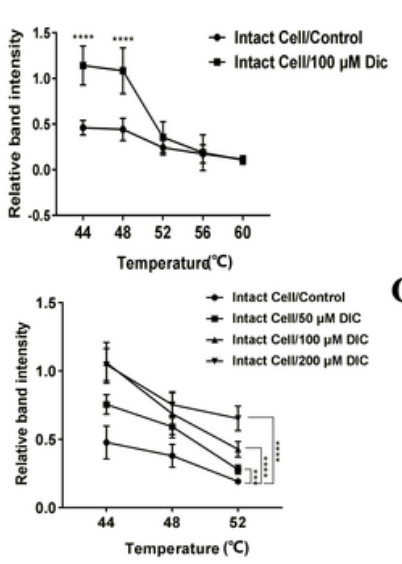

G

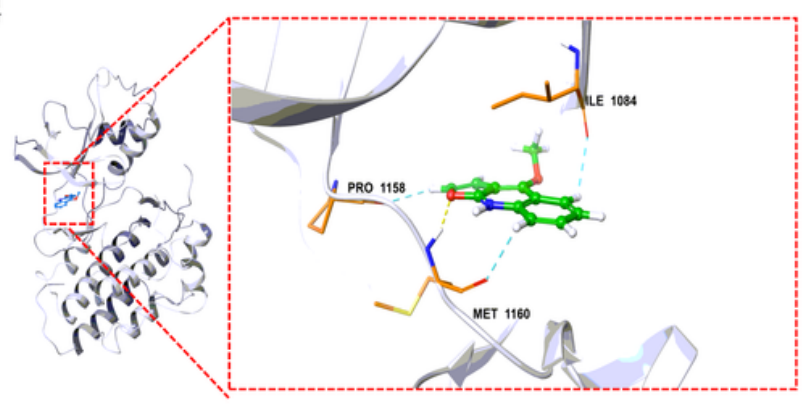

Figure 3

Validation of c-Met as a target protein of Dic by CETSA, DARTS and molecular docking. a and b CETSA was performed on A549 cell lysates (a) and intact A549 cells (b) treated with the same concentration of Dic and heated to different temperatures. c For cell-based CETSA at different concentrations of Dic, A549 cells were treated with different concentrations of Dic for $2 \mathrm{~h}$ and then collected and lysed. The abundance of c-Met in the soluble fraction of cell lysates at different concentrations of Dic and different temperatures were analyzed. d Time course for CETSA in intact A549 cells. A549 cells incubated with 100 $\mu \mathrm{M}$ of Dic for the indicated time periods were heated at $52^{\circ} \mathrm{C}$ for $3 \mathrm{~min}$. The presence of $\mathrm{c}$-Met in the soluble fraction of the cell lysates at different incubation periods was analyzed. The band intensity of cMet and GAPDH was quantified by ImageJ software, the abundance of c-Met normalized to GAPDH is presented. All data represent the mean \pm S.D. of three experiments, ${ }^{*} p<0.05,{ }^{*} p<0.01$, ${ }^{\star *} p<0.001$ and $\star \star \star \star p<0.0001$ were calculated based on comparison with the control (one-way ANOVA with Dunnett's test). e and $f$ The DARTS assay was used to evaluate Dic's ability to bind to and stabilize c-Met. A549 cell lysates were incubated with Dic or vehicle at indicated concentrations for $2 \mathrm{~h}$ at room temperature, followed by digestion with pronase (pronase to protein ratio, 1:3000 or 1:4000) for 20 min at room 
temperature and analysis by Western blotting. The results shown are representative of three independent experiments, GAPDH expression was used as the loading control. g Structural modelling of the Dic and cMet interaction. The c-Met structure is shown as a ribbon representation and Dic is shown in stick form, the hydrogen bonds that formed between c-Met and Dic are shown as dotted lines.

A

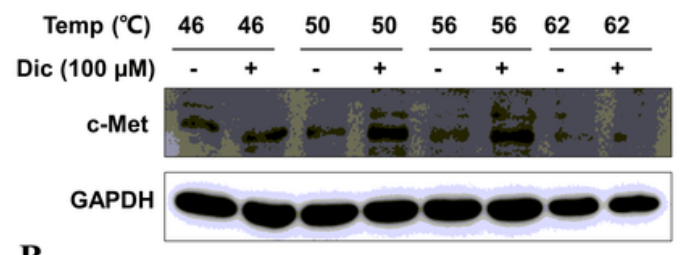

B

$\begin{array}{lllllllllll}\text { Temp }\left({ }^{\circ} \mathrm{C}\right) & 44 & 44 & 48 & 48 & 52 & 52 & 56 & 56 & 60 & 60\end{array}$ Dic $(100 \mu \mathrm{M})+\frac{-+}{-+}+\frac{4}{-+}+$

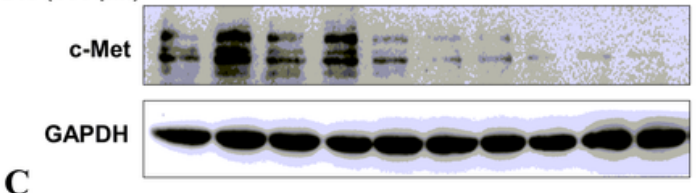

C

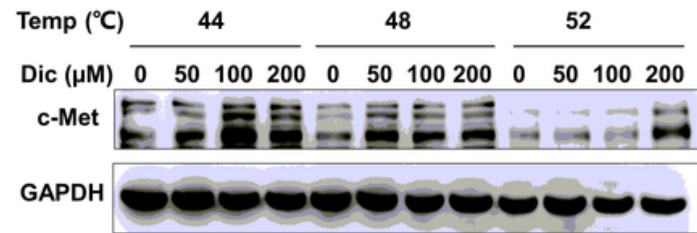

D

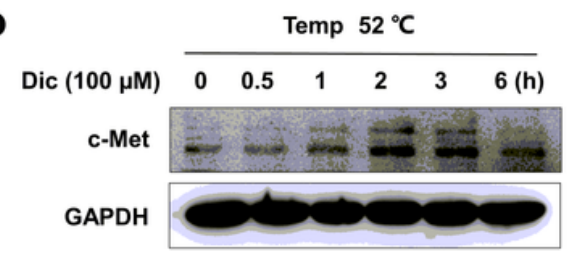

E

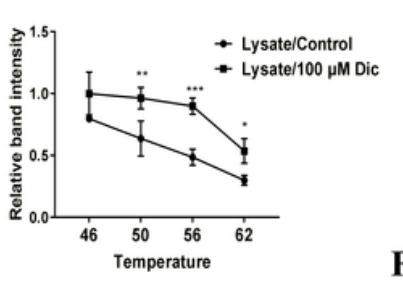

Pronase:Total protein $\quad$ - $\quad 1: 4000$

Pronase:Total protein $\quad$ - $1: 3000$
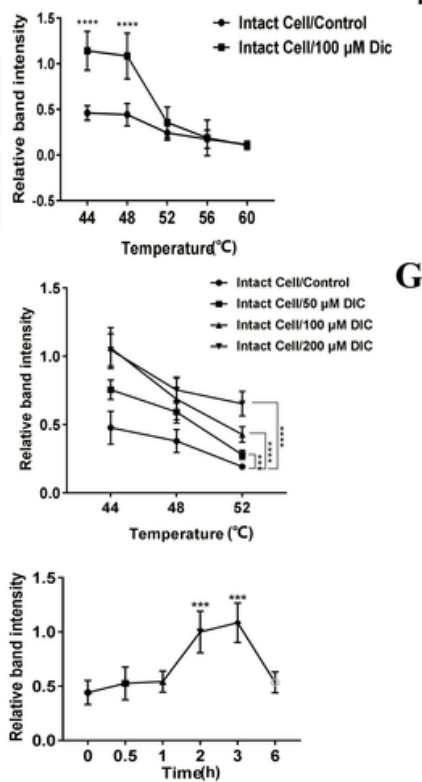

$\mathbf{G}$

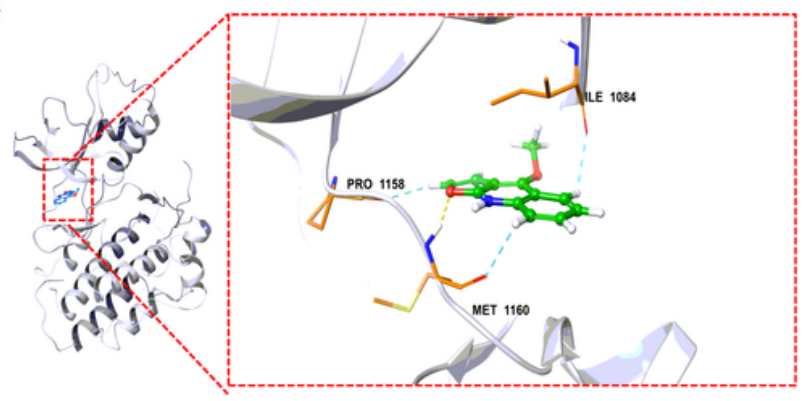

\section{Figure 3}

Validation of c-Met as a target protein of Dic by CETSA, DARTS and molecular docking. a and b CETSA was performed on A549 cell lysates (a) and intact A549 cells (b) treated with the same concentration of Dic and heated to different temperatures. c For cell-based CETSA at different concentrations of Dic, A549 cells were treated with different concentrations of Dic for $2 \mathrm{~h}$ and then collected and lysed. The abundance of c-Met in the soluble fraction of cell lysates at different concentrations of Dic and different temperatures were analyzed. d Time course for CETSA in intact A549 cells. A549 cells incubated with 100 $\mu \mathrm{M}$ of Dic for the indicated time periods were heated at $52^{\circ} \mathrm{C}$ for $3 \mathrm{~min}$. The presence of c-Met in the soluble fraction of the cell lysates at different incubation periods was analyzed. The band intensity of cMet and GAPDH was quantified by ImageJ software, the abundance of c-Met normalized to GAPDH is presented. All data represent the mean \pm S.D. of three experiments, ${ }^{\star} p<0.05,{ }^{* \star} p<0.01,{ }^{\star \star \star} p<0.001$ and $\star \star \star \star x p<0.0001$ were calculated based on comparison with the control (one-way ANOVA with Dunnett's test). e and $f$ The DARTS assay was used to evaluate Dic's ability to bind to and stabilize c-Met. A549 cell 
lysates were incubated with Dic or vehicle at indicated concentrations for $2 \mathrm{~h}$ at room temperature, followed by digestion with pronase (pronase to protein ratio, 1:3000 or 1:4000) for 20 min at room temperature and analysis by Western blotting. The results shown are representative of three independent experiments, GAPDH expression was used as the loading control. g Structural modelling of the Dic and cMet interaction. The c-Met structure is shown as a ribbon representation and Dic is shown in stick form, the hydrogen bonds that formed between c-Met and Dic are shown as dotted lines.

A

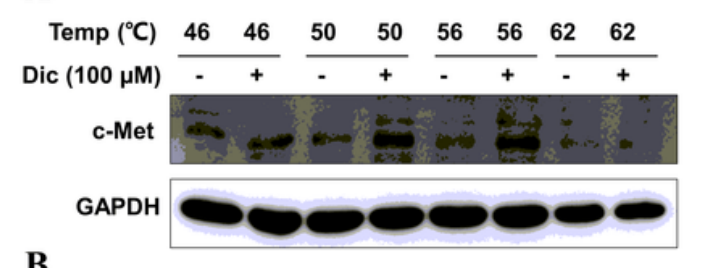

B

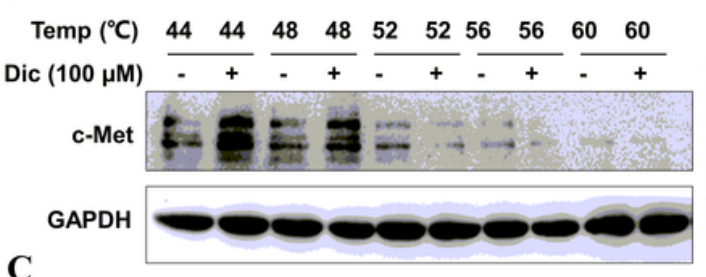

C

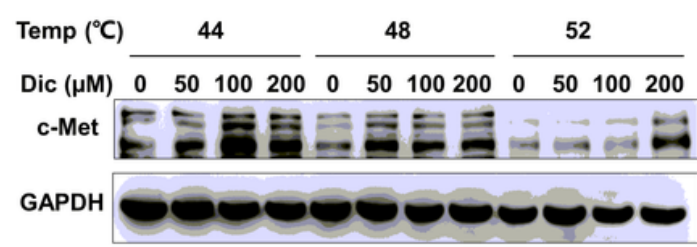

D

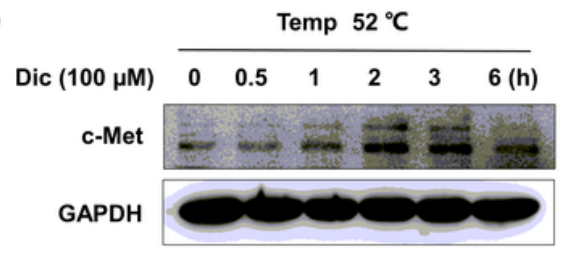

E

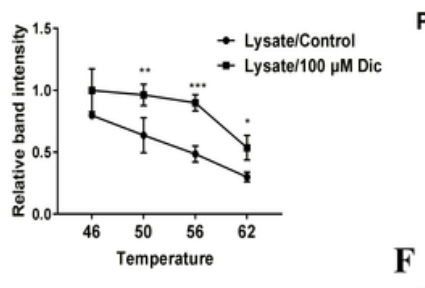

Pronase:Total protein $\quad$ - $\quad 1: 4000$

$\begin{array}{lll}\text { Pronase:Total protein } & - & 1: 3000\end{array}$
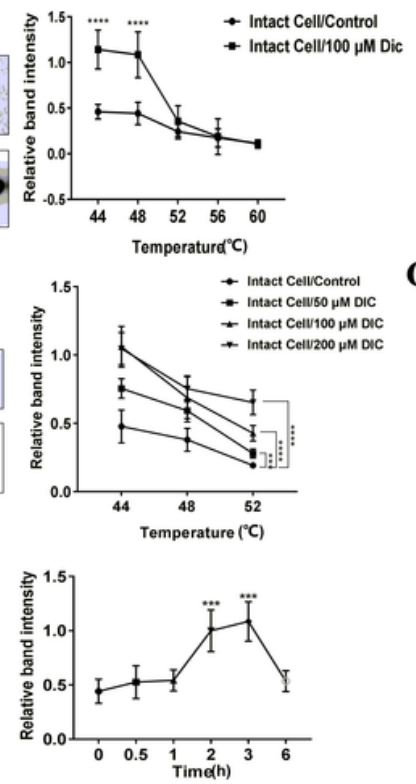

G

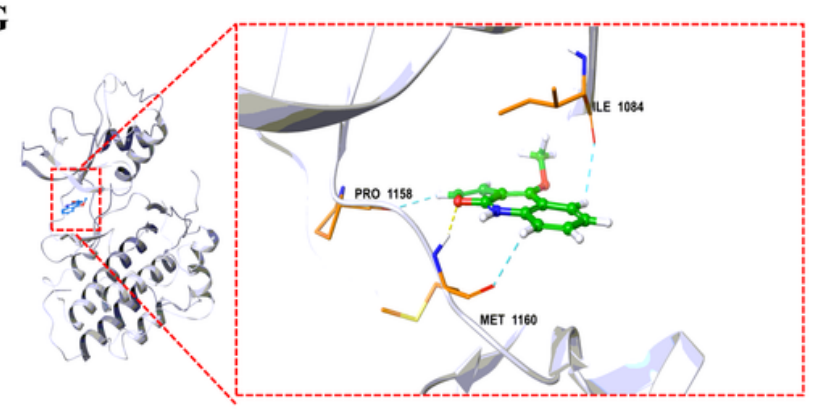

Figure 3

Validation of c-Met as a target protein of Dic by CETSA, DARTS and molecular docking. a and b CETSA was performed on A549 cell lysates (a) and intact A549 cells (b) treated with the same concentration of Dic and heated to different temperatures. c For cell-based CETSA at different concentrations of Dic, A549 cells were treated with different concentrations of Dic for $2 \mathrm{~h}$ and then collected and lysed. The abundance of c-Met in the soluble fraction of cell lysates at different concentrations of Dic and different temperatures were analyzed. $d$ Time course for CETSA in intact A549 cells. A549 cells incubated with 100 $\mu \mathrm{M}$ of Dic for the indicated time periods were heated at $52^{\circ} \mathrm{C}$ for $3 \mathrm{~min}$. The presence of c-Met in the soluble fraction of the cell lysates at different incubation periods was analyzed. The band intensity of cMet and GAPDH was quantified by ImageJ software, the abundance of c-Met normalized to GAPDH is presented. All data represent the mean \pm S.D. of three experiments, ${ }^{\star} p<0.05,{ }^{\star \star} p<0.01,{ }^{\star \star \star} p<0.001$ and 
${ }^{\star \star \star \star} \mathrm{p}<0.0001$ were calculated based on comparison with the control (one-way ANOVA with Dunnett's test). e and $f$ The DARTS assay was used to evaluate Dic's ability to bind to and stabilize c-Met. A549 cell lysates were incubated with Dic or vehicle at indicated concentrations for $2 \mathrm{~h}$ at room temperature, followed by digestion with pronase (pronase to protein ratio, 1:3000 or 1:4000) for 20 min at room temperature and analysis by Western blotting. The results shown are representative of three independent experiments, GAPDH expression was used as the loading control. $\mathrm{g}$ Structural modelling of the Dic and cMet interaction. The c-Met structure is shown as a ribbon representation and Dic is shown in stick form, the hydrogen bonds that formed between c-Met and Dic are shown as dotted lines.

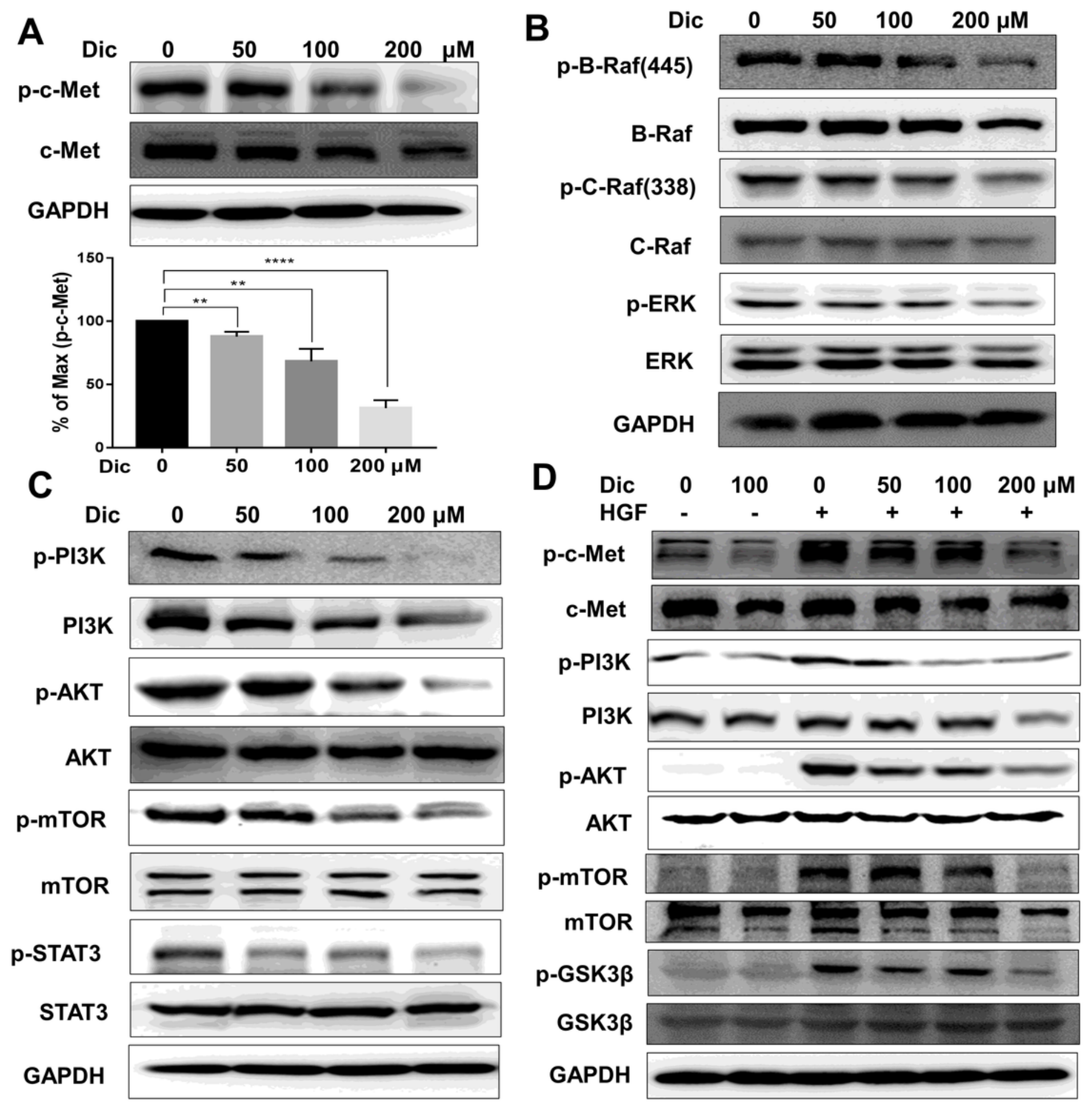




\section{Figure 4}

Dic is a potent c-Met inhibitor and suppresses the c-Met signaling pathway. a The effect of Dic on the phosphorylation level of c-Met in A549 cells. Cells were treated with various concentrations of Dic for 36 $\mathrm{h}$ and analyzed by Western blotting. Each bar represents the mean \pm S.D. of three experiments, ${ }^{\star *} \mathrm{p}<0.01$

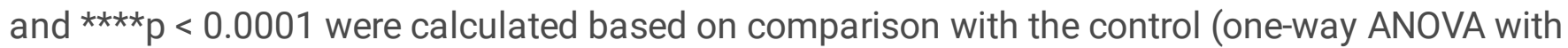
Dunnett's test). The effect of Dic on the inhibition of various MAPK (b) and PI3K/Akt/mTOR (c) signaling pathway components, cells were treated as described in (a). d Dic inhibited HGF-induced activation of cMet signaling pathways in A549 cells. A549 cells were treated with the indicated concentrations of Dic for $24 \mathrm{~h}$ in the absence of fetal bovine serum following stimulation with or without $100 \mathrm{ng} / \mathrm{mL} \mathrm{HGF}$ for $5 \mathrm{~min}$ and indicated proteins were analyzed by Western blotting. The results shown are representative of three independent experiments, GAPDH expression was used as the loading control. 


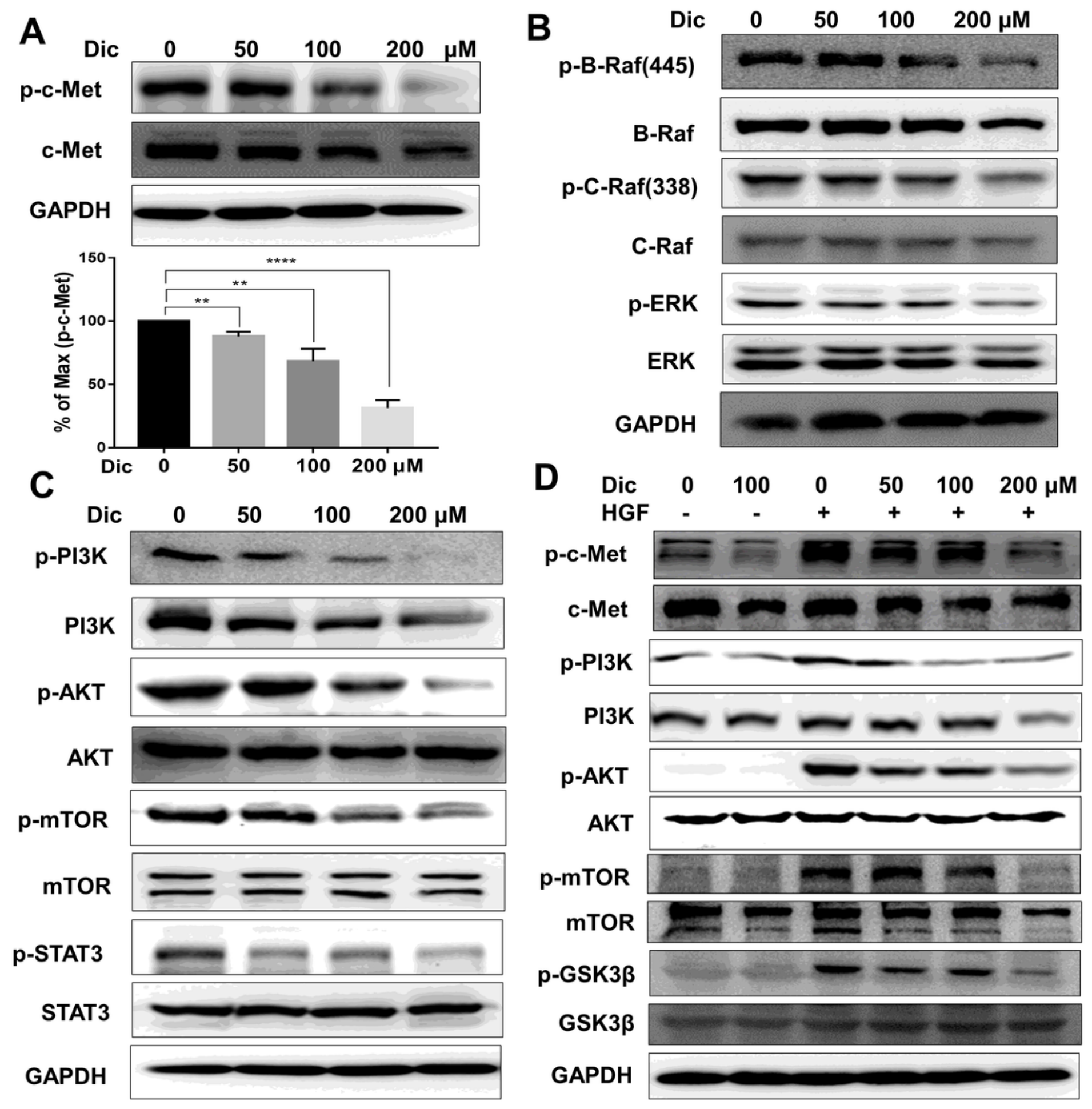

Figure 4

Dic is a potent c-Met inhibitor and suppresses the c-Met signaling pathway. a The effect of Dic on the phosphorylation level of c-Met in A549 cells. Cells were treated with various concentrations of Dic for 36 $\mathrm{h}$ and analyzed by Western blotting. Each bar represents the mean \pm S.D. of three experiments, ${ }^{\star *} \mathrm{p}<0.01$

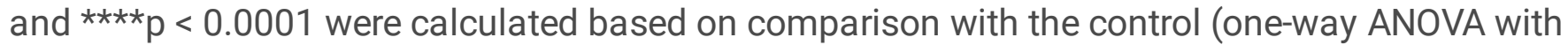
Dunnett's test). The effect of Dic on the inhibition of various MAPK (b) and PI3K/Akt/mTOR (c) signaling 
pathway components, cells were treated as described in (a). d Dic inhibited HGF-induced activation of cMet signaling pathways in A549 cells. A549 cells were treated with the indicated concentrations of Dic for $24 \mathrm{~h}$ in the absence of fetal bovine serum following stimulation with or without $100 \mathrm{ng} / \mathrm{mL} \mathrm{HGF}$ for $5 \mathrm{~min}$ and indicated proteins were analyzed by Western blotting. The results shown are representative of three independent experiments, GAPDH expression was used as the loading control.

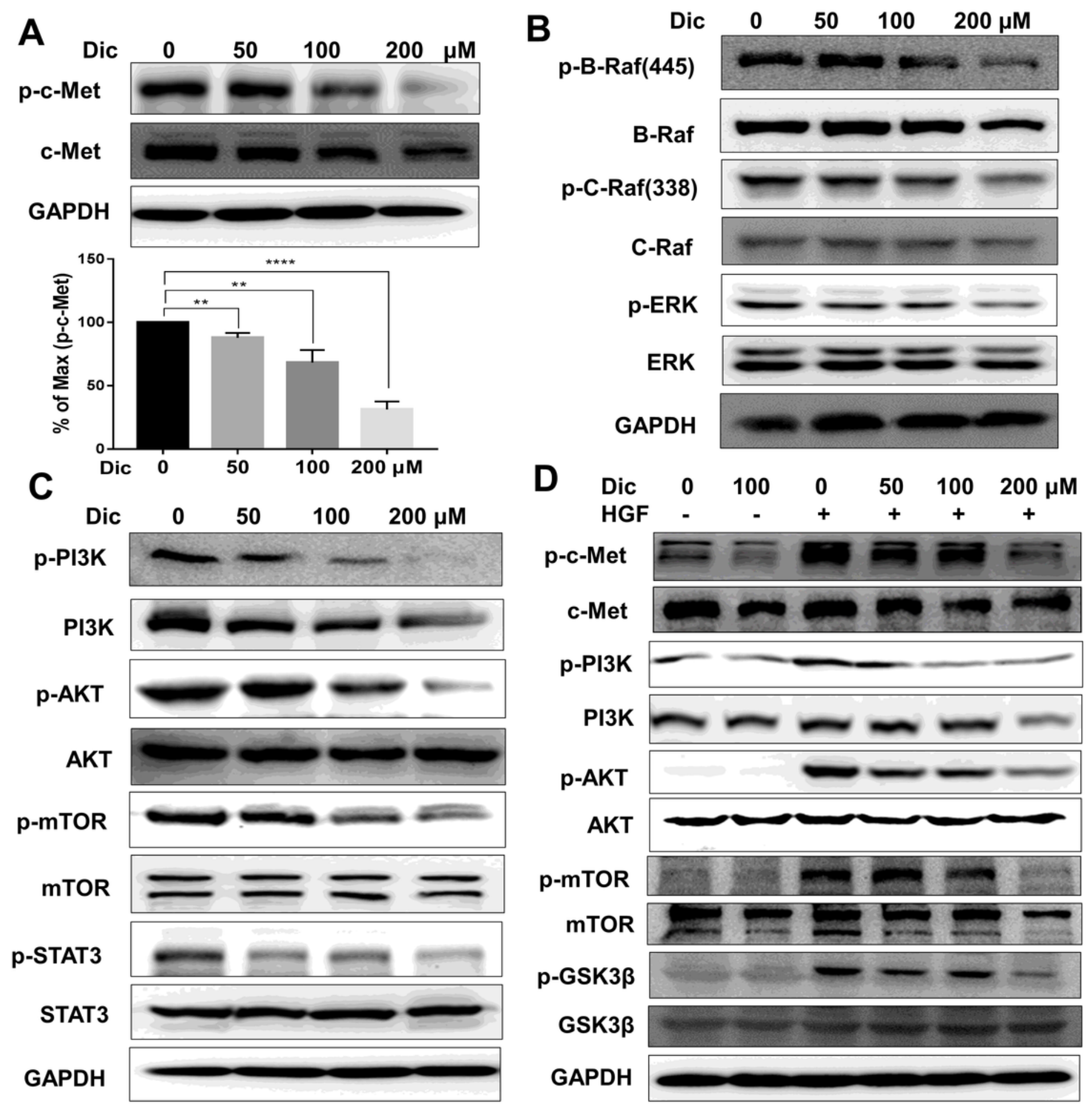

Figure 4 
Dic is a potent c-Met inhibitor and suppresses the c-Met signaling pathway. a The effect of Dic on the phosphorylation level of c-Met in A549 cells. Cells were treated with various concentrations of Dic for 36 $\mathrm{h}$ and analyzed by Western blotting. Each bar represents the mean \pm S.D. of three experiments, ${ }^{\star *} \mathrm{p}<0.01$

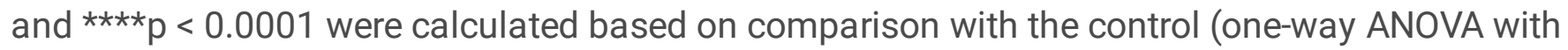
Dunnett's test). The effect of Dic on the inhibition of various MAPK (b) and PI3K/Akt/mTOR (c) signaling pathway components, cells were treated as described in (a). d Dic inhibited HGF-induced activation of cMet signaling pathways in A549 cells. A549 cells were treated with the indicated concentrations of Dic for $24 \mathrm{~h}$ in the absence of fetal bovine serum following stimulation with or without $100 \mathrm{ng} / \mathrm{mL} \mathrm{HGF}$ for $5 \mathrm{~min}$ and indicated proteins were analyzed by Western blotting. The results shown are representative of three independent experiments, GAPDH expression was used as the loading control. 

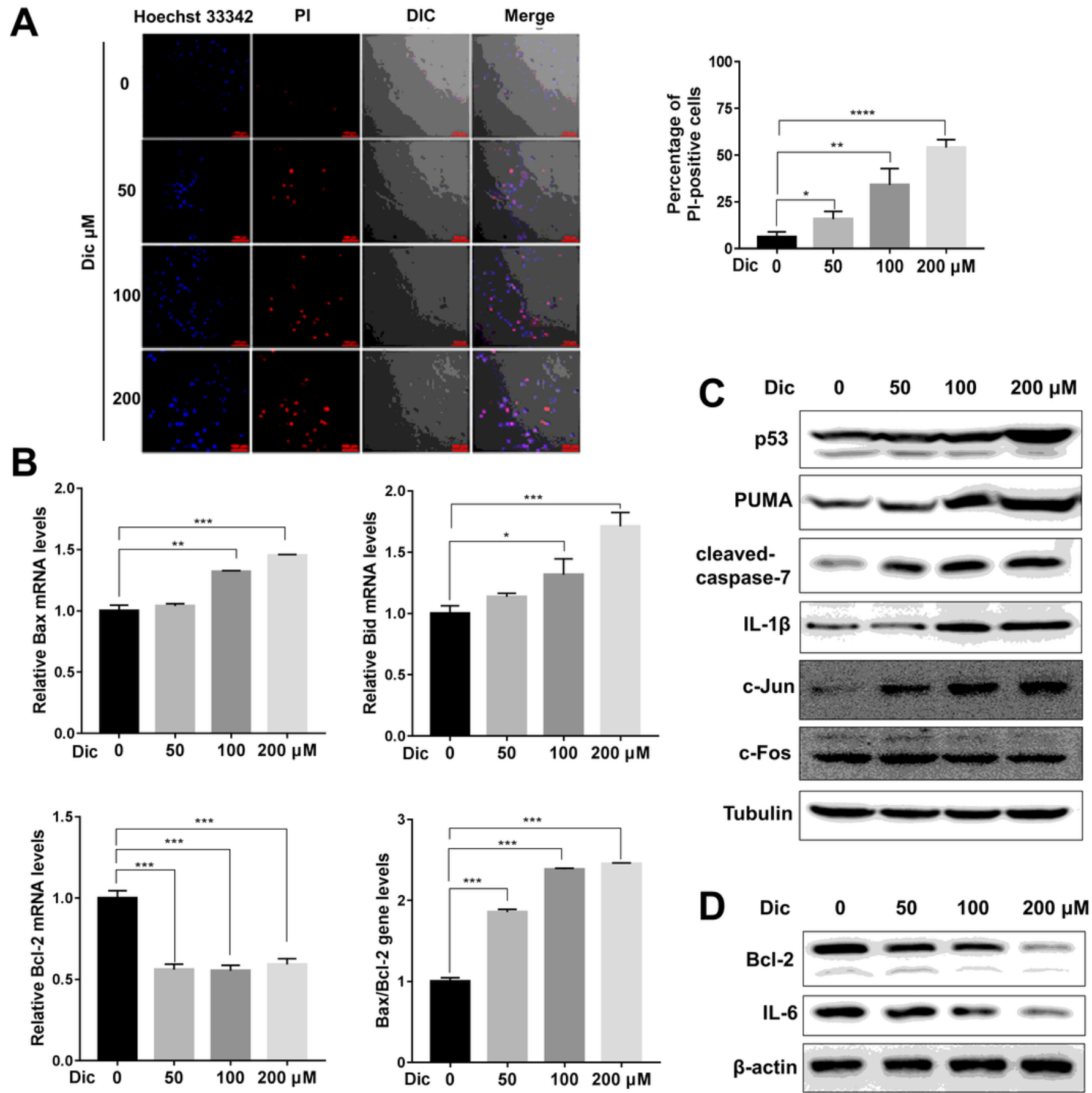

\section{Figure 5}

Dic induces intrinsic apoptosis in A549 cells. a A549 cells were exposed to different concentrations of Dic for $24 \mathrm{~h}$ and cell mortality was quantified by $\mathrm{Pl} /$ Hoechst 33342 staining. Scale bar $=80 \mu \mathrm{m}$. b The effect of Dic on the mRNA expression levels of Bax, Bid and Bcl-2 was determined by qRT-PCR normalized with GAPDH. All data are expressed as the mean \pm S.D. of three experiments, ${ }^{*} p<0.05,{ }^{* \star} p<0.01,{ }^{* \star *} p<0.001$ and ${ }^{* \star \star} p<0.001$ were calculated based on comparison with the control (one-way ANOVA with Dunnett's 
test). The effect of Dic on the expression levels of pro-apoptotic proteins p53, PUMA, Bax, cleavedcaspase-7, IL-1 $\beta$, c-Jun, c-Fos (c) and anti-apoptotic proteins Bcl-2 and IL-6 (d) were determined by Western blotting. For b-d, cells were treated as described in (a). For c-d, similar results were obtained from three independent experiments, tubulin or $\beta$-actin expression was used as the loading control.

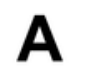

\section{B}
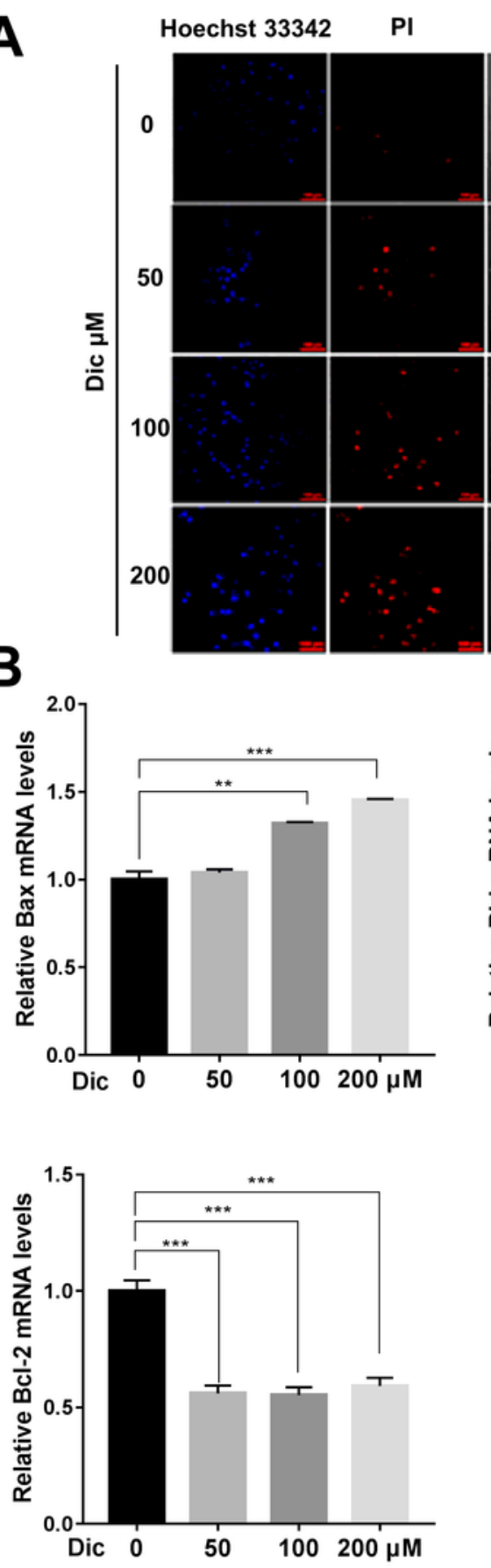
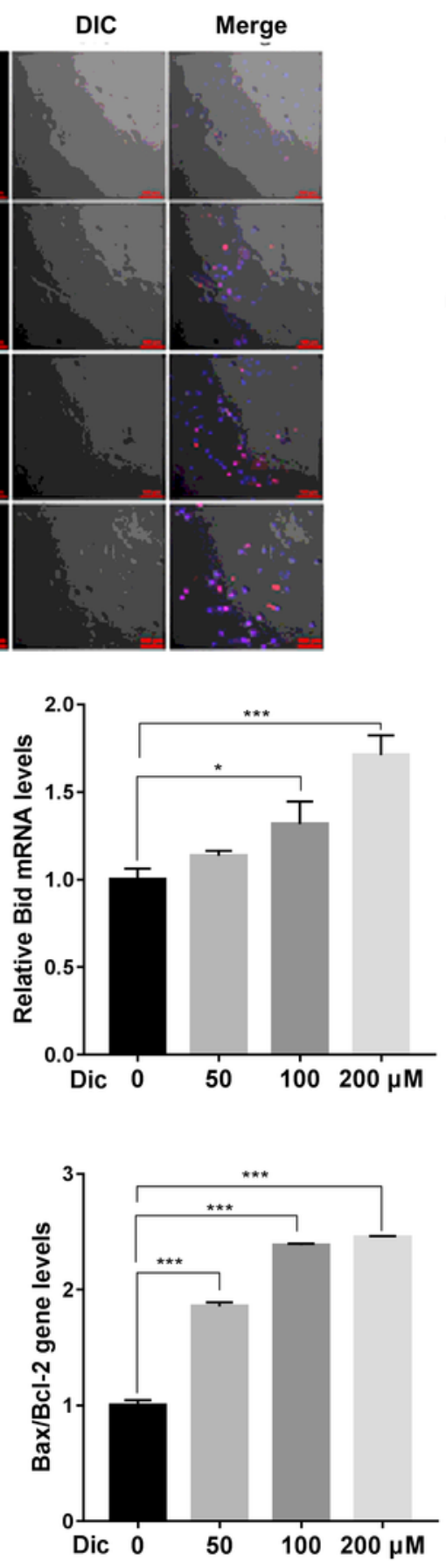
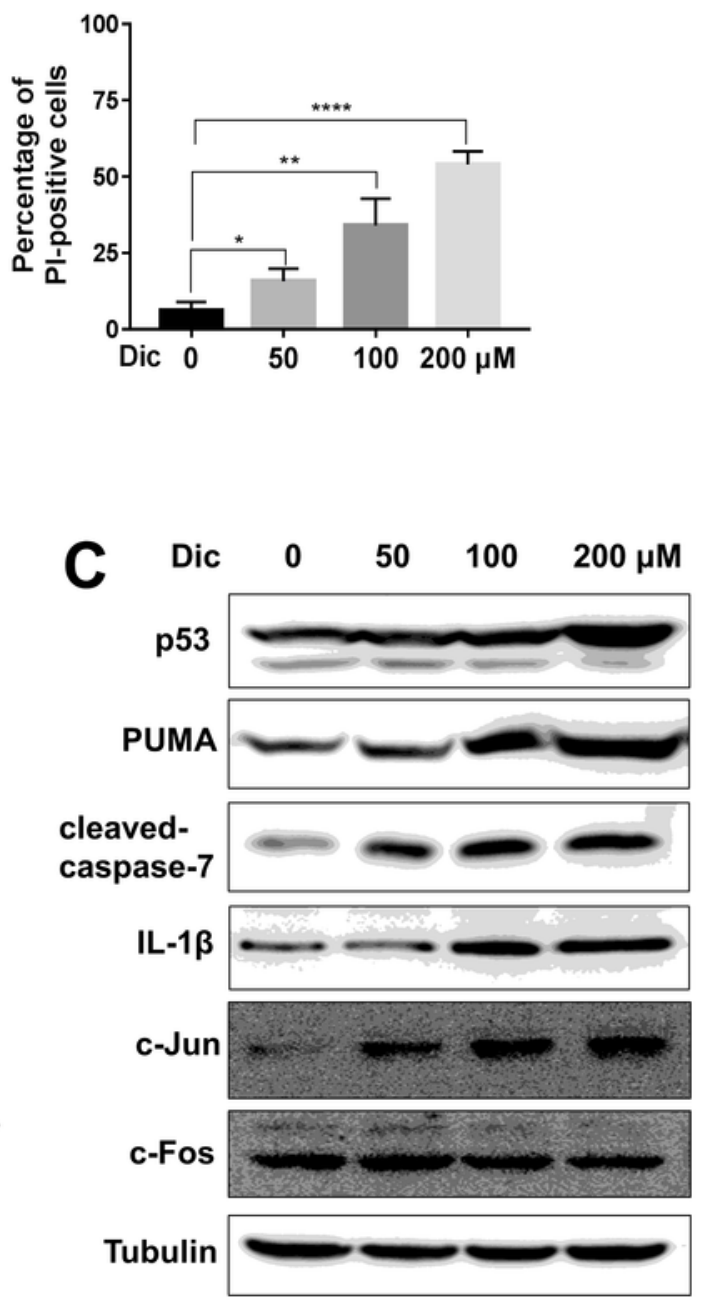

D Dic $\quad 0 \quad 50 \quad 100 \quad 200 \mu \mathrm{M}$

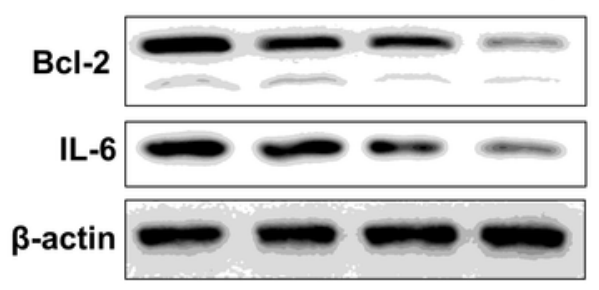

Figure 5 
Dic induces intrinsic apoptosis in A549 cells. a A549 cells were exposed to different concentrations of Dic for $24 \mathrm{~h}$ and cell mortality was quantified by $\mathrm{Pl} /$ Hoechst 33342 staining. Scale bar $=80 \mu \mathrm{m}$. b The effect of Dic on the mRNA expression levels of Bax, Bid and Bcl-2 was determined by qRT-PCR normalized with GAPDH. All data are expressed as the mean \pm S.D. of three experiments, ${ }^{*} p<0.05,{ }^{*} p<0.01,{ }^{* *} p<0.001$

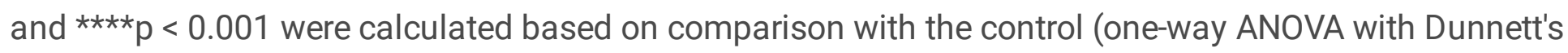
test). The effect of Dic on the expression levels of pro-apoptotic proteins p53, PUMA, Bax, cleavedcaspase-7, IL-1 $\beta$, c-Jun, c-Fos (c) and anti-apoptotic proteins Bcl-2 and IL-6 (d) were determined by Western blotting. For b-d, cells were treated as described in (a). For c-d, similar results were obtained from three independent experiments, tubulin or $\beta$-actin expression was used as the loading control. 

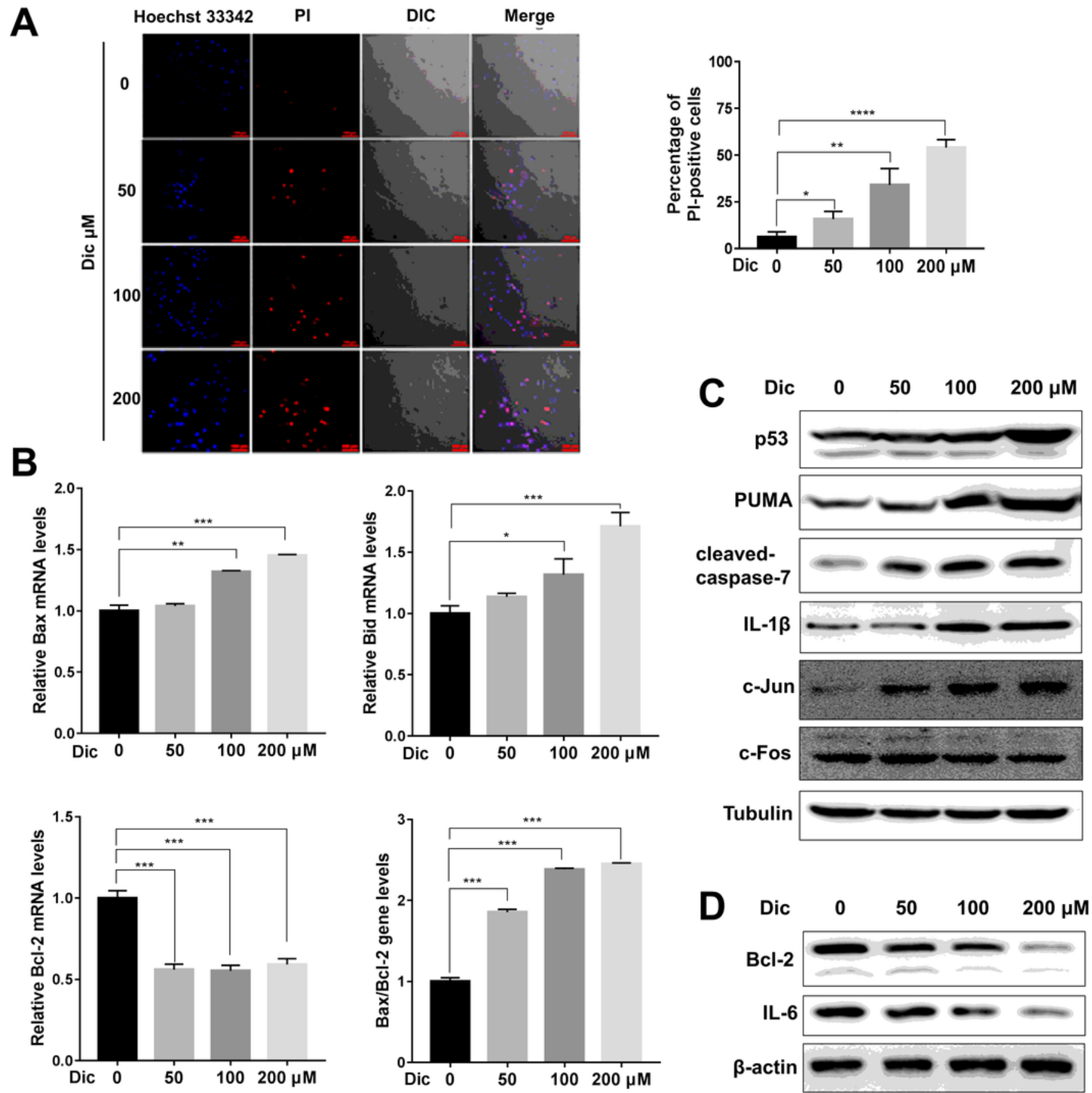

\section{Figure 5}

Dic induces intrinsic apoptosis in A549 cells. a A549 cells were exposed to different concentrations of Dic for $24 \mathrm{~h}$ and cell mortality was quantified by $\mathrm{Pl} /$ Hoechst 33342 staining. Scale bar $=80 \mu \mathrm{m}$. b The effect of Dic on the mRNA expression levels of Bax, Bid and Bcl-2 was determined by qRT-PCR normalized with GAPDH. All data are expressed as the mean \pm S.D. of three experiments, ${ }^{*} p<0.05,{ }^{*} p<0.01, * \star \star p<0.001$ and ${ }^{* \star \star} p<0.001$ were calculated based on comparison with the control (one-way ANOVA with Dunnett's 
test). The effect of Dic on the expression levels of pro-apoptotic proteins p53, PUMA, Bax, cleavedcaspase-7, IL-1 $\beta$, c-Jun, c-Fos (c) and anti-apoptotic proteins Bcl-2 and IL-6 (d) were determined by Western blotting. For b-d, cells were treated as described in (a). For c-d, similar results were obtained from three independent experiments, tubulin or $\beta$-actin expression was used as the loading control.

A

Dic
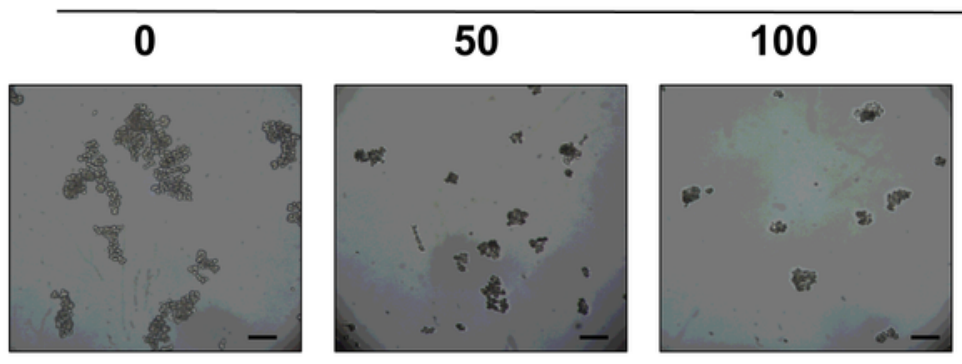

$200 \mu \mathrm{M}$

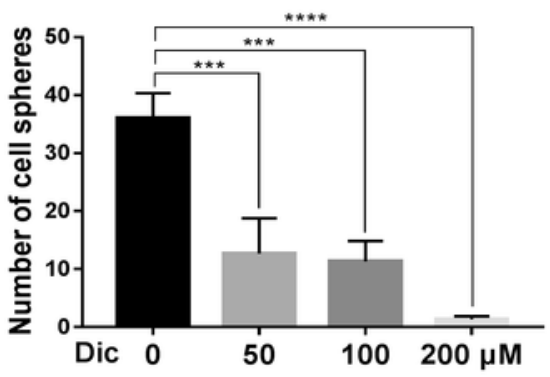

DIC $\quad 0 \quad 50 \quad 100 \quad 200 \mu M$

CD44

GAPDH

B

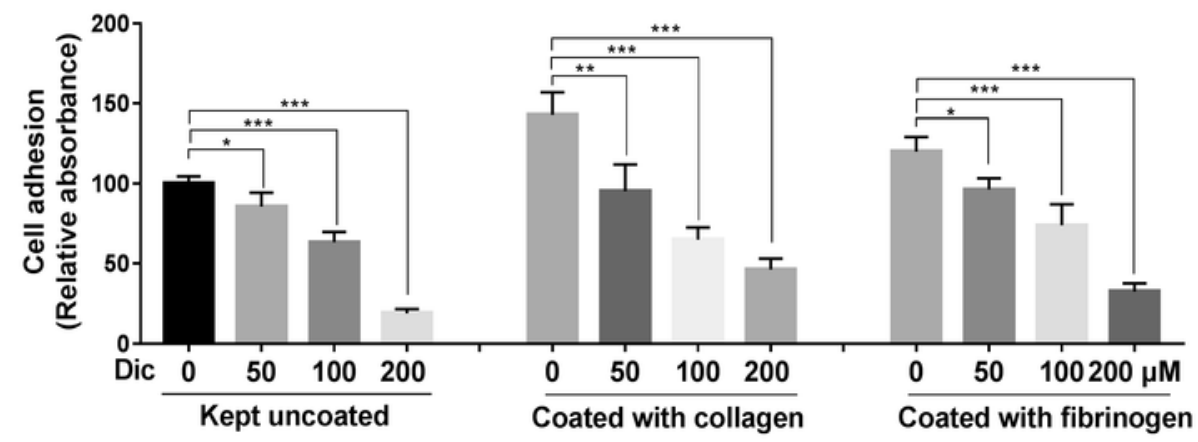

C

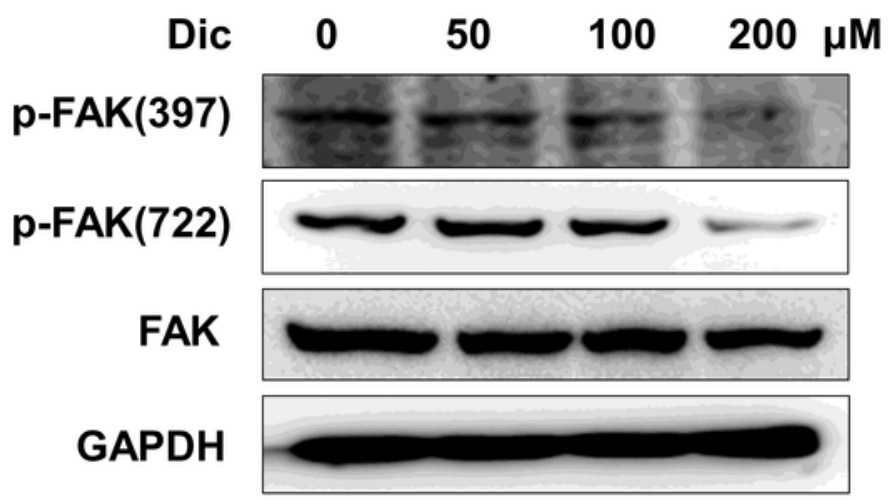

D

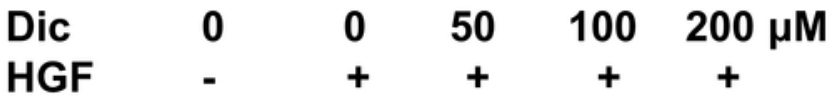

MMP-2

MMP-9

GAPDH

Figure 6 
Dic inhibits the stemness, adhesive ability and MMP2/MMP9 expression of A549 cells. a After treatment with various concentrations of Dic for $48 \mathrm{~h}, \mathrm{~A} 549$ cells were subjected to the tumor sphere-forming assay. Scale bar $=200 \mu \mathrm{m}$. Data are mean \pm S.D. $(n=3)$. Statistical significance was determined by a one-way ANOVA with Dunnett's test: ${ }^{* \star} p<0.001$ and ${ }^{* \star * *} p<0.0001$. Expression of CD44 in A549 cells exposed to the indicated concentrations of Dic for $24 \mathrm{~h}$ was determined by Western blotting. $\mathrm{b}$ A549 cells treated with the indicated concentrations of Dic for $24 \mathrm{~h}$ were seeded into 96-well plates pre-coated with different ECM proteins $(10 \mu \mathrm{g} / \mathrm{mL}$ collagen and $10 \mu \mathrm{g} / \mathrm{mL}$ fibrinogen). Wells coated with $100 \mu \mathrm{g} / \mathrm{mL}$ poly-L-lysine were employed as a control condition. The attached cells were fixed and stained with $0.1 \%$ crystal violet. Absorbance of dye was measured at $590 \mathrm{~nm}$ by using a microplate reader. Each bar represented as the mean \pm S.D. $(n=4)$, and was expressed as a percentage of the control. ${ }^{*} p<0.05$, ${ }^{* *} p<0.01$ and ${ }^{* \star *} p<$ 0.001 compared with untreated group. c A549 cells were treated with various concentrations of Dic for 6 $h$, the phosphorylation levels of FAK at Tyr-397 and Ser-722 were measured by Western blotting. $d$ The effect of Dic on the HGF-induced MMP2/MMP9 expression. Cells were treated with different concentrations of Dic in the presence of $100 \mathrm{ng} / \mathrm{ml} \mathrm{HGF}$ for $24 \mathrm{~h}$. MMP2/MMP9 protein expression was determined by Western blotting. For $C-D$, the results shown are representative of three independent experiments, GAPDH expression was used as the loading control. 
A

Dic
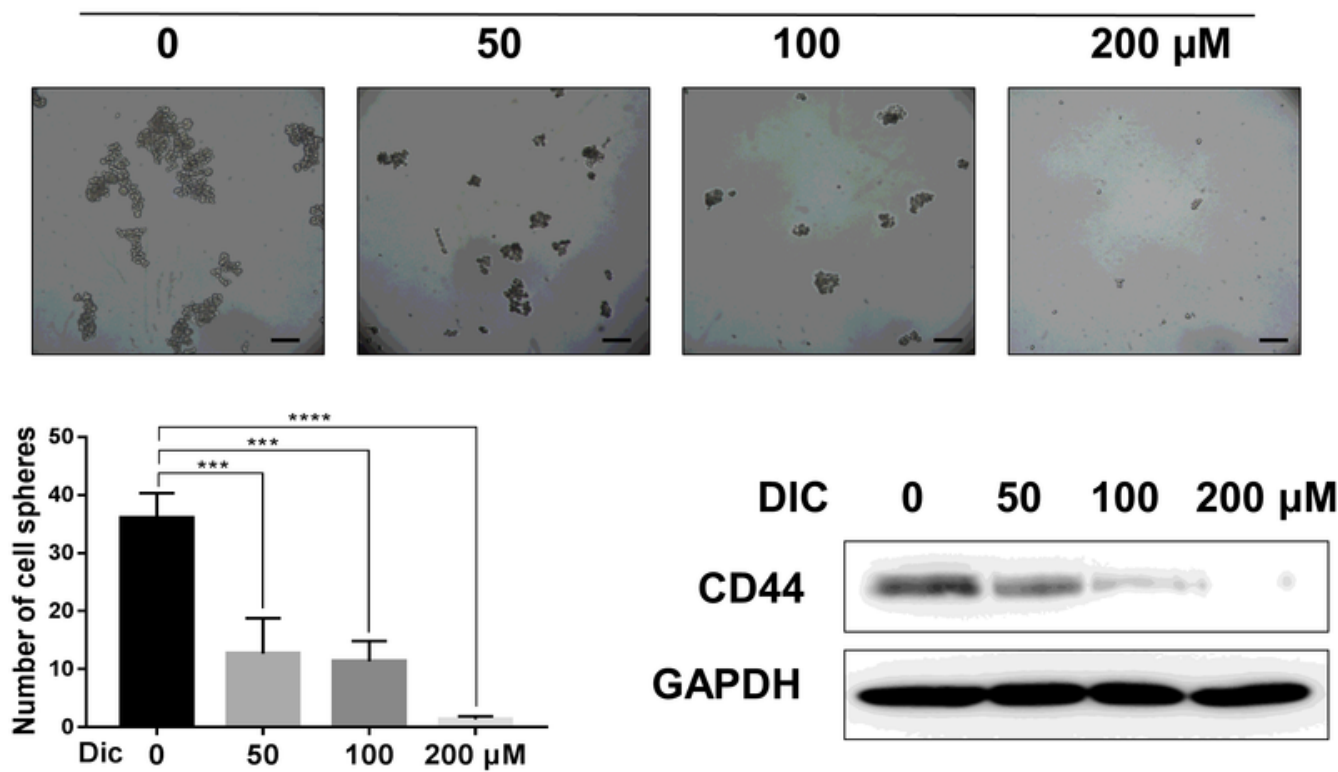

B

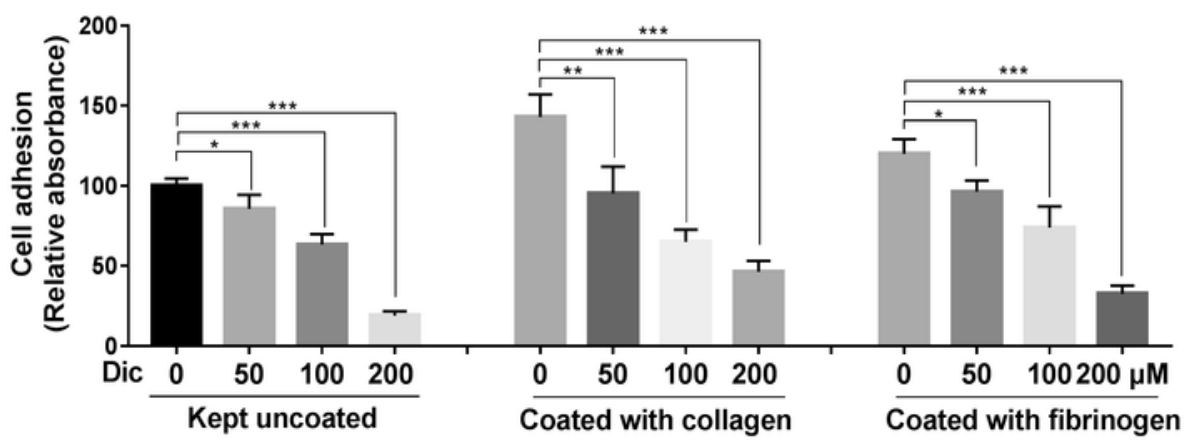

C

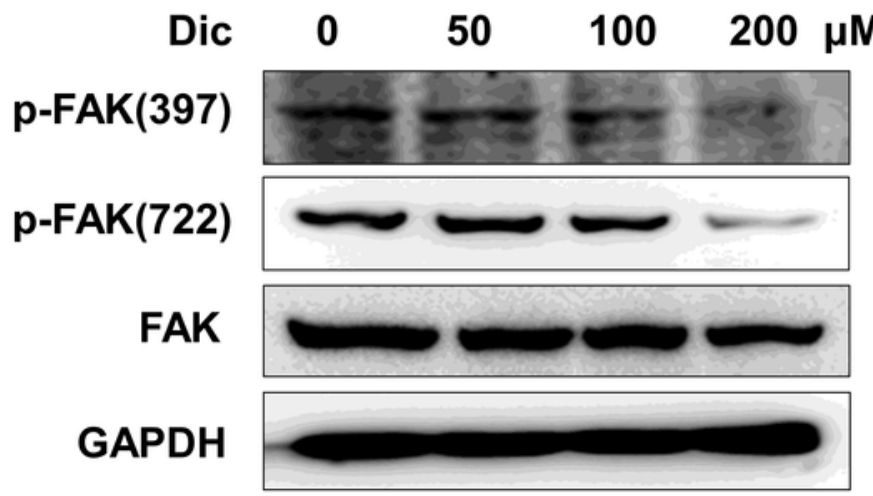

D

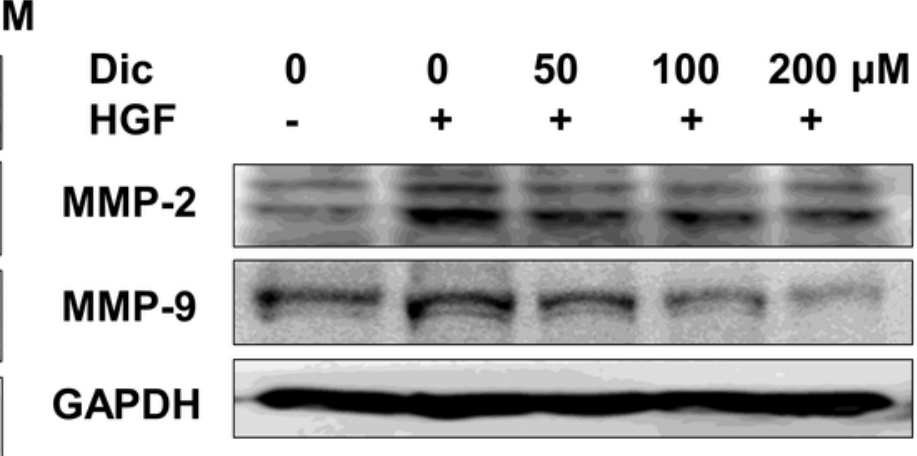

Figure 6

Dic inhibits the stemness, adhesive ability and MMP2/MMP9 expression of A549 cells. a After treatment with various concentrations of Dic for $48 \mathrm{~h}, \mathrm{~A} 549$ cells were subjected to the tumor sphere-forming assay. Scale bar $=200 \mu \mathrm{m}$. Data are mean \pm S.D. $(n=3)$. Statistical significance was determined by a one-way

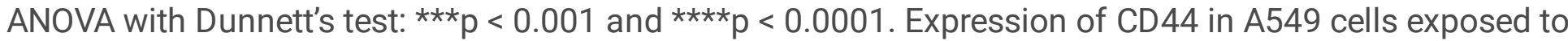
the indicated concentrations of Dic for $24 \mathrm{~h}$ was determined by Western blotting. b A549 cells treated with 
the indicated concentrations of Dic for $24 \mathrm{~h}$ were seeded into 96-well plates pre-coated with different ECM proteins ( $10 \mu \mathrm{g} / \mathrm{mL}$ collagen and $10 \mu \mathrm{g} / \mathrm{mL}$ fibrinogen). Wells coated with $100 \mu \mathrm{g} / \mathrm{mL}$ poly-L-lysine were employed as a control condition. The attached cells were fixed and stained with $0.1 \%$ crystal violet.

Absorbance of dye was measured at $590 \mathrm{~nm}$ by using a microplate reader. Each bar represented as the mean \pm S.D. $(n=4)$, and was expressed as a percentage of the control. ${ }^{*} p<0.05$, $* * p<0.01$ and ${ }^{* \star} p<$ 0.001 compared with untreated group. c A549 cells were treated with various concentrations of Dic for 6 $h$, the phosphorylation levels of FAK at Tyr-397 and Ser-722 were measured by Western blotting. $d$ The effect of Dic on the HGF-induced MMP2/MMP9 expression. Cells were treated with different concentrations of Dic in the presence of $100 \mathrm{ng} / \mathrm{ml} \mathrm{HGF}$ for $24 \mathrm{~h}$. MMP2/MMP9 protein expression was determined by Western blotting. For $C-D$, the results shown are representative of three independent experiments, GAPDH expression was used as the loading control. 
A

Dic
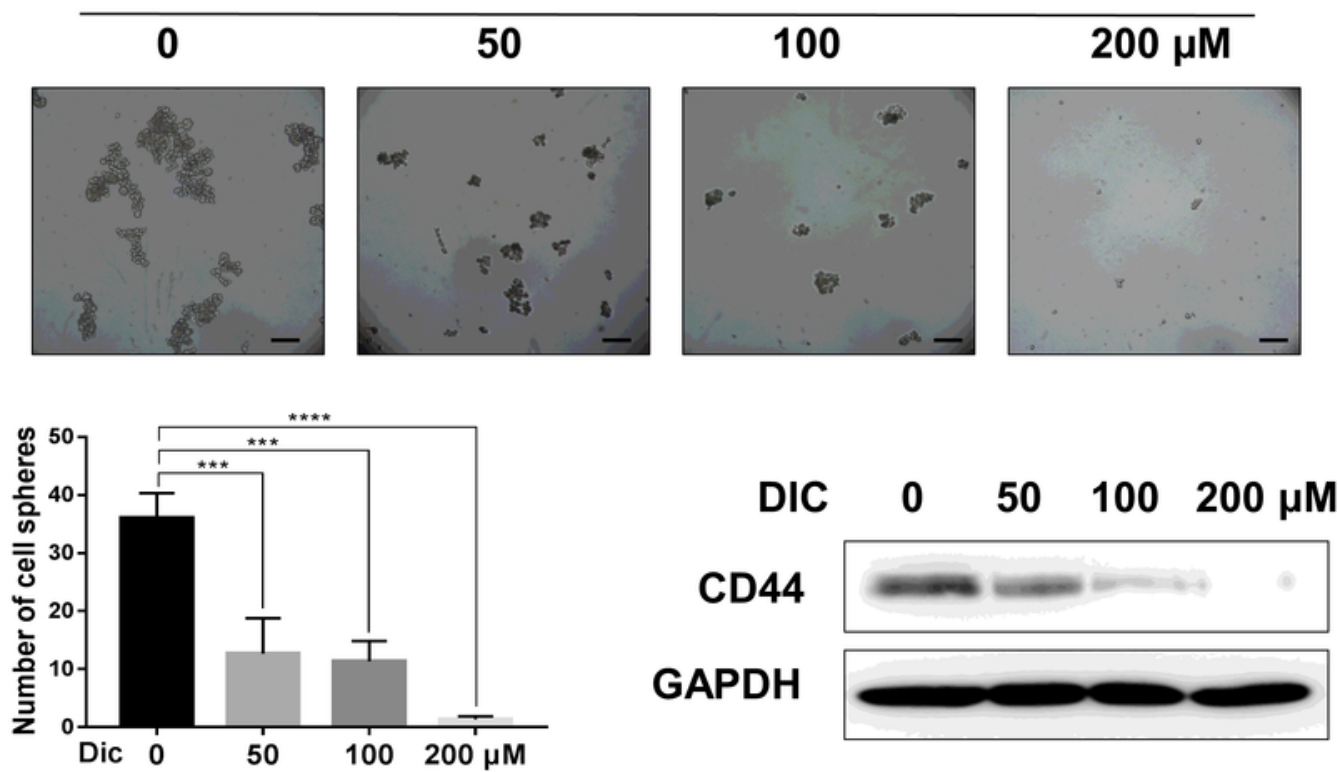

B

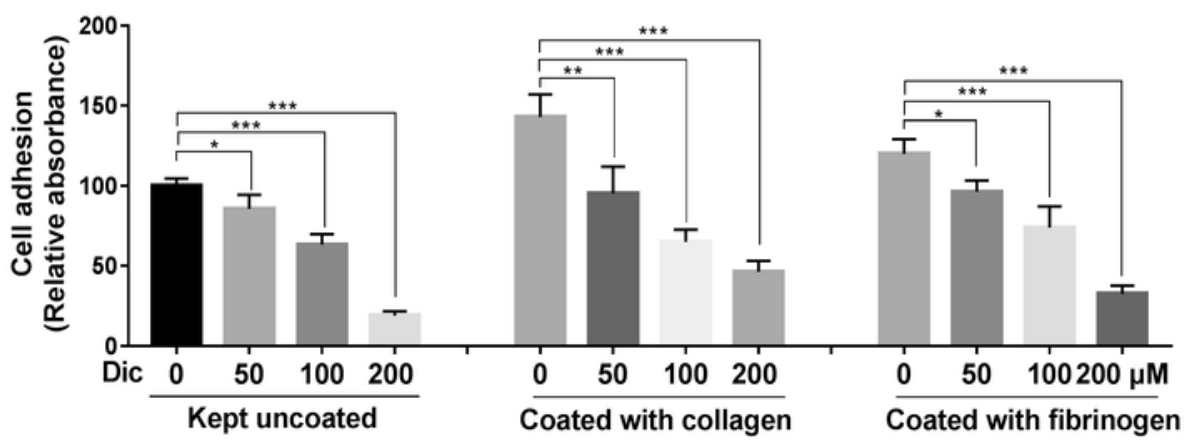

C

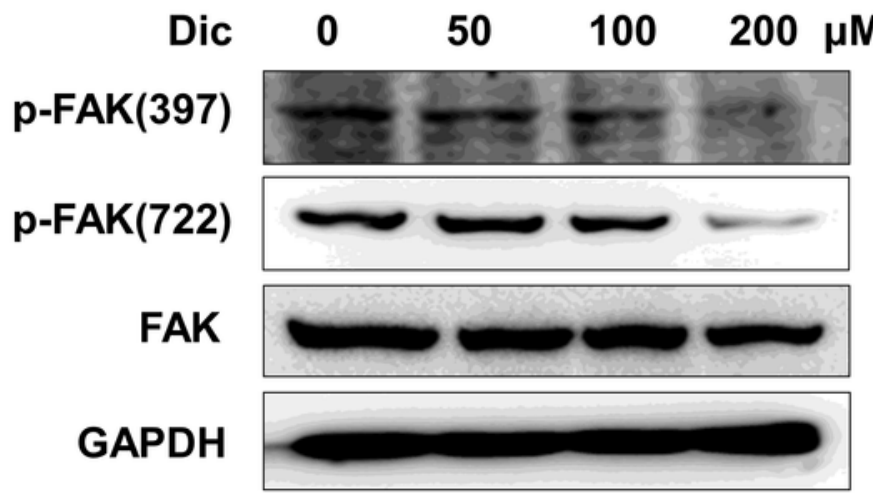

D

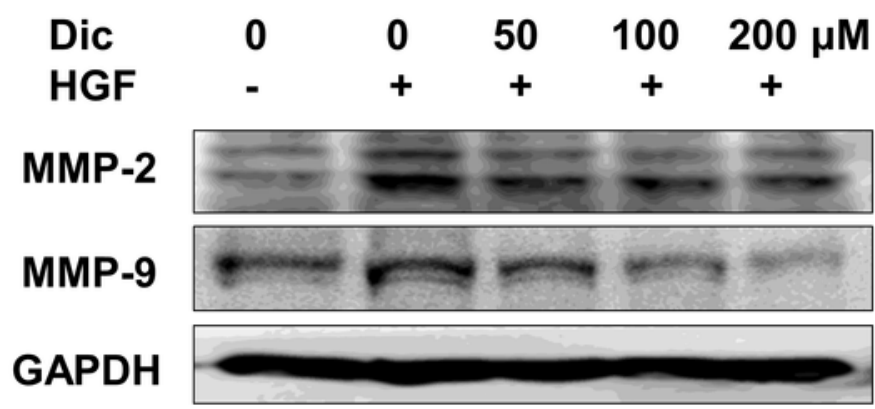

Figure 6

Dic inhibits the stemness, adhesive ability and MMP2/MMP9 expression of A549 cells. a After treatment with various concentrations of Dic for 48 h, A549 cells were subjected to the tumor sphere-forming assay. Scale bar $=200 \mu \mathrm{m}$. Data are mean \pm S.D. $(n=3)$. Statistical significance was determined by a one-way ANOVA with Dunnett's test: $* \star \star p<0.001$ and $* \star \star \star p ~<0.0001$. Expression of CD44 in A549 cells exposed to the indicated concentrations of Dic for $24 \mathrm{~h}$ was determined by Western blotting. b A549 cells treated with 
the indicated concentrations of Dic for $24 \mathrm{~h}$ were seeded into 96-well plates pre-coated with different ECM proteins ( $10 \mu \mathrm{g} / \mathrm{mL}$ collagen and $10 \mu \mathrm{g} / \mathrm{mL}$ fibrinogen). Wells coated with $100 \mu \mathrm{g} / \mathrm{mL}$ poly-L-lysine were employed as a control condition. The attached cells were fixed and stained with $0.1 \%$ crystal violet.

Absorbance of dye was measured at $590 \mathrm{~nm}$ by using a microplate reader. Each bar represented as the mean \pm S.D. $(n=4)$, and was expressed as a percentage of the control. ${ }^{*} p<0.05$, $* * p<0.01$ and ${ }^{* \star} p<$ 0.001 compared with untreated group. c A549 cells were treated with various concentrations of Dic for 6 $h$, the phosphorylation levels of FAK at Tyr-397 and Ser-722 were measured by Western blotting. $d$ The effect of Dic on the HGF-induced MMP2/MMP9 expression. Cells were treated with different concentrations of Dic in the presence of $100 \mathrm{ng} / \mathrm{ml} \mathrm{HGF}$ for $24 \mathrm{~h}$. MMP2/MMP9 protein expression was determined by Western blotting. For $C-D$, the results shown are representative of three independent experiments, GAPDH expression was used as the loading control. 
A
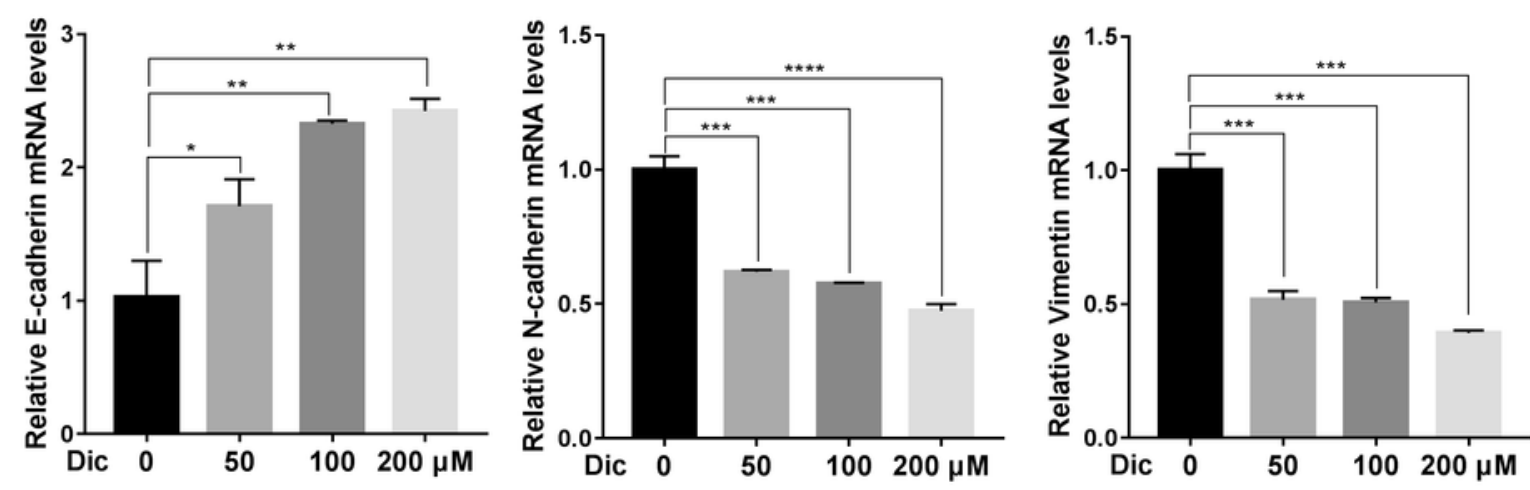

B

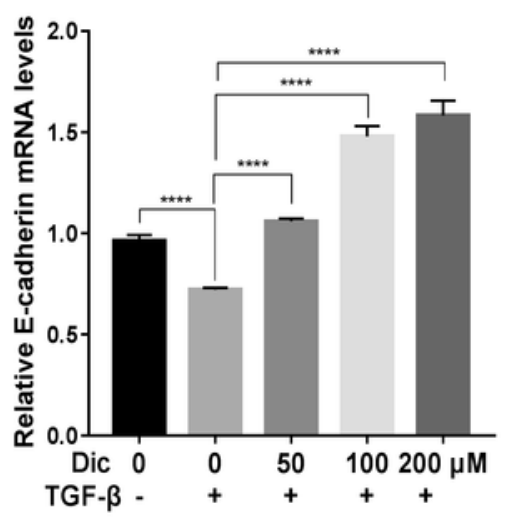

C
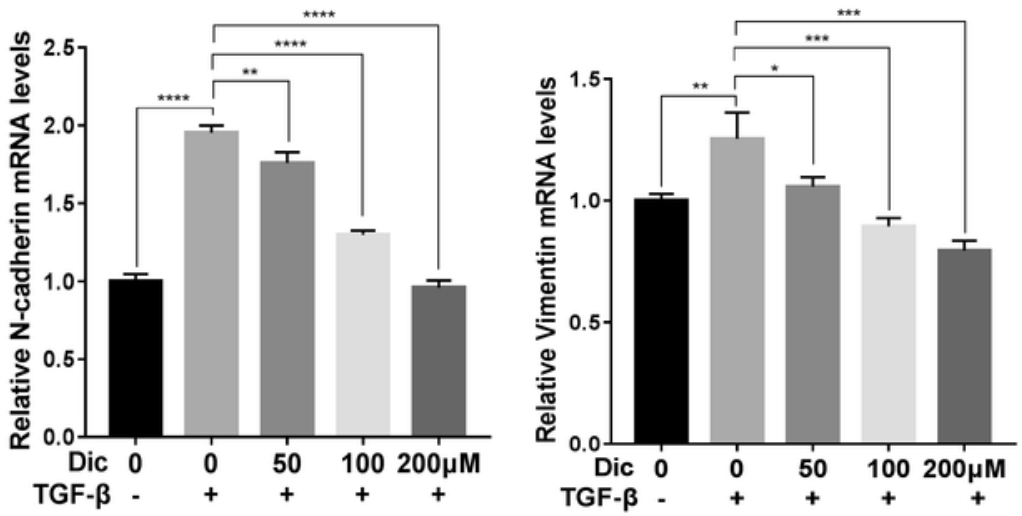

D

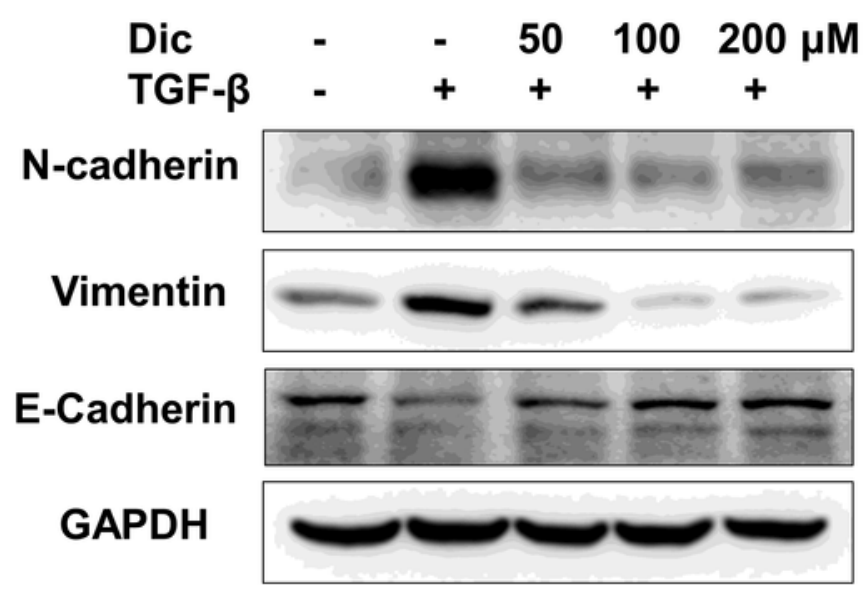

Figure 7

Dic inhibits EMT in A549 cells. A549 cells were treated with different concentrations of Dic in the absence (a) or presence (b) of TGF- $\beta$ ( $3 \mathrm{ng} / \mathrm{mL})$ for $72 \mathrm{~h}$. The mRNA expression levels of N-Cadherin, Vimentin and E-Cadherin were quantified by qRT-PCR normalized with GAPDH. The data were represented as the mean \pm S.D. of three experiments. ${ }^{*} p<0.01$ and ${ }^{* *} p<0.001$ compared with the control group or the TGF- $\beta$ treated group. A549 cells were treated with different concentrations of Dic in the absence (c) or presence 
(d) of TGF- $\beta$ ( $3 \mathrm{ng} / \mathrm{mL})$ for $72 \mathrm{~h}$. the expression levels of N-Cadherin, Vimentin and E-Cadherin were examined by Western blotting. The results shown are representative of three independent experiments, GAPDH expression was used as the loading control.
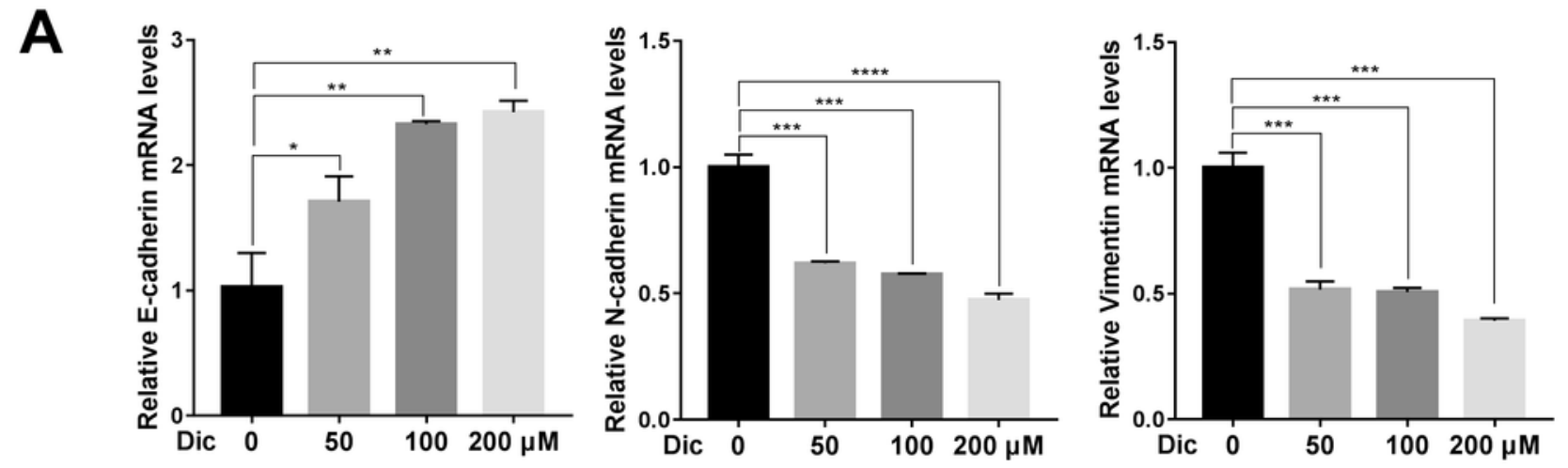

B
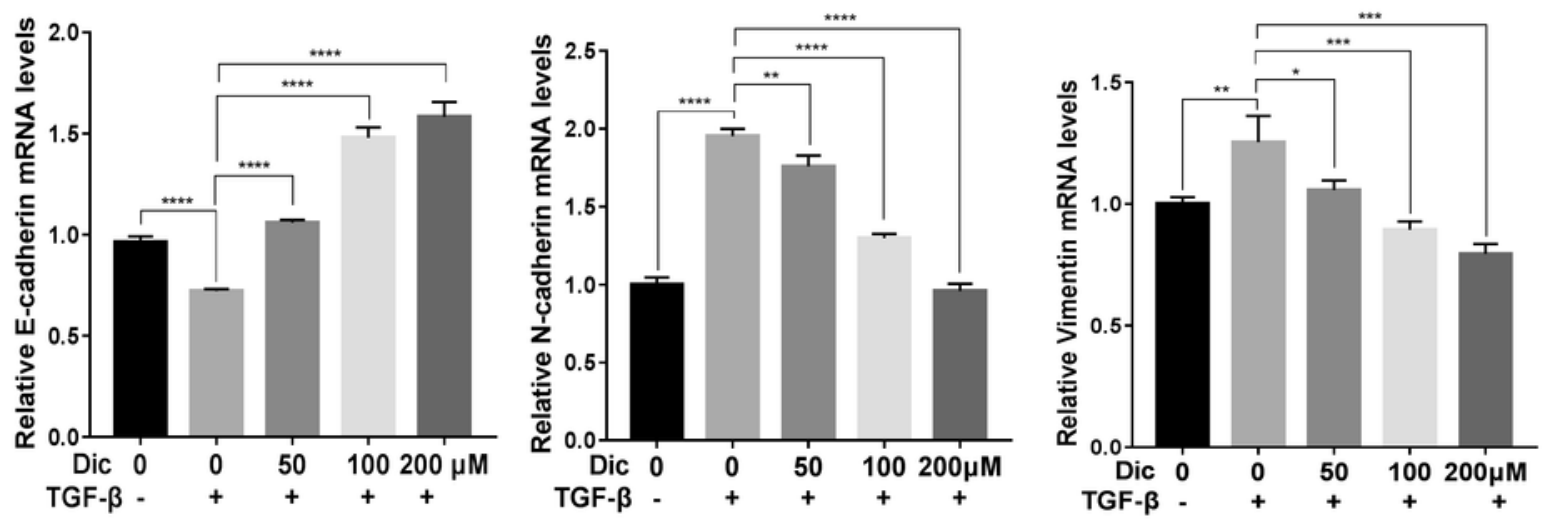

C

D

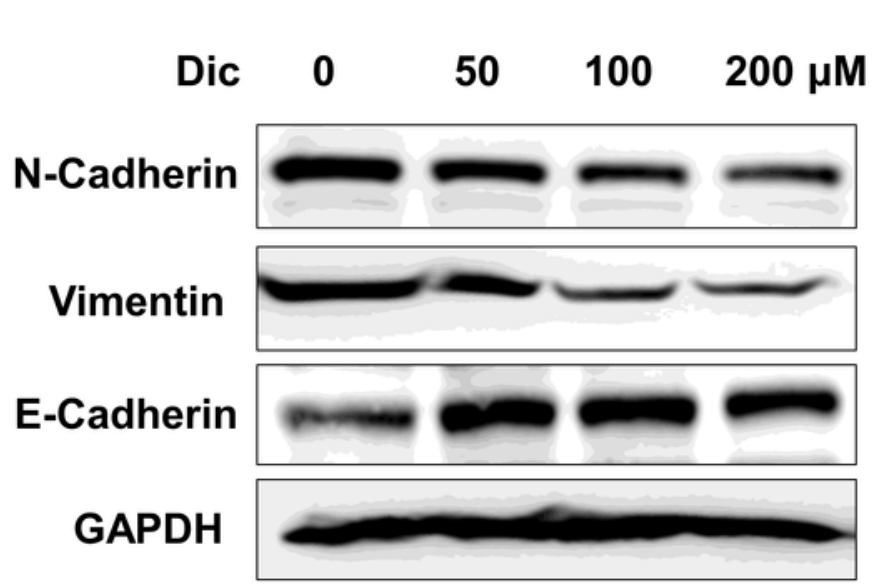


E-Cadherin were quantified by qRT-PCR normalized with GAPDH. The data were represented as the mean \pm S.D. of three experiments. ${ }^{*} p<0.01$ and ${ }^{* \star *} p<0.001$ compared with the control group or the TGF- $\beta$ treated group. A549 cells were treated with different concentrations of Dic in the absence (c) or presence (d) of TGF- $\beta$ ( $3 \mathrm{ng} / \mathrm{mL}$ ) for $72 \mathrm{~h}$. the expression levels of N-Cadherin, Vimentin and E-Cadherin were examined by Western blotting. The results shown are representative of three independent experiments, GAPDH expression was used as the loading control.
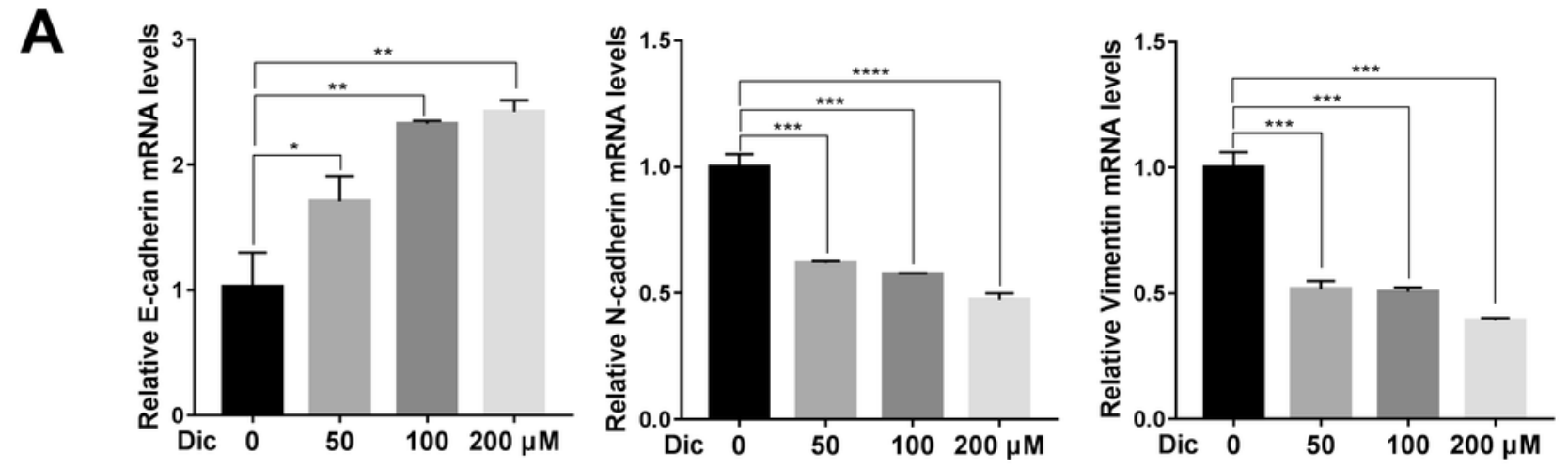

B
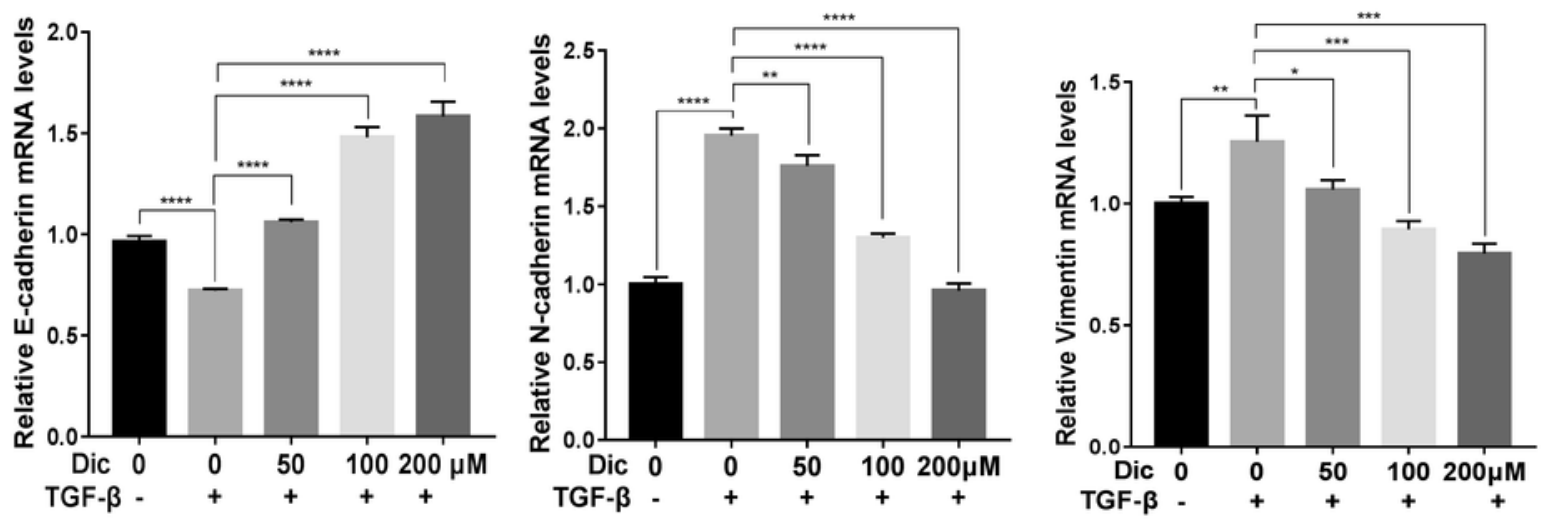

C

D

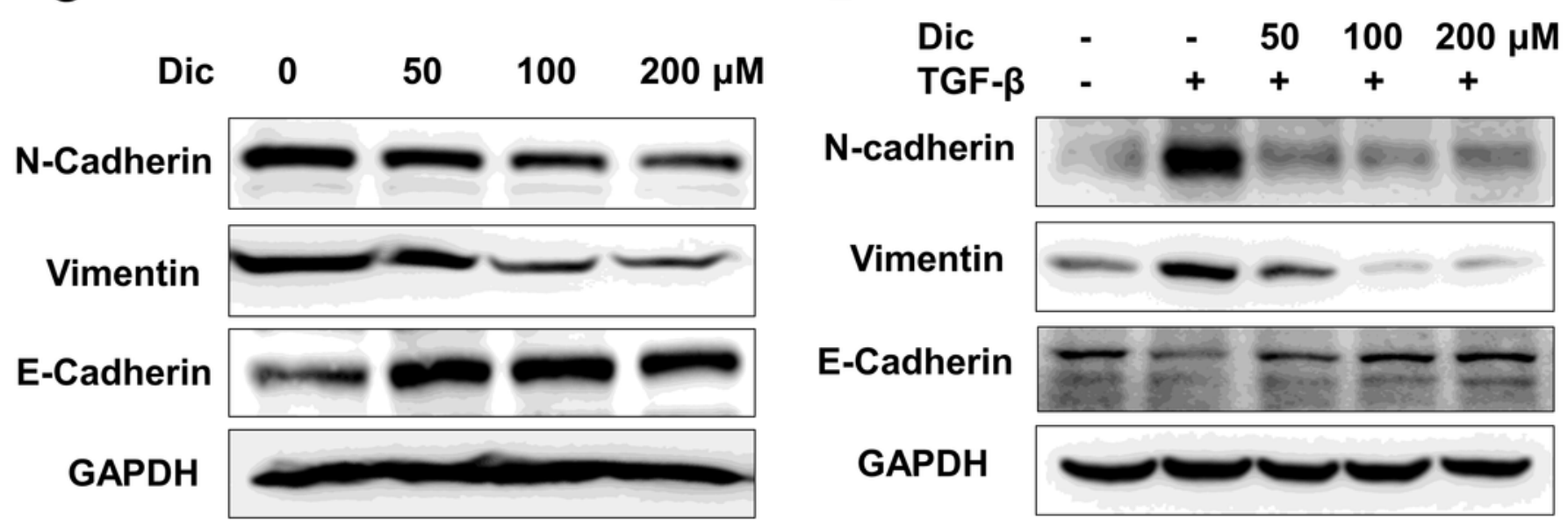

Figure 7 
Dic inhibits EMT in A549 cells. A549 cells were treated with different concentrations of Dic in the absence (a) or presence (b) of TGF- $\beta$ ( $3 \mathrm{ng} / \mathrm{mL})$ for $72 \mathrm{~h}$. The mRNA expression levels of N-Cadherin, Vimentin and E-Cadherin were quantified by qRT-PCR normalized with GAPDH. The data were represented as the mean \pm S.D. of three experiments. ${ }^{*} \mathrm{p}<0.01$ and ${ }^{* \star *} \mathrm{p}<0.001$ compared with the control group or the TGF- $\beta$ treated group. A549 cells were treated with different concentrations of Dic in the absence (c) or presence (d) of TGF- $\beta(3 \mathrm{ng} / \mathrm{mL})$ for $72 \mathrm{~h}$. the expression levels of N-Cadherin, Vimentin and E-Cadherin were examined by Western blotting. The results shown are representative of three independent experiments, GAPDH expression was used as the loading control. 

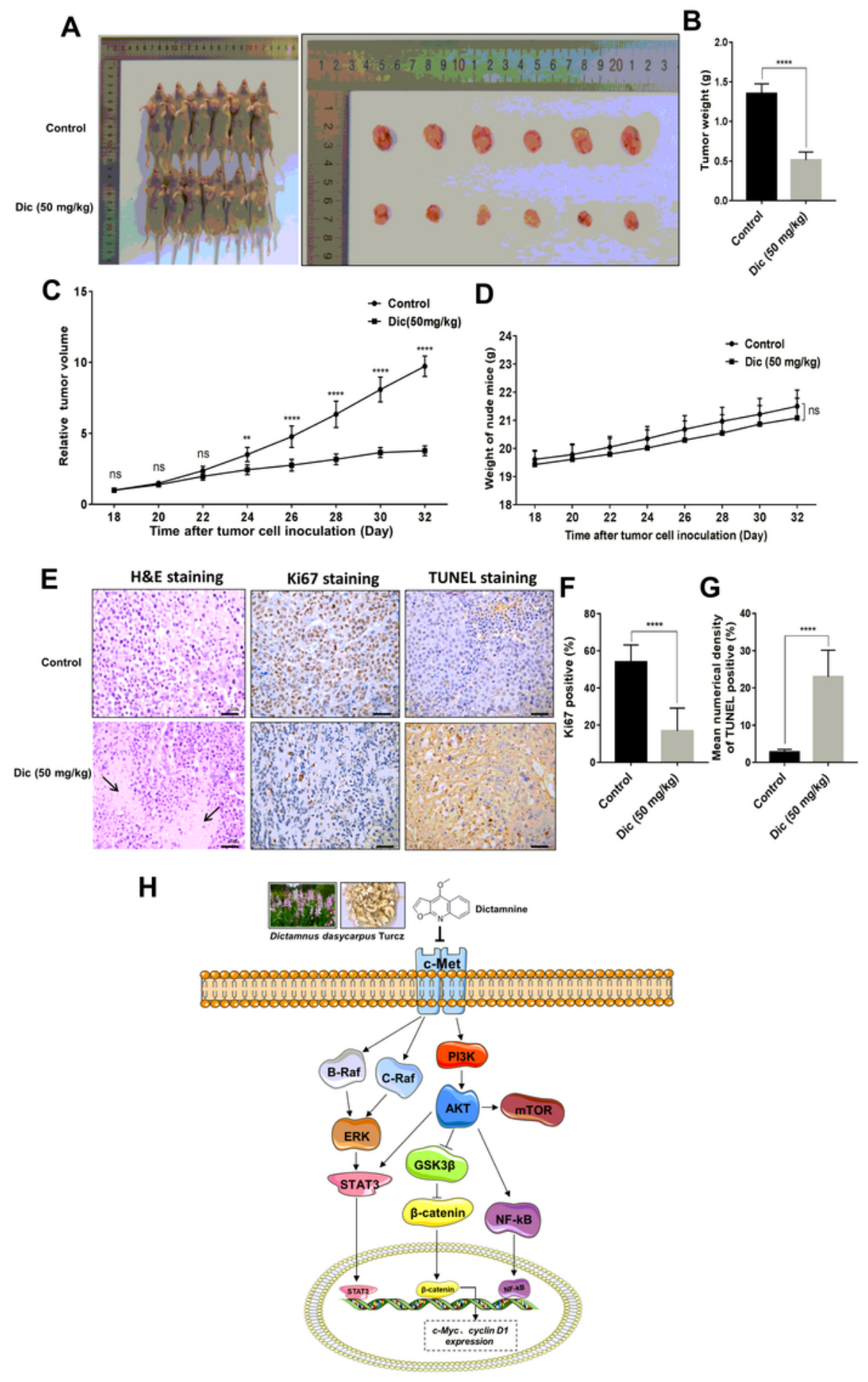

\section{Figure 8}

Effects of Dic on A549 growth in a xenograft mouse model. a-g A549 cells $(5 \times 106$ cells/mice) were injected subcutaneously into the right armpits of mice. On the 9th day after inoculation, when the tumors reached a volume of 100-150 mm3, two groups of tumor-bearing nude mice ( $\mathrm{n}=6$, each group) were injected intraperitoneally with either Dic $(50 \mathrm{mg} / \mathrm{kg})$ or physiological saline $(0.9 \% \mathrm{NaCl})$, respectively. After 15 days of consecutive injections, the mice were sacrificed. a Representative necropsy images of mice 
and dissected tumors are shown. b Tumor weight of dissected tumors from the two groups of mice was measured at the end of the experiment. The results are expressed as the mean \pm S.D., ${ }^{\star \star \star \star} p<0.0001$ compared with control (one-way ANOVA with Dunnett's test). c Tumor volumes were measured during the experiment, and these data are represented as the mean \pm S.D., ${ }^{\star *} p<0.01$ and ${ }^{\star \star \star *} p<0.0001$ compared with the control (one-way ANOVA with Dunnett's test). $d$ Body weight changes in mice treated with Dic or vehicle. Data are represented as the mean \pm S.D., ns, not significant. e Histological features were analyzed by H\&E staining in sections from the tumors. (e-g) Immunohistochemical analysis was performed with

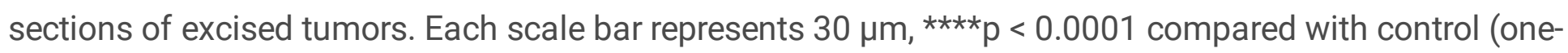
way ANOVA with Dunnett's test). $\mathrm{h}$ Scheme of the proposed mechanism. This shows that Dic directly targets c-Met, leading to the downregulation of the PI3K/Akt/mTOR, MAPK signaling pathways and proliferation-related gene expression, eventually inhibiting lung cancer cell proliferation and tumor growth. 

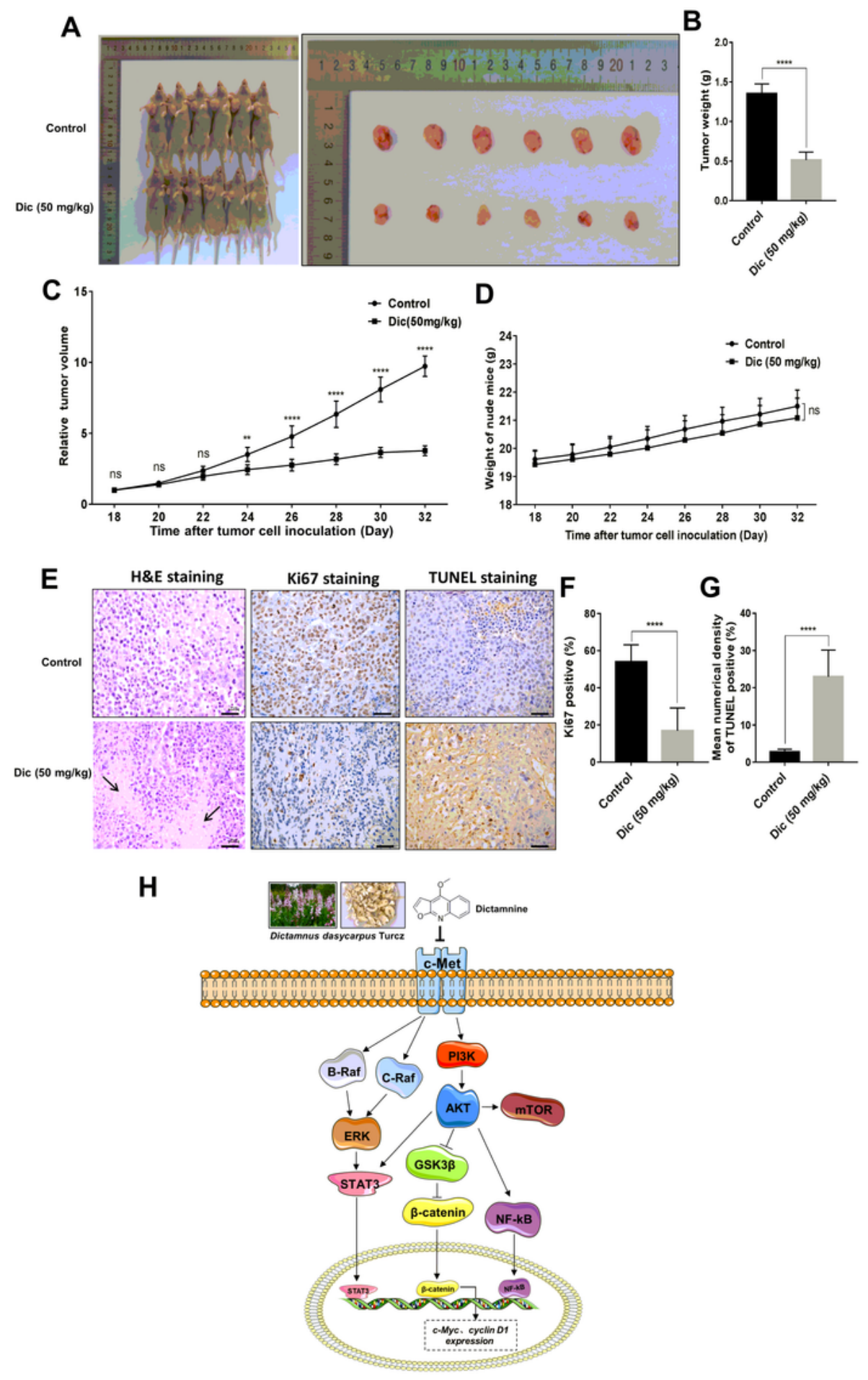

\section{Figure 8}

Effects of Dic on A549 growth in a xenograft mouse model. a-g A549 cells $(5 \times 106$ cells/mice) were injected subcutaneously into the right armpits of mice. On the 9th day after inoculation, when the tumors reached a volume of 100-150 mm3, two groups of tumor-bearing nude mice ( $\mathrm{n}=6$, each group) were injected intraperitoneally with either Dic $(50 \mathrm{mg} / \mathrm{kg})$ or physiological saline $(0.9 \% \mathrm{NaCl})$, respectively. After 15 days of consecutive injections, the mice were sacrificed. a Representative necropsy images of mice 
and dissected tumors are shown. b Tumor weight of dissected tumors from the two groups of mice was measured at the end of the experiment. The results are expressed as the mean \pm S.D., ${ }^{\star \star \star \star} p<0.0001$ compared with control (one-way ANOVA with Dunnett's test). c Tumor volumes were measured during the experiment, and these data are represented as the mean \pm S.D., ${ }^{\star *} p<0.01$ and ${ }^{\star \star \star *} p<0.0001$ compared with the control (one-way ANOVA with Dunnett's test). $d$ Body weight changes in mice treated with Dic or vehicle. Data are represented as the mean \pm S.D., ns, not significant. e Histological features were analyzed by H\&E staining in sections from the tumors. (e-g) Immunohistochemical analysis was performed with

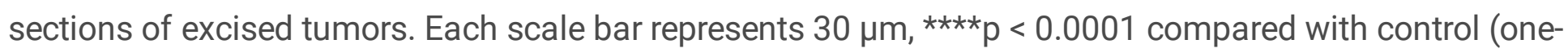
way ANOVA with Dunnett's test). $\mathrm{h}$ Scheme of the proposed mechanism. This shows that Dic directly targets c-Met, leading to the downregulation of the PI3K/Akt/mTOR, MAPK signaling pathways and proliferation-related gene expression, eventually inhibiting lung cancer cell proliferation and tumor growth. 

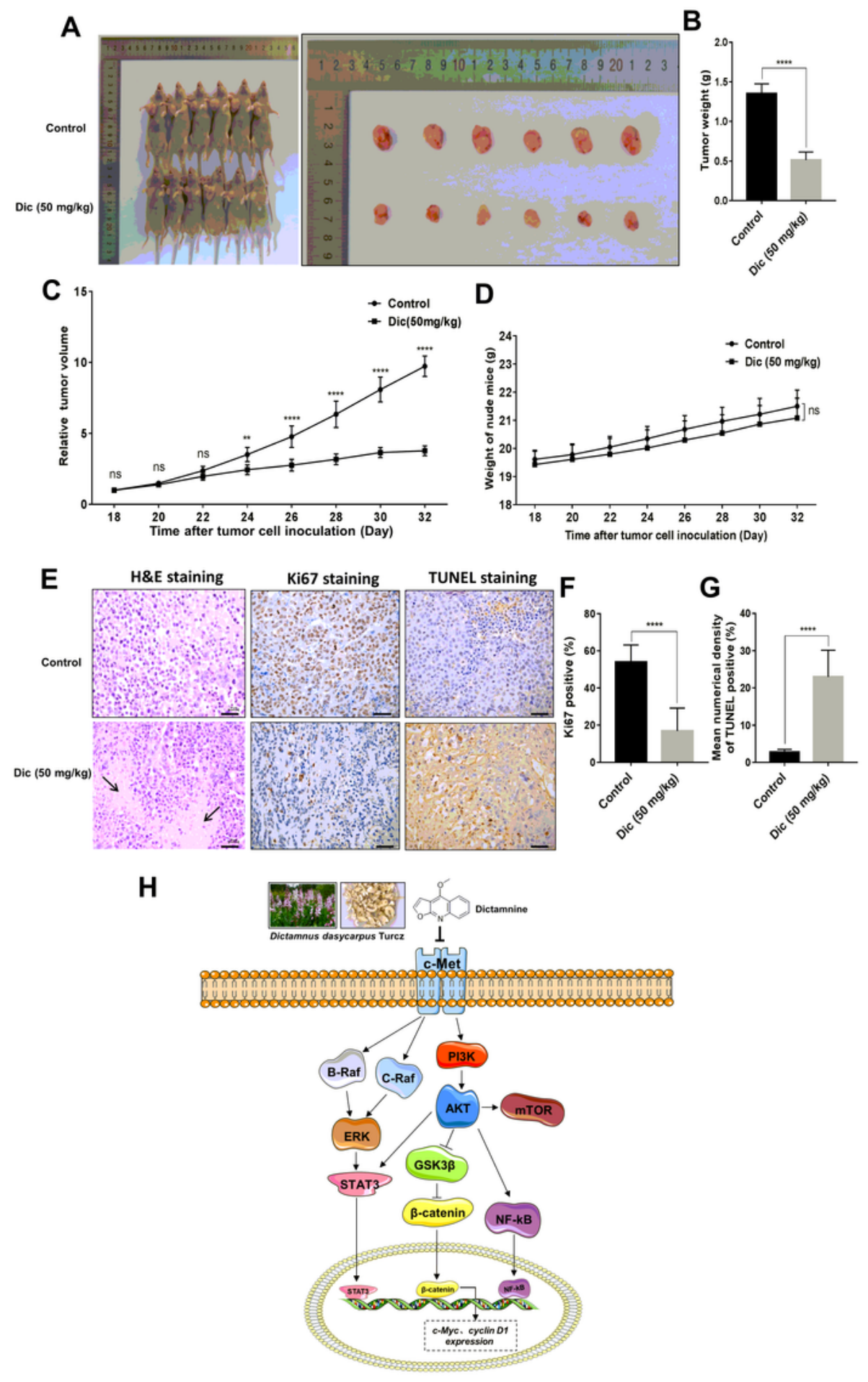

\section{Figure 8}

Effects of Dic on A549 growth in a xenograft mouse model. a-g A549 cells $(5 \times 106$ cells/mice) were injected subcutaneously into the right armpits of mice. On the 9th day after inoculation, when the tumors reached a volume of 100-150 mm3, two groups of tumor-bearing nude mice ( $\mathrm{n}=6$, each group) were injected intraperitoneally with either Dic $(50 \mathrm{mg} / \mathrm{kg})$ or physiological saline $(0.9 \% \mathrm{NaCl})$, respectively. After 15 days of consecutive injections, the mice were sacrificed. a Representative necropsy images of mice 
and dissected tumors are shown. b Tumor weight of dissected tumors from the two groups of mice was measured at the end of the experiment. The results are expressed as the mean \pm S.D., ${ }^{\star \star \star \star} p<0.0001$ compared with control (one-way ANOVA with Dunnett's test). c Tumor volumes were measured during the experiment, and these data are represented as the mean \pm S.D., ${ }^{\star *} p<0.01$ and ${ }^{\star \star \star *} p<0.0001$ compared with the control (one-way ANOVA with Dunnett's test). $d$ Body weight changes in mice treated with Dic or vehicle. Data are represented as the mean \pm S.D., ns, not significant. e Histological features were analyzed by H\&E staining in sections from the tumors. (e-g) Immunohistochemical analysis was performed with

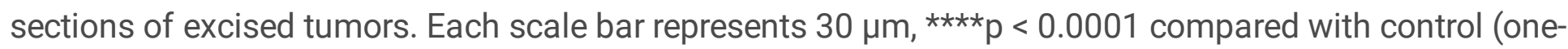
way ANOVA with Dunnett's test). $\mathrm{h}$ Scheme of the proposed mechanism. This shows that Dic directly targets c-Met, leading to the downregulation of the PI3K/Akt/mTOR, MAPK signaling pathways and proliferation-related gene expression, eventually inhibiting lung cancer cell proliferation and tumor growth.

\section{Supplementary Files}

This is a list of supplementary files associated with this preprint. Click to download.

- Additionalfile2.docx

- Additionalfile2.docx

- Additionalfile2.docx

- Additionalfile1.docx

- Additionalfile1.docx

- Additionalfile1.docx 